\title{
OceanGliders: A Component of the Integrated GOOS
}

\begin{abstract}
Pierre Testor ${ }^{1 *}$, Brad de Young ${ }^{2}$, Daniel L. Rudnick ${ }^{3}$, Scott Glenn ${ }^{4}$, Daniel Hayes ${ }^{5}$, Craig M. Lee ${ }^{6}$, Charitha Pattiaratchi ${ }^{7}$, Katherine Hill ${ }^{8}$, Emma Heslop ${ }^{9}$, Victor Turpin ${ }^{1}$, Pekka Alenius ${ }^{10}$, Carlos Barrera ${ }^{11}$, John A. Barth ${ }^{12}$, Nicholas Beaird ${ }^{4}$, Guislain Bécu ${ }^{13}$, Anthony Bosse ${ }^{14}$, François Bourrin ${ }^{15}$, J. Alexander Brearley ${ }^{16}$, Yi Chao ${ }^{17}$, Sue Chen ${ }^{18}$, Jacopo Chiggiato ${ }^{19}$, Laurent Coppola ${ }^{20}$, Richard Crout ${ }^{21}$, James Cummings ${ }^{18}$, Beth Curry ${ }^{6}$, Ruth Curry ${ }^{22}$, Richard Davis ${ }^{23}$, Kruti Desai ${ }^{24}$, Steve DiMarco ${ }^{25}$, Catherine Edwards ${ }^{26}$, Sophie Fielding ${ }^{16}$, Ilker Fer ${ }^{14}$, Eleanor Frajka-Williams ${ }^{27}$, Hezi Gildor ${ }^{28}$, Gustavo Goni ${ }^{29}$, Dimitri Gutierrez ${ }^{30}$, Peter Haugan ${ }^{14,31}$, David Hebert ${ }^{32}$, Joleen Heiderich ${ }^{33,34}$, Stephanie Henson ${ }^{27}$, Karen Heywood ${ }^{35}$, Patrick Hogan ${ }^{36}$, Loïc Houpert ${ }^{27,37}$, Sik Huh ${ }^{38}$, Mark E. Inall ${ }^{37}$, Masso Ishii ${ }^{39}$, Shin-ichi Ito ${ }^{40}$, Sachihiko Itoh ${ }^{40}$, Sen Jan ${ }^{41}$, Jan Kaiser ${ }^{35}$, Johannes Karstensen ${ }^{42}$, Barbara Kirkpatrick ${ }^{43}$, Jody Klymak ${ }^{44}$, Josh Kohut ${ }^{4}$, Gerd Krahmann ${ }^{42}$, Marjolaine Krug ${ }^{45}$, Sam McClatchie ${ }^{46}$, Frédéric Marin ${ }^{47}$, Elena Mauri ${ }^{48}$, Avichal Mehra ${ }^{49}$, Michael P. Meredith ${ }^{16}$, Thomas Meunier ${ }^{50}$, Travis Miles ${ }^{4}$, Julio M. Morell ${ }^{51}$, Laurent Mortier ${ }^{52}$, Sarah Nicholson ${ }^{45}$, Joanne O'Callaghan ${ }^{53}$, Diarmuid O'Conchubhair ${ }^{54}$, Peter Oke ${ }^{55}$, Enric Pallàs-Sanz ${ }^{50}$, Matthew Palmer ${ }^{27}$, JongJin Park ${ }^{56}$, Leonidas Perivoliotis ${ }^{57}$, Pierre-Marie Poulain ${ }^{58}$, Ruth Perry ${ }^{59}$, Bastien Queste ${ }^{35}$, Luc Rainville ${ }^{6}$, Eric Rehm ${ }^{13}$, Moninya Roughan ${ }^{60}$, Nicholas Rome ${ }^{24}$, Tetjana Ross ${ }^{61}$, Simon Ruiz ${ }^{62}$, Grace Saba ${ }^{4}$, Amandine Schaeffer ${ }^{60}$, Martha Schönau ${ }^{63}$, Katrin Schroeder ${ }^{19}$, Yugo Shimizu ${ }^{63}$, Bernadette M. Sloyan ${ }^{55}$, David Smeed ${ }^{27}$, Derrick Snowden ${ }^{64}$, Yumi Song ${ }^{56}$, Sebastian Swart ${ }^{65,66}$, Miguel Tenreiro ${ }^{50}$, Andrew Thompson ${ }^{67}$, Joaquin Tintore ${ }^{68}$, Robert E. Todd ${ }^{34}$, Cesar Toro ${ }^{69}$, Hugh Venables ${ }^{16}$, Taku Wagawa ${ }^{70}$, Stephanie Waterman ${ }^{71}$, Roy A. Watlington ${ }^{72}$ and Doug Wilson ${ }^{72}$
\end{abstract}

${ }^{1}$ CNRS-Sorbonne Universités (UPMC Univ. Pierre et Marie Curie, Paris 06)-CNRS-IRD-MNHN, UMR 7159, Laboratoire d'Océanographie et de Climatologie (LOCEAN), Institut Pierre Simon Laplace (IPSL), Observatoire Ecce Terra, Paris, France, ${ }^{2}$ Department of Physics and Physical Oceanography, Memorial University, Memorial University of Newfoundland, St. John's, NL, Canada, ${ }^{3}$ Scripps Institution of Oceanography, San Diego, CA, United States, ${ }^{4}$ Department of Marine and Coastal Sciences, Rutgers University, New Brunswick, NJ, United States, ${ }^{5}$ Oceanography Centre, University of Cyprus (OC-UCY), Nicosia, Cyprus, ${ }^{6}$ Applied Physics Laboratory, University of Washington, Seattle, WA, United States, ${ }^{7}$ Oceans Graduate School, The University of Western Australia, Perth, WA, Australia, ${ }^{8}$ World Meteorological Organization, Geneva, Switzerland, ${ }^{9}$ UNESCO, Paris, France, ${ }^{10}$ Finnish Meteorological Institute, Helsinki, Finland, ${ }^{11}$ Oceanic Platform of the Canary Islands, Telde, Spain, ${ }^{12}$ College of Earth, Ocean, and Atmospheric Sciences, Oregon State University, Corvallis, OR, United States, ${ }^{13}$ Takuvik, Quebec, QC, Canada, ${ }^{14}$ Geophysical Institute, University of Bergen, Bergen, Norway, ${ }^{15}$ CEFREM, Perpignan, France, ${ }^{16}$ British Antarctic Survey, Cambridge, United Kingdom, ${ }^{17}$ Seatrec, Monrovia, CA, United States, ${ }^{18}$ Naval Research Laboratory, Monterey, CA, United States, ${ }^{19} \mathrm{CNR}$ - Institute of Marine Sciences (ISMAR), Venice, Italy, ${ }^{20}$ Laboratoire d'Océanographie de Villefranche (LOV), UMR7093 (Sorbonne Université/CNRS), Institut de la Mer de Villefranche (IMEV), Villefranche-sur-Mer, France, ${ }^{21}$ Naval Research Laboratory, Stennis, MS, United States, ${ }^{22}$ Bermuda Institute of Ocean Sciences, Saint George, Bermuda, ${ }^{23}$ Department of Oceanography, Dalhousie University, Halifax, NS, Canada, ${ }^{24}$ OceanLeadership, Washington, DC, United States, ${ }^{25}$ Department of Oceanography, Texas A\&M University, College Station, TX, United States, ${ }^{26}$ Skidaway Institute of Oceanography, University of Georgia, Athens, GA, United States, ${ }^{27}$ National Oceanography Centre, Southampton, United Kingdom, ${ }^{28}$ Institute of Earth Sciences, The Hebrew University of Jerusalem, Jerusalem, Israel, ${ }^{29}$ NOAA Atlantic Oceanographic and Meteorological Laboratory, Miami, FL, United States, ${ }^{30}$ Institute of the Sea of Peru, Callao, Peru, ${ }^{31}$ Institute of Marine Research, Bergen, Norway, ${ }^{32}$ Department of Fisheries and Oceans, Bedford Institute of Oceanography, Dartmouth, NS, Canada, ${ }^{33}$ Massachusetts Institute of Technology, Cambridge, MA, United States, ${ }^{34}$ Woods Hole Oceanographic Institution, Woods Hole, MA, United States, ${ }^{35}$ School of Environmental Sciences, Centre for Ocean and Atmospheric Sciences, University of East Anglia, Norwich, United Kingdom, ${ }^{36}$ United States Naval Research Laboratory, Washington, DC, United States, ${ }^{37}$ Scottish Association for Marine Science, Oban, United Kingdom, ${ }^{38}$ Korea Institute of Ocean Science and Technology, Ansan-si, South Korea, ${ }^{39}$ Meteorological Research Institute, Tsukuba, Japan, ${ }^{40}$ Atmosphere and Ocean Research Institute, The University of Tokyo, Chiba, Japan, ${ }^{41}$ Institute of Oceanography, National Taiwan University, Taipei, Taiwan, ${ }^{42}$ GEOMAR Helmholtz Center for Ocean Research Kiel, Kiel, Germany, ${ }^{43}$ Gulf of Mexico Coastal Ocean Observing System, College Station, TX, United States 


\begin{abstract}
${ }^{44}$ Ocean Physics Group, University of Victoria, Victoria, BC, Canada, ${ }^{45}$ Council for Scientific and Industrial Research, Cape Town, South Africa, ${ }^{46}$ FishOcean Enterprises, Auckland, New Zealand, ${ }^{47}$ LEGOS/IRD, Toulouse, France, ${ }^{48}$ Istituto Nazionale di Oceanografia e di Geofisica Sperimentale, Trieste, Italy, ${ }^{49}$ NOAA National Centers for Environmental Prediction, College Park, MD, United States, ${ }^{50}$ Ensenada Center for Scientific Research and Higher Education, Ensenada, Mexico, ${ }^{51}$ Department of Marine Sciences, University of Puerto Rico at Mayagüez, Mayagüez, Puerto Rico, ${ }^{52}$ ENSTA/LOCEAN, Palaiseau, France, ${ }^{53}$ National Institute of Water and Atmospheric Research, Wellington, New Zealand, ${ }^{54}$ Marine Institute, Galway, Ireland, ${ }^{55}$ CSIRO, Oceans and Atmosphere, Hobart, TAS, Australia, ${ }^{56}$ School of Earth System Sciences, Kyungpook National University, Daegu, South Korea, ${ }^{57}$ Hellenic Center for Marine Research, Heraklion, Greece, ${ }^{58}$ Centre for Maritime Research and Experimentation, La Spezia, Italy, ${ }^{59}$ Shell, Houston, TX, United States, ${ }^{60}$ School of Mathematics and Statistics, University of New South Wales, Sydney, NSW, Australia, ${ }^{61}$ Department of Fisheries and Oceans, Institute of Ocean Sciences, Sidney, BC, Canada, ${ }^{62}$ Instituto Mediterráneo de Estudios Avanzados, CSIC-UIB, Esporles, Spain, ${ }^{63}$ Applied Ocean Science, Fairfax Station, VA, United States, ${ }^{64}$ National Oceanic and Atmospheric Administration, Washington DC, United States, ${ }^{65}$ Department of Marine Sciences, University of Gothenburg, Gothenburg, Sweden, ${ }^{66}$ Department of Oceanography, University of Cape Town, Cape Town, South Africa, ${ }^{67}$ California Institute of Technology, Pasadena, CA, United States, ${ }^{68}$ SOCIB and IMEDEA (CSIC-UIB), Palma de Mallorca, Spain, ${ }^{69}$ IOC-UNESCO, IOCARIBE, Paris, France, ${ }^{70}$ Japan Fisheries Research and Education Agency, Yokohama, Japan, ${ }^{71}$ Department of Earth, Ocean and Atmospheric Sciences, University of British Columbia, Vancouver, BC, Canada, ${ }^{72}$ Caribbean Coastal Ocean Observing System, Mayagüez, Puerto Rico
\end{abstract}

The OceanGliders program started in 2016 to support active coordination and enhancement of global glider activity. OceanGliders contributes to the international efforts of the Global Ocean Observation System (GOOS) for Climate, Ocean Health, and Operational Services. It brings together marine scientists and engineers operating gliders around the world: (1) to observe the long-term physical, biogeochemical, and biological ocean processes and phenomena that are relevant for societal applications; and, (2) to contribute to the GOOS through real-time and delayed mode data dissemination. The OceanGliders program is distributed across national and regional observing systems and significantly contributes to integrated, multi-scale and multi-platform sampling strategies. OceanGliders shares best practices, requirements, and scientific knowledge needed for glider operations, data collection and analysis. It also monitors global glider activity and supports the dissemination of glider data through regional and global databases, in realtime and delayed modes, facilitating data access to the wider community. OceanGliders currently supports national, regional and global initiatives to maintain and expand the capabilities and application of gliders to meet key global challenges such as improved measurement of ocean boundary currents, water transformation and storm forecast.

Keywords: in situ ocean observing systems, gliders, boundary currents, storms, water transformation, ocean data management, autonomous oceanic platforms, GOOS

\section{INTRODUCTION}

The ocean is an important component of the global earth system influencing the global/regional climate, weather, ecosystems, living resources and biodiversity. The ocean plays a major role in many human activities including coastal protection, tourism, search and rescue, defense and security, shipping, aquaculture and fisheries, offshore industry and marine renewable energy. Ocean observation serves to enable us to better understand ocean functions and to meet the societal needs related to these activities. The Intergovernmental Oceanographic Commission (IOC of UNESCO) developed the Global Ocean Observing System (GOOS) more than two decades ago to coordinate the different national efforts in terms of sustained ocean observations throughout the world and to maximize the societal benefits of ocean observations. The GOOS has three observation panels for the development of observing strategies for climate, biogeochemistry and biology/ecosystems and the Observation Coordination group (OCG) of the World Meteorological Organization (WMO)/Intergovernmental Oceanographic Commission (IOC) Joint Commission on Oceanography and Marine Meteorology (JCOMM) for technical coordination of on-going observations. GOOS also serves as the ocean component of the Global Climate Observing system (GCOS). It is implemented through GOOS Regional Alliances and supported by a wide range of bodies, such as the Committee on Earth Observing Satellites (CEOS), the Partnership for Observation of the Global Ocean (POGO) and the GEO Blue Planet initiative.

The OceanObs' 99 conference stimulated the first design of the GOOS and 10 years later, the OceanObs'09 conference assessed the progress made in implementing the GOOS. At that time, an international consensus was reached on how the GOOS should continue to evolve. Discussions around the GOOS highlighted 
the tremendous potential value for physical, biogeochemical, and biological observations, particularly in the transition between the open ocean and the coastal environment, which is a key area for societal issues, economical applications and at the same time is a prime area for autonomous underwater glider (Davis et al., 2002) observations. Gliders were considered in this global framework from the very beginning. Developed in the 1980-1990s (Lee and Rudnick, 2018), they arose from the vision that a network of small, intelligent, mobile and cheap observing platforms could fill sampling gaps left by the other ocean observing platforms (Stommel, 1989). This idea was first discussed at OceanObs' 99 (see Conference Statement ${ }^{1}$ ), when the technology was immature, and further developed at OceanObs'09, when the technology was still maturing but poised to make a substantial contribution to global ocean observing (Testor et al., 2010). It was agreed that gliders could fill important gaps left by other observing systems and thus greatly enhance the GOOS if fully integrated into the system, and recommendations were made for the next decade.

\section{Progress Over the Last Decade}

Since OceanObs'09, autonomous underwater gliders have reached a mature state and are now operated routinely. They offer persistent fine resolution observations in the coastal and open ocean, even at high latitudes (at least during summer months). Typically, gliders profile from the surface to the bottom, or to $200-1,000 \mathrm{~m}$ depth, taking $0.5-6 \mathrm{~h}$ to complete a cycle from the surface to depth and back. During that time they travel $0.5-6 \mathrm{~km}$ horizontally at speeds of about $1 \mathrm{~km} / \mathrm{h}$, even during very severe weather conditions. Deployments of about a year are now possible, with deployments of 3-6 months now routine, and survey tracks extending over 1,000s kilometers. Sensors on gliders measure physical variables such as pressure, temperature, salinity, currents, turbulence and wind speed (Cauchy et al., 2018), biological variables relevant to phytoplankton and zooplankton, and ecologically important chemical variables such as dissolved oxygen, irradiance, carbon dioxide, pH (Saba et al., 2018), nitrate and hydrocarbon. Gliders have been developed to sample under-sea ice and ice shelves (Webster et al., 2015; Nelson et al., 2016; Lee et al., 2017), to recover data from other deep instruments via acoustic telemetry and send them to land while at the surface (Send et al., 2013), to detect acoustic tags on fishes (Oliver et al., 2013, 2017) and marine mammals. Improved gliders have reached depths of up to $6,000 \mathrm{~m}$ (Osse and Eriksen, 2007). All these improvements greatly open up the range of possible applications.

Their unique sampling capacities (high resolution and long term) are especially suitable for some key oceanic phenomena. They have yielded major scientific breakthroughs, revealing new insights into ocean physical, biogeochemical and biological processes. In particular, there are new results on (1) high latitudes oceanography, air-sea-ice interactions and intermediate/deep convection, (2) the variability of boundary currents, (3) (sub)mesoscale processes, (4) phytoplankton phenology and biogeochemistry, (5) higher trophic levels and biology, (6) shallow and marginal seas, (7) climate and variability of the

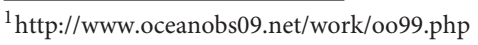

water column, (8) internal waves, turbulence, tides, diffusivity and vertical mixing, and (9) particles fluxes and sedimentology (see Table 1).

Glider data are used for many applications in ocean physics, chemistry and biology (Rudnick, 2016). Glider data management by the scientific community has made data available to the public in real time for classical measured variables. Ocean numerical modeling and forecast activities already benefit from these data (Table 1). Models of ocean circulation, particularly for regional and coastal domains, have benefited from glider data in terms of validation and data assimilation, particularly in regional and coastal models. Glider data can improve hurricane intensity forecast models and has led to major results in ocean forecasting, weather forecasting including hurricane intensity, climatologies, and state estimates.

Underwater gliders will enable us to enter a new era of ocean observation and state estimates more effectively, meeting the needs of society and marine researchers. Gliders are a vital component in the portfolio of ocean observing platforms for most of the national ocean observation agencies. These agencies have invested in developing glider observing capability, and there are now about 400-500 gliders in the world actively being used to better observe the ocean (it is difficult to have exact numbers but based on our community knowledge we estimate $\sim 250$ gliders in the USA; $\sim 100$ in Europe; $\sim 50$ in China; $\sim 30$ in Australia; $\sim 30$ in Canada; 9 in Mexico; 9 in South Korea; 5 in South Africa; 3 in Israel; 3 in Peru; 2 in New Zealand; 2 in India, 2 in Taiwan, etc.). Glider technology has also been used by the private sector during the last decade for applications in pollution events, defense, environment, and the offshore industry (Fragoso et al., 2016).

\section{The Evolution of a Glider Observing Community-OceanGliders}

Today, underwater gliders are operated by many teams around the world that have developed end-to-end systems able to steer their gliders and collect their data through their own facilities and Iridium satellite-based communications. Glider deployments are challenging because they must be managed in real-time throughout their deployment with the two-way communications needed for active piloting by the different operating teams. Glider technology requires a high level of expertise on the scientific and technological aspects in order to effectively operate the vehicles. Thanks to networking, coordination and capacitybuilding, training, liaison between providers and users, advocacy, and provision of expert advice, the global glider community has become more organized, grown rapidly, and responded to some of the system challenges. The idea for a glider community emerged in October 2005 at the first "EGO (Everyone's Gliding Observatories) Workshop and Glider School" and since then, collaborations have further developed. EGO Workshops and Glider Schools have been organized on an annual basis, to present and discuss scientific and technological issues, and to train and engage new users and countries worldwide. The formation of a user group and global coordination has improved glider operational reliability and data management, and resulted in improved glider monitoring, ocean observing and developments of the glider platform. Over the last decade, this coordination 
TABLE 1 | Highlights on results during the past decade using the glider technology.

\section{High latitudes oceanography, air-sea-ice interactions, or} intermediate/deep convection

Variability of boundary currents

Mesoscale and submesoscale processes

Phytoplankton phenology and biogeochemistry

Higher trophic levels and biology

Shallow and marginal seas

Climate and variability of the water column

Internal waves, turbulence, tides, diffusivity and vertical mixing

Particles fluxes and sedimentology

Ocean forecasting, climatology, and state estimates
Beszczynska-Möller et al., 2011; Frajka-Williams et al., 2011; Beaird et al., 2012, 2013; Evans et al., 2013; Fan et al., 2013; Høydalsvik et al., 2013; Kohut et al., 2013; Queste et al., 2013; Guihen et al., 2014; Heywood et al., 2014; Carvalho et al., 2016; Houpert et al., 2016; Nelson et al., 2016; Azaneu et al., 2017; Couto et al., 2017; Jones and Smith, 2017; Lee et al., 2017; Timmermans and Winsor, 2013; Weingartner et al., 2013; Thompson et al., 2014; Ullgren et al., 2014; Venables and Meredith, 2014; Schofield et al., 2015; Swart et al., 2015; Thomalla et al., 2015; Testor et al., 2018; Våge et al., 2018; Viglione et al., 2018 Pascual et al., 2010; Pattiaratchi et al., 2010, 2017; Ramp et al., 2011; Todd et al., 2011a,b, 2016, 2018; Albretsen et al., 2012; Davis et al., 2012; McClatchie et al., 2012; Sherwin et al., 2012; Høydalsvik et al., 2013; Johnston et al., 2013; Lien et al., 2014, 2015; Pietri et al., 2014; Schaeffer and Roughan, 2015; Schönau et al., 2015; Yang et al., 2015; Lee et al., 2016; Mensah et al., 2016; Schaeffer et al., 2016a; Zaba and Rudnick, 2016; Andres et al., 2017; Anutaliya et al., 2017; Durand et al., 2017; Todd, 2017; Todd and Locke-Wynn, 2017; Aulicino et al., 2018; Houpert et al., 2018; Krug et al., 2018; Seim and Edwards, 2019 Bouffard et al., 2010, 2012; Baird et al., 2011; Baird and Ridgway, 2012; Heslop et al., 2012; Mahadevan et al., 2012; Ruiz et al., 2012; Todd et al., 2012, 2013; Alvarez et al., 2013; Pelland et al., 2013, 2014, 2016, 2018; Pietri et al., 2013; Piterbarg et al., 2013; Timmermans and Winsor, 2013; Caldeira et al., 2014; Hristova et al., 2014; Bosse et al., 2015, 2016; Everett et al., 2015; Farrar et al., 2015; Omand et al., 2015; Schönau and Rudnick, 2015, 2017; Sherwin et al., 2015; Borrione et al., 2016; Caballero et al., 2016; Freitas et al., 2016; Mauri et al., 2016; Thompson et al., 2016; Thomsen et al., 2016; Brannigan et al., 2017; Buffett et al., 2017; Du Plessis et al., 2017; Gourdeau et al., 2017; Itoh and Rudnick, 2017; Karstensen et al., 2017; Kokkini et al., 2017; Krug et al., 2017; Mancero-Mosquera et al., 2017; Margirier et al., 2017; Morrow et al., 2017; Pascual et al., 2017; Ruan et al., 2017; Yu et al., 2017; Zacharia et al., 2017; Gula et al., 2019

Asper et al., 2011; Briggs et al., 2011; Martin et al., 2011; Xu et al., 2011; Alkire et al., 2012, 2014; Cetinić et al., 2012, 2015; Pierce et al., 2012; Gower et al., 2013; Zhao et al., 2013; Foloni-Neto et al., 2014; Kaufman et al., 2014, 2017; Olita et al., 2014, 2017; Biddle et al., 2015; Evans et al., 2015; Hemsley et al., 2015; Nicholson et al., 2015; Queste et al., 2015; Seegers et al., 2015; Adams et al., 2016; Cotroneo et al., 2016; Fiedler et al., 2016; Jacox et al., 2016; Loginova et al., 2016; Pizarro et al., 2016; Porter et al., 2016; Schaeffer et al., 2016b; Schuette et al., 2016; Thomsen et al., 2016; Bosse et al., 2017; Hemming et al., 2017; Mayot et al., 2017; Ross et al., 2017; Thomalla et al., 2017; Little et al., 2018

Kahl et al., 2010; Klinck et al., 2012; McClatchie et al., 2012; Powell and Ohman, 2012, 2015; Wall et al., 2012; Baumgartner et al., 2013, 2014; Ohman et al., 2013; Oliver et al., 2013; Guihen et al., 2014; Kohut et al., 2014a; Pelland et al., 2014; Ainley et al., 2015; Goericke and Ohman, 2015; Swart et al., 2016; Kusel et al., 2017; Taylor and Lembke, 2017; Benoit-Bird et al., 2018; Chave et al., 2018

Castelao et al., 2010; Shulman et al., 2010; Karstensen et al., 2014; Kohut et al., 2014b; Mazzini et al., 2014; Schaeffer et al., 2014; Piero Mazzini et al., 2015; Qiu et al., 2015; Dever et al., 2016; Mahjabin et al., 2016; Saldias et al., 2016; Heslop et al., 2017; Zarokanellos et al., 2017

Cole and Rudnick, 2012; Schlundt et al., 2014; Domingues et al., 2015; Farrar et al., 2015; Houpert et al., 2015; Damerell et al., 2016; Schaeffer et al., 2016a; Rudnick et al., 2017; Portela et al., 2018

Alford et al., 2012; Thorpe, 2012; Beaird et al., 2013; Johnston et al., 2013; Rainville et al., 2013, 2017; Fer et al., 2014; Peterson and Fer, 2014; Boettger et al., 2015; Cronin et al., 2015; Johnston and Rudnick, 2015; Palmer et al., 2015; Klymak et al., 2016; Hall et al., 2017; Schultze et al., 2017; St Laurent and Merrifield, 2017; Todd, 2017; Evans et al., 2018; Ma et al., 2018; Scheifele et al., 2018

Briggs et al., 2011; Miles et al., 2013; Bourrin et al., 2015; Omand et al., 2015; Many et al., 2016; Churnside et al., 2017; Durrieu de Madron et al., 2017

Dobricic et al., 2010; Oke et al., 2010, 2015; Zhang et al., 2010a,b; Chudong et al., 2011; Ramp et al., 2011; Todd et al., 2011a, 2012; Yaremchuk et al., 2011; Jones et al., 2012; Melet et al., 2012; Mourre and Alvarez, 2012; Gangopadhyay et al., 2013; L'Heveder et al., 2013; Li et al., 2013; Rayburn and Kamenkovich, 2013; Wilkin and Hunter, 2013; Alvarez and Mourre, 2014; Chen et al., 2014; Drillet et al., 2014; Mourre and Chiggiato, 2014; Ngodock and Carrier, 2014; Pan et al., 2014, 2017; Durski et al., 2015; Miles et al., 2015; Rudnick et al., 2015; Estournel et al., 2016a,b; Fragoso et al., 2016; Kerry et al., 2016, 2018; Chao et al., 2017a,b; Damien et al., 2017; Dong et al., 2017; Goni et al., 2017; Halliwell et al., 2017; Kurapov et al., 2017; Onken, 2017; Todd and Locke-Wynn, 2017; Verdy et al., 2017 activity has also developed nationally and regionally. Many national facilities have been established to serve their national communities such as the IMOS (Integrated Marine Observing System) Ocean Gliders facility, Ocean Gliders Canada, GMOG (Grupo de Monitoreo Oceanográfico con Gliders) in Mexico, MARS (Marine Autonomous and Robotic Systems) in the UK, Norwegian National Facility for Ocean Gliders (NorGliders) in Norway, "Parc National de Gliders" in France, etc. Glider groups have also been set up for coordination within integrated ocean observation initiatives such as the Integrated Ocean Observing System (IOOS), the Integrated Marine Observing System (IMOS) and the European Ocean Observing System (EOOS)/EuroGOOS.
There are now several levels of coordination and this greatly facilitates scientific and technological exchanges between glider operators and users, in academia and industry.

Building on this diverse community, the OceanGliders program started in September 2016 at the 7th EGO conference. It was set up in recognition of the maturity of the glider systems and their potential role in the GOOS in coming years. The OceanGliders program as a component of the GOOS was approved by the Joint WMO-IOC Technical Commission for Oceanography and Marine Meteorology (JCOMM) at their 5th Intergovernmental Session in October 2017 and the OceanGliders Steering Team reports to OCG. Here we review the progress 
made in implementing a glider component of the GOOS, one of the key recommendations from OceanObs'09, present the recently established program and components, and offer a vision for the coming decade.

\section{MOVING FROM THE REGIONAL TO THE GLOBAL}

The progress of gliders in moving from a developing to a mature technology is exemplified by the programs that have been run continuously for over 10 years, for example, in the California Current (Adams et al., 2016; Rudnick et al., 2017), and the Solomon Sea (Davis et al., 2012). Long-term observations lasting several years are becoming widespread (Heslop et al., 2012; Schaeffer et al., 2016a; Yu et al., 2017; Du Plessis et al., 2019). The capability to sustain these programs relies on the improved dependability of gliders (Brito et al., 2014; Rudnick et al., 2016a; Brito and Griffiths, 2018) and the experience, skill and confidence of the operators. The success of these projects can be summarized in the likelihood of a glider completing a desired mission, and the fraction of the time that a glider is in the water. Typical success rates of 0.9 have been achieved by experienced teams. The delivery of data from gliders in real time has become routine, with main glider data assembly centers in Europe (EGO/Coriolis $\left.{ }^{2}\right)$, Australia $\left(\mathrm{IMOS}^{3}\right)$, and the USA $\left(\operatorname{IOOS}^{4}\right)$.

Underwater gliders play a special role in observing systems designed to support regional modeling activities, because gliders generate many profiles at controlled locations. The potential for glider development was recognized quite early on, leading to the influential Autonomous Ocean Sampling Network (Ramp et al., 2009). Glider data are often used with models for two purposes: (1) verification, meaning to evaluate model output for fidelity to the ocean; and/or, (2) assimilation, the use of data to constrain model output (Edwards et al., 2015; Hayes et al., 2019). Models can either (1) forecast ocean variables in advance of any access to data for verification; or (2) hindcast to deliver state estimates that use data to create a complete set of ocean variables. Many combinations of using glider data for verification or assimilation of forecast or hindcast models have been tried in many regions around the world. For example, off California, Kurapov et al. (2017) used glider data (Rudnick et al., 2017) to verify a forecast model, while Chao et al. (2018) assimilated the same glider data to create forecasts. Temperature and salinity data from these gliders were assimilated into a state estimate (Todd et al., 2011a, 2012; Zaba et al., 2018), while velocity data were not assimilated so they could be used for verification. In the Mediterranean, Dobricic et al. (2010) showed the large-scale impact of the repetition of a glider section and in particular when depth-average currents were also assimilated while Mourre and Chiggiato (2014) and Onken (2017) assimilated glider data for a forecast and verified against data from a ship survey. A state estimate of the tropical Pacific (Verdy et al., 2017) was verified against withheld glider

\footnotetext{
${ }^{2}$ http://www.coriolis.eu.org/Data-Products/Catalogue\#/metadata/589bfa512219-4cc8-a19e-83f3c3f27bb4

${ }^{3}$ https://portal.aodn.org.au/

${ }^{4} \mathrm{https} / / /$ gliders.ioos.us/data/
}

observations on either side of the Pacific basin. These examples illustrate the character of recent work. Ongoing work is expected to improve regional observing modeling in the coming decade.

Underwater gliders are especially well-suited for sustained, fine-spatial-resolution observations near the ocean boundaries. They allow cross-front measurements to help resolve mesoscale/sub-mesoscale fronts and associated shear-driven instabilities in both the coastal and open ocean. The long times for deployments of gliders are possible because they move slowly $(10 \mathrm{~s} \mathrm{~cm} / \mathrm{s})$ and because energy lost to drag is proportional to the cube of the speed through water. Gliders must profile continuously in order to make way through water, so fine resolution in the order of a few kilometers is common. Gliders can be deployed and recovered from small boats, thereby minimizing costs and allowing flexible operation. Sustained, fineresolution operations near boundaries are ideal for monitoring the regional effects of climate variability. Gliders fill the gap between the coast and the open ocean, as tracks of thousands of kilometers are typical, making traversing the 200 nautical mile Exclusive Economic Zone practical. Gliders could revolutionize regional oceanographic observing just as Argo did for observing the open ocean over the last two decades.

\section{OceanGliders Terms of Reference}

The international OceanGliders program was created as a component of the GOOS with the broad goals of strengthening the glider community (users, scientists, engineers, operators, manufacturers) and facilitating the sustained worldwide use of gliders for the benefit of society and science ${ }^{5}$. An initial structure and set of governance rules were agreed upon, as well as more detailed ways to maintain and develop the program, briefly summarized in Table 2 . Because of their proven ability to fill gaps and needs in the existing observation system, gliders are on the cusp of a transition from isolated, regional use by a few expert teams, to widespread use around the globe by coordinated groups with a wider range of applications. The glider community has realized the many benefits of sharing expertise, best practices, data, and even infrastructure components among existing and new members. Providing a global program, in which new ideas can be discussed and coordinated for larger-scale adoption, will turn regional efforts into integrated global efforts. This fits perfectly into the GOOS mission to promote feasible, high-impact observing programs.

\section{Data Management}

OceanGliders targets high-impact, societally-relevant, sciencebased observing through a number of initial scientific Task Teams (OceanGliders TT). They are developed in the following section, but one Task Team in particular relates to the smooth, coordinated functioning of each TT with each other and with the rest of the GOOS: the data management TT. This team aims to address the needs of long-term observation aspects of data management, benefiting the wider community, supporting and encouraging scientists designing and executing process studies, as well as engineers developing new gliders, sensors, and computing

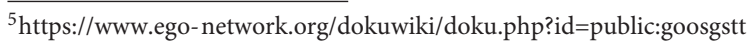


TABLE 2 | Summary of OceanGliders terms of reference and objectives.

\begin{tabular}{|c|c|}
\hline Purpose & $\begin{array}{l}\text { To provide scientific leadership to promote and strengthen } \\
\text { the glider community and facilitate their sustained use } \\
\text { globally in order to respond to the integrated requirements } \\
\text { of the Global Ocean Observing system (GOOS). Oversee } \\
\text { the development and implementation of a global-scale } \\
\text { glider array for observing key regions of the ocean on the } \\
\text { long term, based on national and regional projects (https:// } \\
\text { www.ego-network.org/dokuwiki/lib/exe/fetch.php?media= } \\
\text { public:gst:glider-st_tor.pdf) }\end{array}$ \\
\hline Membership & $\begin{array}{l}\text { Anyone willing to contribute to the different Task Teams is } \\
\text { considered as a member, keeping in mind the focus on } \\
\text { developing sustained glider activity and the "Framework for } \\
\text { Ocean Observing." }\end{array}$ \\
\hline Steering Team & $\begin{array}{l}\text { Reflect and represent the sustained glider activity and to } \\
\text { drive OceanGliders toward its goal of filling gaps in } \\
\text { GOOS/GCOS }\end{array}$ \\
\hline Exec Committee & Chair, co-Chair, Task Teams Leaders and GOOS advisor \\
\hline \multirow[t]{5}{*}{ Task Teams } & $\begin{array}{l}\text { Design network, define targets for Task Teams missions } \\
\text { (optimum strategy) }\end{array}$ \\
\hline & Define science implementation plans \\
\hline & Describe scientific requirements and societal requirements \\
\hline & Describe the global costs and cost-effectiveness \\
\hline & $\begin{array}{l}\text { Define the contribution of Task Teams in a multi-platform } \\
\text { system designed to address scientific and societal issues, } \\
\text { including unique roles of gliders }\end{array}$ \\
\hline Meetings & Annual Steering Committee meetings \\
\hline
\end{tabular}

technologies to participate in metadata and data management. Data management implies not only data repositories of a certain standard, but the guidance and coordination in the development of new standards and best practices (Pearlman et al., 2019) for data collection, processing, and quality control. Data management requires metadata and its description, storage, and access. One of the benefits of coordination will be improved and sustained quality control of glider data.

\section{Network Monitoring and Data Dissemination}

One main goal for glider operators is to make data publicly available and in particular to publish data in near-real time on the GTS (Global Telecommunication System) and in CF (Climate and Forecast) compliant formats for operational services. They provide their metadata and data to a Data Assembly Center (DAC) in charge of the data management and linked to a Global Data Assembly Center (GDAC) for further dissemination and archive. Three de facto GDACs are currently operating: Australia (IMOS), Europe and partners (EGO/Coriolis), and the United States (IOOS). Each GDAC has adopted similar strategies and conventions: CF-compliant NetCDF observation file formats can be uploaded by operators, and public sites and tools are provided for downloading and visualization. There are minor differences in formats, and the implementation of tools for raw file conversion, discovery, download and visualization varies widely. Numerous regional and local efforts have developed important tools but this has made it painfully obvious that coordination is needed for global-scale visibility and availability of ocean observations of known quality control. Initial efforts by IMOS, EGO/Coriolis and IOOS at collecting daily glider data illustrate some of the extent of glider activity worldwide over the past decade (Figures 1, 2). This also represents the commitments from glider teams that have fed these systems, showing most of the glider deployments carried out so far in the world. The next step of unifying and providing data seamlessly from any region through one portal must be simpler. Already, the three GDACs have shared detailed information on how to upload, discover, download, and visualize using their tools. Simplifications have been made to provide easy access among the GDACs. This information will be centralized as in Figure 3 and accessible on the OceanGliders website www.oceangliders.org and will be an important tool to monitor global glider activity and promote its objectives.

The first dedicated global glider data management meeting has stimulated further developments (Genova, Italy, 1719 September, 2018). Besides sharing expertise and latest developments at the regional level, this meeting produced a global consensus about how glider data can be made more useful to society, considering both historical and near real time data sets, now and in the future. Short-term goals include: setting up a solution to access all glider data in a single format; define indices for glider activity monitoring; handling the real time and delayed mode quality controls and assessments at the global level. Further development and sharing of best practices on data and metadata management are key for the OceanGliders Data Management Task Team. To that end, there is now a new central directory at www.oceanbestpractices.net, hosted by IODE, for OceanGliders.

Glider-specific tools have been developed at the GDAC and regional/institutional (or DAC) level to complement the other elements of the GOOS. The unique trajectory character of glider data, and of the wide range of metadata can cause these tools to be quite complex. Even the familiar concepts of "cruise," "mission," "transect," and "profile" do not adequately describe the nature of glider flight and programmable behavior in real time.

There are too many to exhaustively list here, but notable examples include: GliderScope ${ }^{6}$ (Hanson et al., 2017), IOOS $^{7}$, EGO GFCP ${ }^{8}$, NorGliders GliderPage ${ }^{9}$, SOCIB $^{10}$ (Troupin et al., 2015), MARS ${ }^{11}$, and GANDALF ${ }^{12}$. Going forward, standardized data and metadata interfaces will benefit the future development of such tools and enable easier, global access to the full set of quality-controlled glider data and metadata [e.g., the Sensor Web Enablement framework and associated standards (Bröring et al., 2017)].

\section{Emerging Requirements}

Glider data management will need to encompass developments within the glider networks, the GOOS and outside of the oceanographic domain in order to anticipate future changes in global data management. The implementation of FindableAccessible-Interoperable-Reusable (FAIR) data principles is a

\footnotetext{
${ }^{6}$ http://imos.org.au/gliderscope/

${ }^{7}$ https://gliders.ioos.us/map/

${ }^{8}$ https://www.ego-network.org/dokuwiki/doku.php

${ }^{9}$ http://gp.gfi.uib.no

${ }^{10} \mathrm{http}: / /$ www.socib.eu/?seccion=observingFacilities\&facility=glider

${ }^{11}$ https://mars.noc.ac.uk/

${ }^{12} \mathrm{http}: / /$ gandalf.gcoos.org
} 

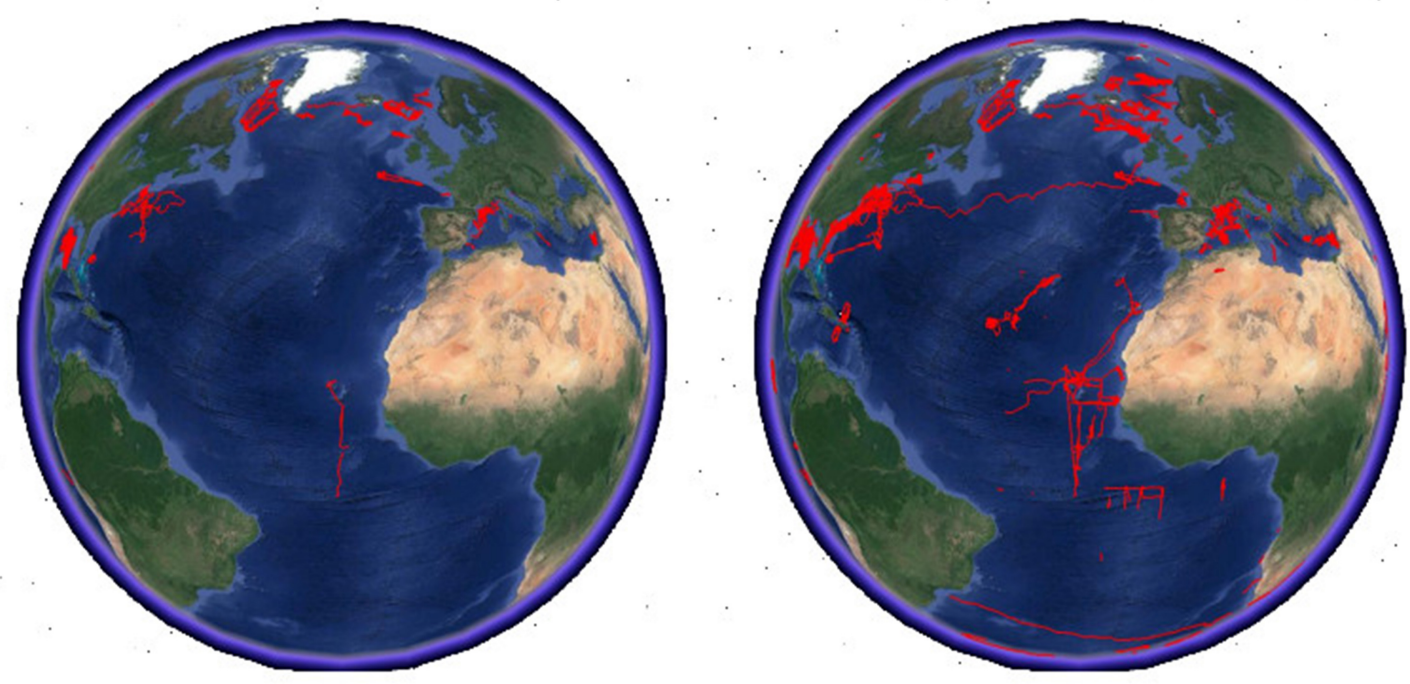

FIGURE 1 | Development of the glider activity over the past decade. Gliders tracks of past deployments (left) until December 2009 (OceanObs'09) and (right) until October 2018 (OceanObs'19 submissions), as can be viewed using google-earth.

common theme in environmental data management and will place demands for development on glider data infrastructure (Tanhua et al., 2019). The integration of data from different networks within the GOOS and the implementation of new Essential Ocean Variables (EOVs) are also emerging as requirements. Furthermore, additional demands on data management will emerge with such as automated piloting (e.g., Chang et al., 2015; Smedstad et al., 2015) and operational glider network monitoring technologies.

\section{ADDRESSING GLOBAL OBSERVING NEEDS}

The OceanGliders group met to discuss possible areas of focus and beyond the central need for improved data management, identified three key areas of focus for the developing program. These areas of interest were organized into Task Teams (TT) whose goals are to address the societal needs for ocean data and to entrain the community into discussions around the role of gliders in meeting these needs. It is expected that the mission-based TTs will organically develop by organizing the different initiatives into integrated and coordinated global efforts.

\section{Boundary Currents}

Society experiences changes in the global ocean at the ocean's boundaries. These boundary regions are the nexus of societal use of the ocean for fisheries, transportation, and recreation. The boundary regions are also where the intense ocean currents are key to the transport of mass, heat, salt, biogeochemical variables and plankton. In the large ocean basins, the subtropical western boundary currents dominate the surface poleward transport of warm water or equatorward transport of cold water at depth and are major drivers of climate variability. Subtropical eastern boundary currents are often upwelling systems that comprise some of the most biologically productive regions in the world and host the world's Oxygen Minimum Zones (OMZ). Subpolar eastern boundary currents induce significant poleward heat transport in the downwelling eastern part of the subpolar gyres. Boundary currents in marginal seas provide the major means of exchange with the open ocean and impact regional ecosystems. Finally, the communication between the coast and open ocean is regulated by the boundary currents that flow along the continental slopes, affecting ecosystems, flood levels, erosion and commercial activity. To summarize, there is a great need for sustained observations of these highly dynamic boundary current regions.

Underwater gliders are particularly effective at measuring and monitoring subsurface biogeochemical fields that are both key to marine ecosystem productivity and involved in some of the most pressing ocean challenges like ocean acidification and hypoxia. For instance, glider capabilities are well-suited to sample the upwelling source waters transported to the edge of the continental shelf by eastern boundary currents. Recent studies in the Pacific and Atlantic reveal details of the spatial structure and time evolution of, for example, low-oxygen zones in such regions (Pierce et al., 2012; Pietri et al., 2013; Adams et al., 2016; Pizarro et al., 2016; Thomsen et al., 2016; Karstensen et al., 2017).

From their earliest conception, underwater gliders were viewed as components of observing/modeling systems, and progress over the past decade has proven the efficacy of this approach. The data provided by underwater gliders are a natural match for regional models of coastal ocean circulation. These regional models are necessary, as the currents and water properties in the coastal ocean vary on the relatively small scales 

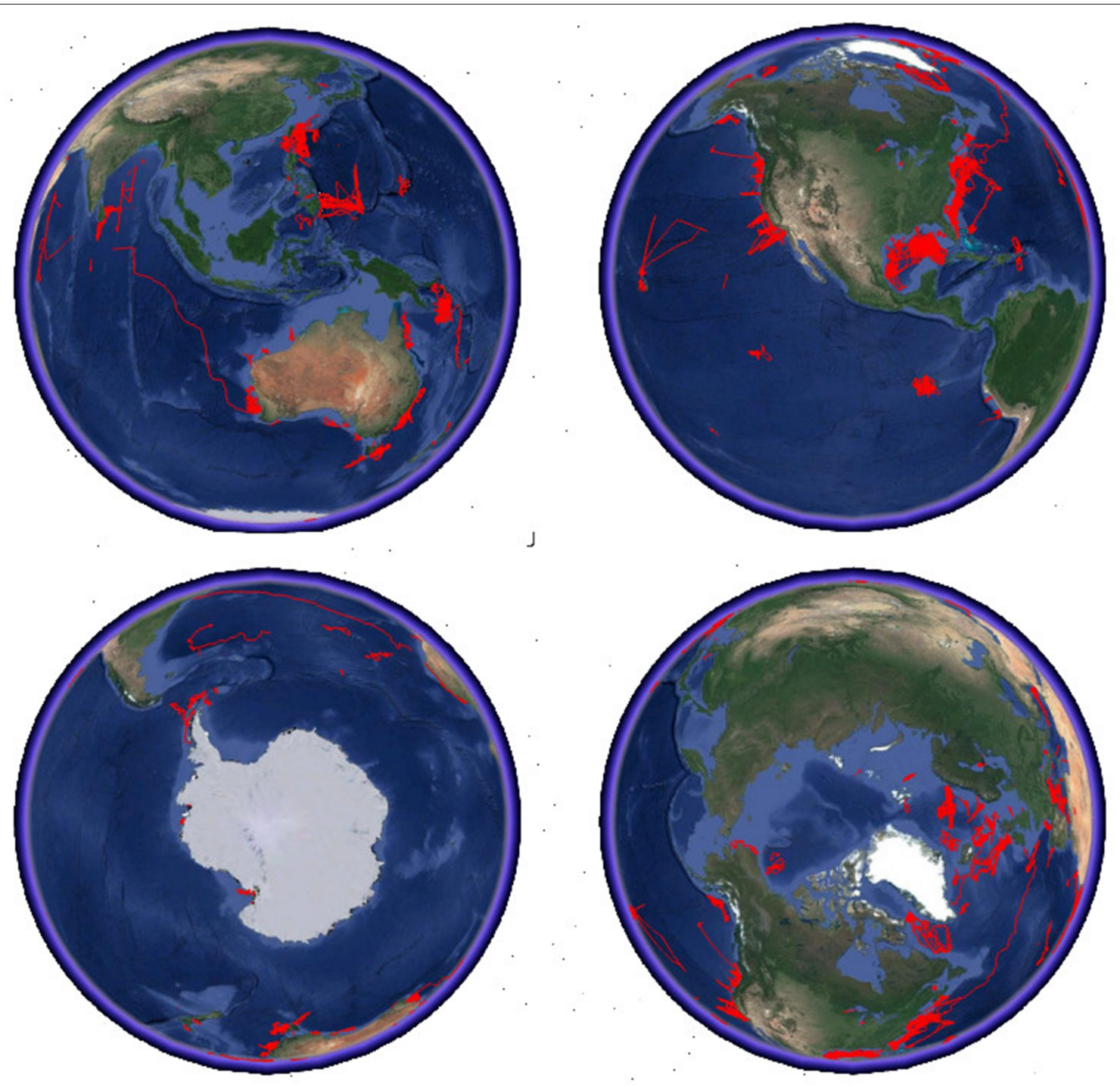

FIGURE 2 | Gliders tracks of past deployments until October 2018 (OceanObs'19 submissions), as can be viewed using google-earth from different locations.

set by topography. Accurate forecasting depends on initialization on these small scales, which can be satisfied by a network of gliders.

The most widespread application of sustained glider programs has been in boundary currents. These efforts range from the significant western boundary currents, to the highly productive eastern boundary upwelling systems, to regionally important boundary currents in marginal seas. Initial targets are often the mean and variability of velocity, temperature, and salinity, and now moving to include biogeochemical and biological variables. As the sustained time series increase in length, interannual climate variability is resolved. The remarkable increase in sustained glider observations in the last 10 years is summarized below and illustrated by Figures 4-6.

Sustained projects in the Atlantic include observations on the western, eastern and northern boundaries of the North Atlantic. The marginal seas of the Atlantic, including the
Mediterranean and the Gulf of Mexico are also home to longterm observations.

- The Davis Strait was observed repeatedly during 2005-2014 to quantify the exchange between the Arctic Ocean/Baffin Bay and the subpolar North Atlantic (Figure 5A; BeszczynskaMöller et al., 2011; Curry et al., 2014; Webster et al., 2015). Although this effort succeeded in collecting yearround observations across the seasonally ice-covered strait, challenging logistics, harsh operating conditions and funding prevented continuous occupation of the section over the entire 2005-2014 period.

- The warm water paths of the North Atlantic Current over the Rockall-Hatton Plateau at $58^{\circ} \mathrm{N}$ are being observed using repeat glider sections between 15 and $21^{\circ} \mathrm{W}$ as part of OSNAP since 2014 (Figure 5E; Houpert et al., 2018; Lozier et al., 2019). 


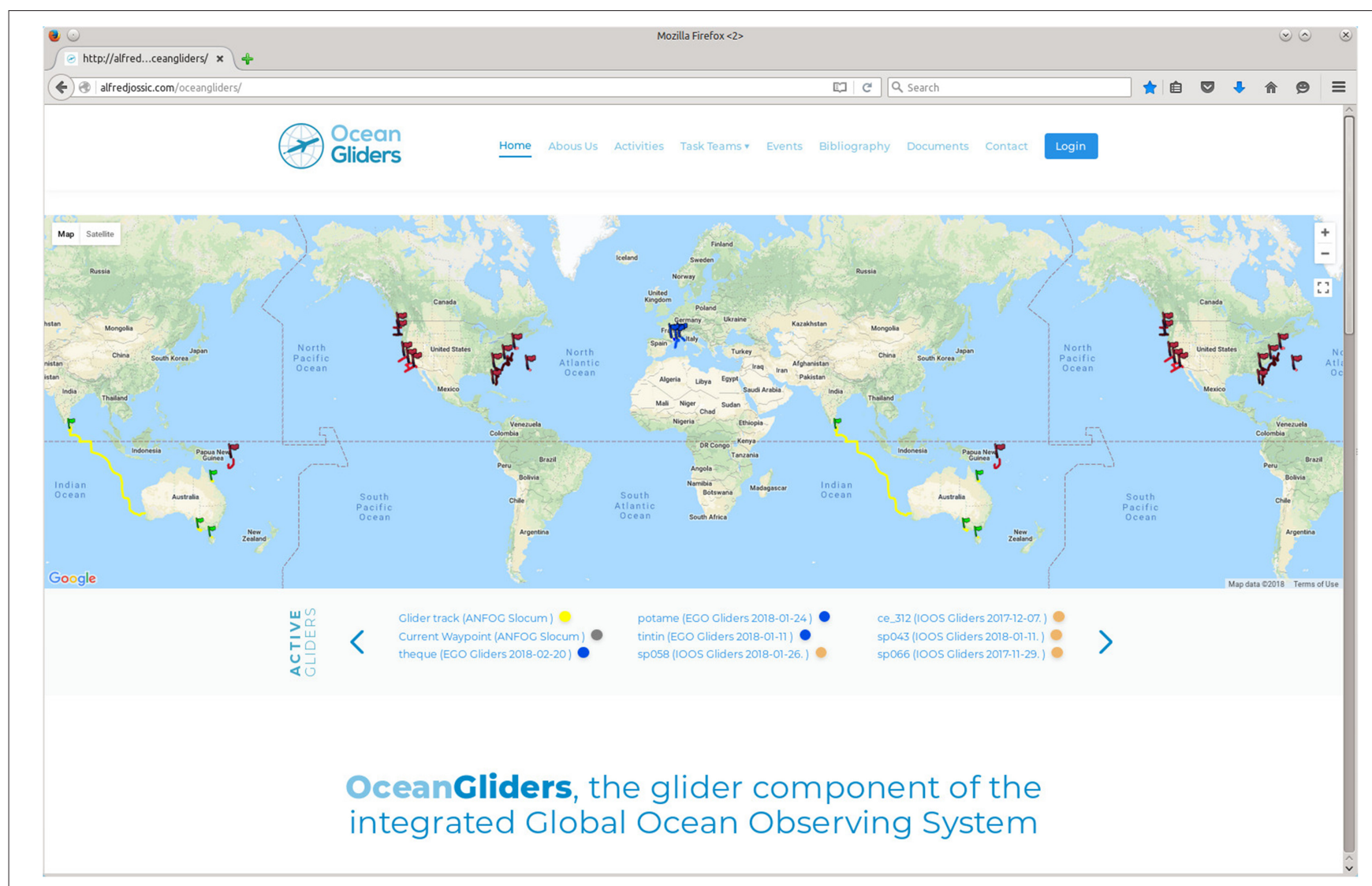

FIGURE 3 | The global active glider fleet trajectory map, updated daily (from http://anfog.ecm.uwa.edu.au/index.php?page=global_gliders, accessed 23 August, 2018).

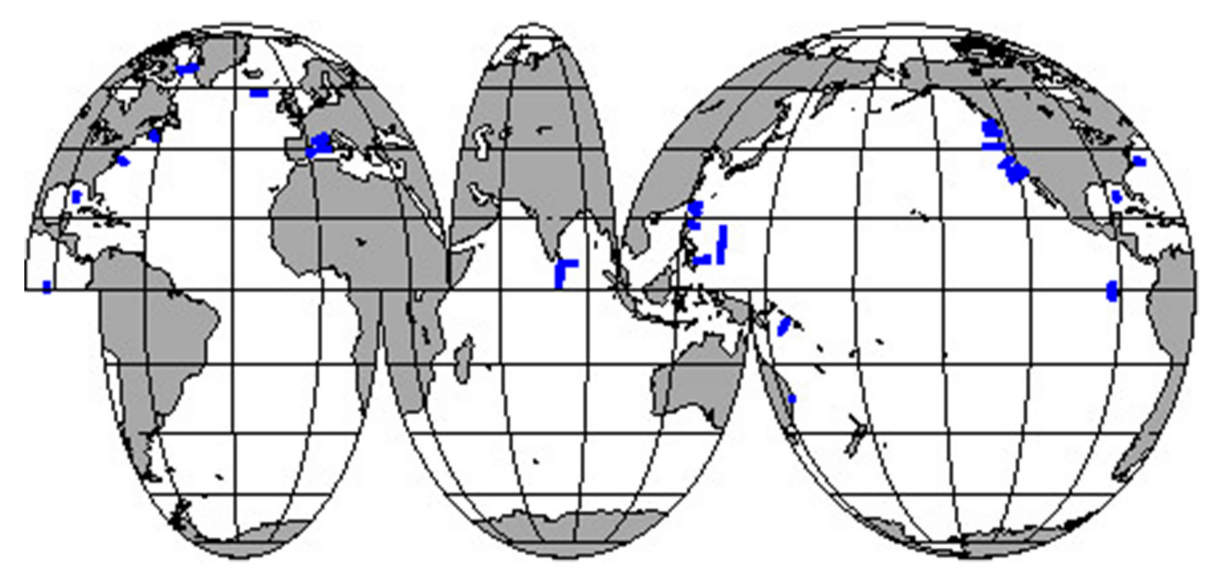

FIGURE 4 | Sustained observations of boundary currents of duration from at least one to over a dozen years. Mean sections of absolute geostrophic velocity are a unique product of underwater gliders, calculated by combining geostrophic shear with directly measured depth-average velocity. These sections at the locations in this figure are shown in Figures 5, 6.

- The Nova Scotia Current was observed during 2011-2014 by repeat glider sections as part of the Ocean Tracking Network (Figure 5B; Dever et al., 2016) and re-established by Fisheries and Oceans Canada in 2018 as part of its monitoring programs.
- Along the East Coast of the United States, a program of routine glider surveys across the Gulf Stream is underway. Commanded to steer across strong currents of the western boundary current, gliders are able to occupy cross-Gulf Stream transects as they are advected downstream (Figure 5C; Todd 


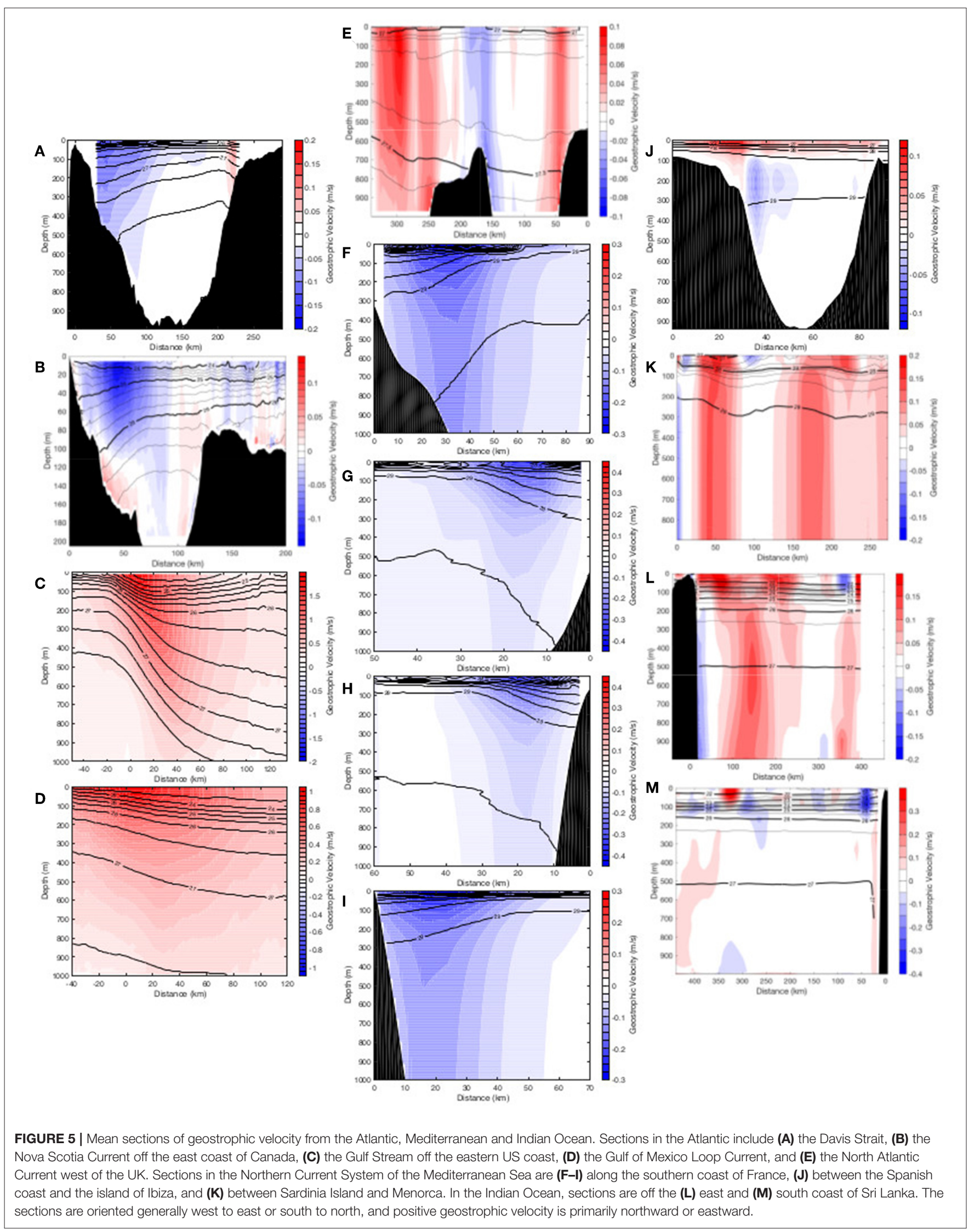




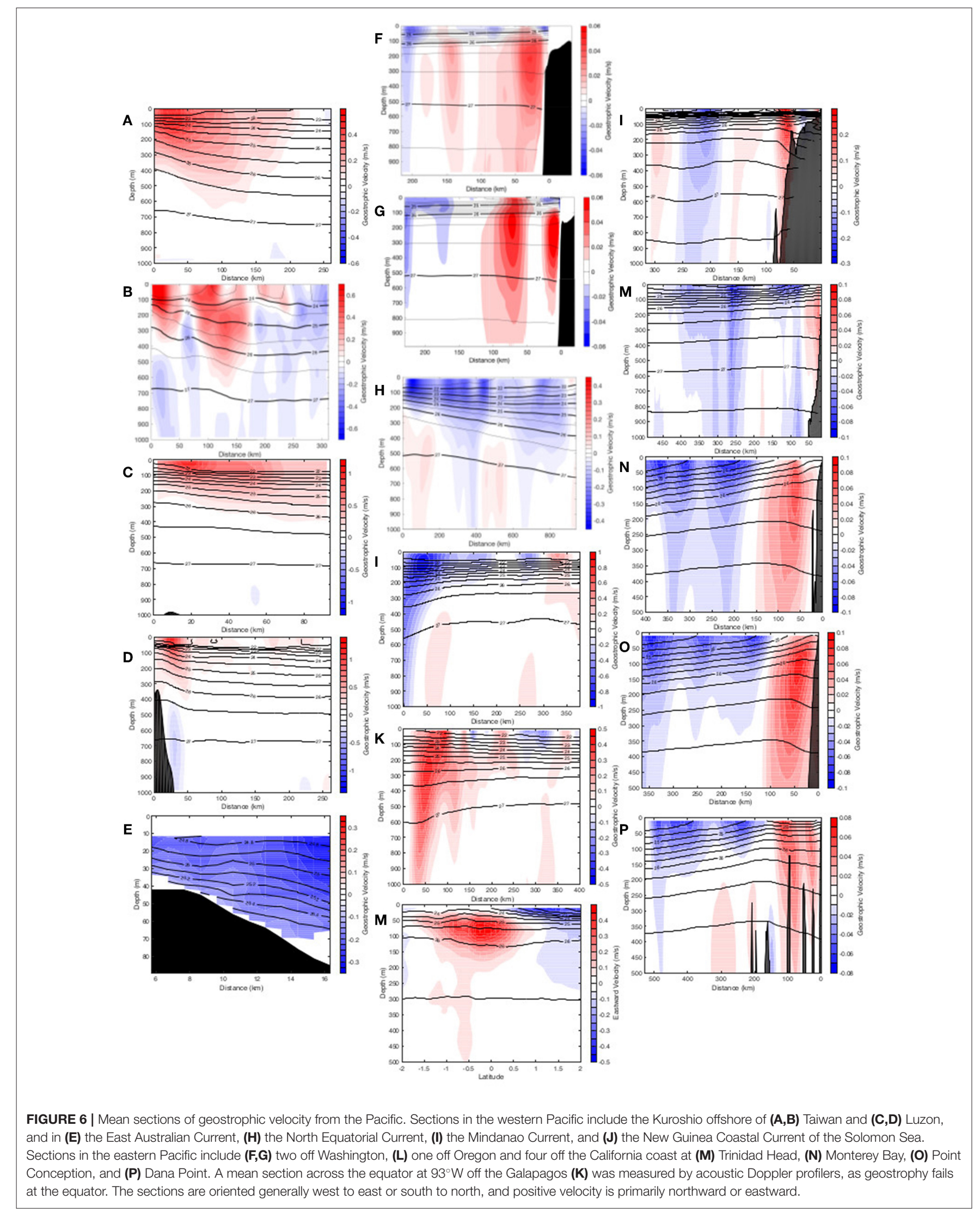


et al., 2016, 2018; Todd, 2017; Todd and Locke-Wynn, 2017; Gula et al., 2019).

- The Gulf of Mexico Loop Current was observed starting in 2007, and continuously during 2011-2014 with a focus on mean structure, eddies and separation processes (Figure 5D; Rudnick et al., 2015; Todd et al., 2016). Along-gradient glider trajectories of mesoscale eddies ubiquitous in the central and western Gulf of Mexico have been repeatedly carried out since May 2016 to present as a component of a quasi-continuous ( $90 \%$ of time) monitoring program conducted by GMOG.

- European Slope Current at $56.5 \mathrm{~N}$ as part of the sustained Ellett Line program. Gliders have been occupying this section in winter since 2009, and several times per year since 2015 (Sherwin et al., 2015).

- In the Western Mediterranean, repeat glider transects have been conducted to monitor the variability of the Northern Current System, over 10 years in the north of the basin (Figures 5E-H; Testor et al., 2018), for 6 years at a circulation "choke" point (Figure 5I; Heslop et al., 2012), for 8 years at the Mallorca Channel (Barceló-Llul et al., 2019) and more recently between Sardinia and Balearic Islands (Figure 5J) and between Mallorca Island and the African coast (Cotroneo et al., 2016; Aulicino et al., 2018).

- The Norwegian Atlantic Current Observatory has undertaken long term glider monitoring across 2 transects over 4 years, monitoring northward flow to the Arctic regions (Høydalsvik et al., 2013). Gliders have been used to monitor the topographic steering of warm Atlantic waters toward Arctic tidewater glaciers on the west Spitsbergen margin (Fraser et al., 2018).

- Since 2012, gliders have been deployed in the Subantarctic Zone of the South Atlantic each year, as part of the Southern Ocean Seasonal Cycle Experiments (SOSCEx; Swart et al., 2012). Deployment have covered all seasons except late austral autumn to assess bio-physical interactions from sub seasonal to seasonal scales (Du Plessis, 2015; Swart et al., 2015; Thomalla et al., 2015; Little et al., 2018; Du Plessis et al., 2019).

- Repeated sections were carried out off Cape Verde Islands as part of the Collaborative Research Center 754 (DFG; Oschlies et al., 2018), Senegal (Kolodziejczyk et al., 2018) and Angola, primarily to study the OMZ.

Projects in the Indian Ocean range from the Bay of Bengal to the currents that connect to the Southern Ocean:

- Gliders in the Bay of Bengal off the east and south coasts of Sri Lanka (Figures 5K,L; Lee et al., 2016).

- Repeated sections in the Agulhas Current since 2017 as part of Gliders IN the Agulahas (GINA, Krug et al., 2018) following the Shelf Agulhas Glider Experiment (SAGE) in 2015. Initial results include observations of cyclones on the inshore edge of the current (Krug et al., 2017).

- Many cross sections of the Leeuwin Current, the poleward flowing eastern boundary current in the southern Indian Ocean (Pattiaratchi et al., 2017).

Projects in the Pacific include sustained observations in the eastern boundary current of the North Pacific, and both the midlatitude and low-latitude western boundary currents of the North and South Pacific:

- The Kuroshio off Taiwan (Figures 6A-D; Lien et al., 2014; Yang et al., 2015), the North Equatorial Current north of Palau (Figure 6H; Schönau and Rudnick, 2015) and the Mindanao Current off the Philippines (Figure 6I; Schönau and Rudnick, 2017) were occupied continuously from 2007 to 2014 to quantify transports and water masses as part of the project Origins of the Kuroshio and Mindanao Current (OKMC). Observations began again in 2017 with a line off Taiwan.

- Repeated sections across Solomon Sea were made for nearly a decade to monitor the low latitude western boundary current that feeds the Pacific equatorial current system from the Southern Hemisphere (Figure 6J; Davis et al., 2012).

- The California Underwater Glider Network has occupied three lines in the California Current System for the past decade with a primary goal of monitoring the regional effect of climate variability as caused by El Niño (Figures $\mathbf{6 N - P}$; Rudnick et al., 2017). A fourth line off northern California has been occupied for 2 years (Figure 6M).

- The inshore edge of the East Australian Current (EAC) has had repeated sections run since 2010 (Figure 6E) to observe the separation of the current, and the momentum balance at that point (Schaeffer and Roughan, 2015), the hydrographic structure of the current (Schaeffer et al., 2016a), the biogeochemistry (Schaeffer et al., 2016b).

- Sections across the California Current, immediately south of the West Wind Drift bifurcation region, were occupied continuously from 2003 to 2009, and then annually, for 6-9 months per year, from 2010 to 2015 (Figures 6F,G). These observations provide data to advance the understanding of the regional response to climate variability and California Undercurrent Eddies (Pelland et al., 2013).

- The Ocean Observatories Initiative began occupying 5 sections off Oregon and Washington, starting in 2014 to address the influence of climate variability on eastern boundary ecosystems. One of these lines, off Oregon, has been occupied continuously since spring 2006 (Figure 6L; Mazzini et al., 2014).

- Repeated sections off Peru started in 2008 (Pietri et al., 2013) to study the Humbolt system.

- Repeated sections off Chile (Pizarro et al., 2016) primarily to study the OMZ.

- Repeated sections in the Coral Sea adjacent to the north Queensland coast (Australia) have been used to estimate boundary current transport (Ridgway and Godfrey, 2015).

- The Equatorial Current System was observed during 20132016 using acoustic Doppler profilers (Todd et al., 2017; Figure $6 \mathrm{H}$ ), as geostrophy fails at the equator. These measurements were undertaken as part of the Repeat Observations by Gliders in the Equatorial Region (ROGER) program (Rudnick, 2016).

- Glider transects at $37.9^{\circ} \mathrm{N}$ across the East Korean Warm Current along the Korean Peninsula have been conducted since 2017. 
Underwater gliders can measure absolute geostrophic velocity. The geostrophic shear may be calculated from glider sections by estimating the horizontal gradient of density. This shear is referenced to the depth-average velocity that is calculated by dead reckoning between navigational fixes at the beginning and end of dives. This absolute, depth-dependent geostrophic velocity normal to the glider section allows calculation of the transport of mass, heat and salt. These transports are the fundamental quantities needed for baseline monitoring of boundary currents. Much work has been done to quantify the scales resolved and the accuracy of the velocity. For example, high frequency motions, such as internal waves, are projected into spatial variability in a glider section, with the result that horizontal wavelengths longer than $30 \mathrm{~km}$ are resolved in midlatitudes (Rudnick and Cole, 2011). The accuracy of the depth-average velocity, is of order $0.01 \mathrm{~ms}^{-1}$, as inferred in early design studies, and confirmed by decades of observations (Rudnick et al., 2018). The sustained observations have produced several estimates of the boundary currents (Figures 4-6).

The goal of the OceanGliders Boundary Ocean Observing Network (BOON) is to provide coordination for a global observing program. Because boundary currents invariably reside in EEZs, their observation must depend on regional efforts respectful of the coastal countries. The goal of BOON is to sustain observations year-round. The result will be a global network of regional networks that monitor boundary current variability across international borders to the world's benefit.

The OceanGliders BOON complements existing ocean observing networks. Argo has transformed ocean science with its global coverage. BOON connects Argo's observations of the open ocean with the coastal ocean by operating the transects that are required to monitor boundary currents. BOON expands the footprint of site-specific moorings of OceanSites by repeated sections that may connect to mooring locations. Repeated surveys by ships form the backbone for many existing regional efforts, in some cases going back decades. BOON will step change our ability to observe boundary current variability in real-time, across all seasons and in difficult conditions and locations, building on the historical record and improving temporal and spatial resolution by overlapping with these ship surveys. BOON will identify gaps in the observation of boundary currents, with the goal of filling them by the most appropriate technology (Todd et al., 2019).

\section{Storms}

Tropical and extra-tropical storms are among the most destructive natural events on Earth. Tropical storms cause an average of 10,000 deaths per year and will potentially cost the global economy more than $\$ 9.7$ trillion over the next century. Growing coastal populations, urbanization, and rising sea levels magnify our vulnerabilities to storms, escalating the need for more accurate storm tracking, intensity and impact forecasts. Tropical storm tracking forecasting has shown steady improvement over the past 25 years due, in part, to the improvements in the global atmospheric forecast ensembles. But similar improvements in tropical storm intensity forecasts have lagged, in part due to the paucity of upper ocean data defining its pre-storm heat content, the inability of operational ocean models to forecast with sufficient accuracy the rapid changes in upper ocean heat content in conditions of extreme forcing, and the uncertainty in the processes that influence the transfer of heat between the ocean and atmosphere. Tropical storm impacts, such as wind and storm surge, require accurate tracking and intensity forecasts.

Gliders have been the critical observing system element for two study areas in particular, one focused on an area of potential rapid intensification surrounding the Caribbean Islands, and another in the Mid Atlantic Bight where rapid intensity reductions have challenged forecasters.

In the tropical Atlantic and Caribbean Sea, early research carried out by NOAA/AOML, NOAA/NHC, and University of Miami scientists has demonstrated that the upper ocean is linked to hurricane intensification and/or weakening provided that the appropriate atmospheric conditions are present (Shay et al., 2000). For example, several studies have shown how major hurricanes, including Hurricane Katrina (2005), rapidly intensified while traveling over a warm Loop Current and Eddy feature in the Gulf of Mexico (Mainelli et al., 2008). Studies carried out for other Atlantic hurricanes have shown the close link between the upper ocean heat content and the intensity changes observed in Cat 3 and above hurricanes. Since this link has been established in this region, efforts are now geared toward improving hurricane intensification forecasts of numerical operational and experimental models to produce a correct representation of the upper ocean density (temperature and salinity) structure. For example, recent research has shown that the appropriate initialization of the ocean component within the HYCOM-HWRF intensity forecast model has improved the representation of the upper ocean while reducing the error of the intensity forecast of Hurricane Gonzalo (2014) by almost 50\% (Dong et al., 2017; Figure 7). In this case, underwater glider data were critical to improving the hurricane forecast because they were the only ocean observations that captured the salinity-stratified barrier layer that inhibited the mixing of colder subsurface waters and subsequent upper ocean cooling ultimately allowing for hurricane intensification (Domingues et al., 2015).

NOAA OAR research has established the relationship between hurricane intensity and the Mid Atlantic's two-layer water column. The missing essential ocean feature is the unseen bottom Cold Pool. This vast $(1,000 \mathrm{~km}$ long $\times 100 \mathrm{~km}$ wide $)$ cold water mass $\left(\sim 10^{\circ} \mathrm{C}\right)$ lies below a thin warm layer $\left(>28^{\circ} \mathrm{C}\right)$ during the Atlantic hurricane season and is unobservable by satellites. By deploying autonomous underwater gliders ahead of Mid Atlantic land-falling hurricanes, the Cold Pool was mapped and its evolution monitored, leading to the discovery of rapid storm induced mixing that cooled the ocean ahead-of-eye-center by up to $11^{\circ} \mathrm{C}$ (Glenn et al., 2016). This new ahead-of-eyecenter cooling process was shown to be region-wide in multiple hurricanes (Seroka et al., 2017) and is responsible for over $75 \%$ of the observed storm-driven cooling in the Mid Atlantic since 1985 (Glenn et al., 2016). Furthermore, the cooling of the surface ocean by the entrainment of the sub-surface Cold Pool was the missing component required to accurately forecast 

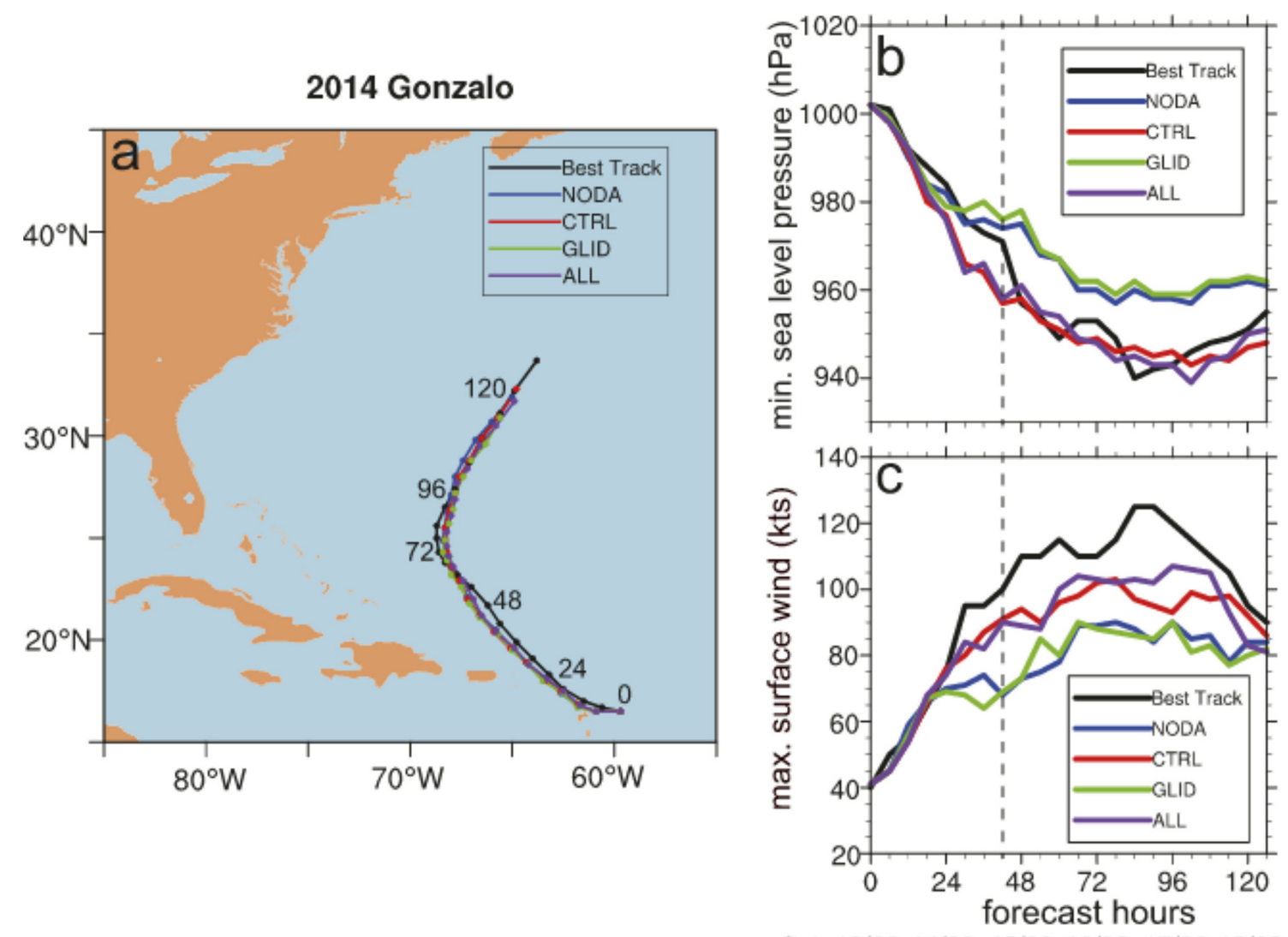

Oct. $13 / 00$ 14/00 15/00 16/00 17/00 18/00

FIGURE 7 | (a) Hurricane Gonzalo track forecast, (b) minimum sea level pressure (center pressure), and (c) maximum wind forecasts, along with the best track. Gliders improve hurricane forecast. The dashed line denotes the track location closest to the glider at 0000 UTC 13 Oct 2014. (Figure 12 from Dong et al., 2017).

the rapid de-intensification of Hurricane Irene (Seroka et al., 2016). In stark contrast, gliders deployed ahead of Superstorm Sandy revealed a different Cold Pool response and impact on intensity. The onshore track, large wind field, and slow approach forced the Cold Pool more than $70 \mathrm{~km}$ offshore. This removed the bottom Cold Pool water and resulted in limited surface cooling and little storm weakening ahead of Sandy's historic storm surge in the region (Miles et al., 2017). The warm surface layer and the bottom Cold Pool, and their rapid evolution during hurricanes, must be well-resolved to reduce the uncertainty of hurricane intensity predictions. This can only be accomplished with underwater gliders reporting whatever the sea conditions are, and real-time subsurface profiles over the GTS, since operational ocean models cut off satellite altimeter data assimilation for water depths $<150 \mathrm{~m}$, leaving satellite Sea Surface Temperature (SST) as the only operational data contribution on continental shelves.

Picket lines of subsurface gliders sustained for the hurricane season in areas of rapid intensity change where identified as the most critical addition to the integrated ocean observations required to improve the ocean component of coupled oceanatmosphere forecast models. A U.S. collaborative effort between NOAA, Navy, NSF, Industry and Academia implemented the hurricane glider picket line concept for the first time during the 2018 hurricane season. Data flow from individual glider operators to the GTS was coordinated through the U.S. IOOS Glider Data Assembly Center (DAC). The system was tested in September when 3 hurricanes were simultaneously present in the North Atlantic, each with gliders deployed in their path. This included Hurricane Florence, a category 4 storm at its peak that impacted the eastern seaboard of the US (Figure 8). The glider data transmitted over the GTS were used as input to the operational Ocean Heat Content maps that were used to help with NHC forecast intensity decisions.

OceanGliders supports the development of sustained glider observations to address hurricane issues worldwide as well as additional ones related to extra-tropical storms. Extra-tropical storms, also referred to as mid-latitude cyclones, are large scale $(>1,000 \mathrm{~km})$ low pressure weather systems that occur in middle and high latitudes and are associated with frontal systems. The wind speeds of these storms can be as high as those associated with tropical storms but their impacts last longer because of their greater spatial extent. Due to the large-scale features, extratropical storms are well-represented in atmospheric models. Hence, ocean gliders have mainly contributed to understanding the impacts of the storms on the ocean and coastal environments, particularly in terms of changes to the heat content (e.g., rapid 


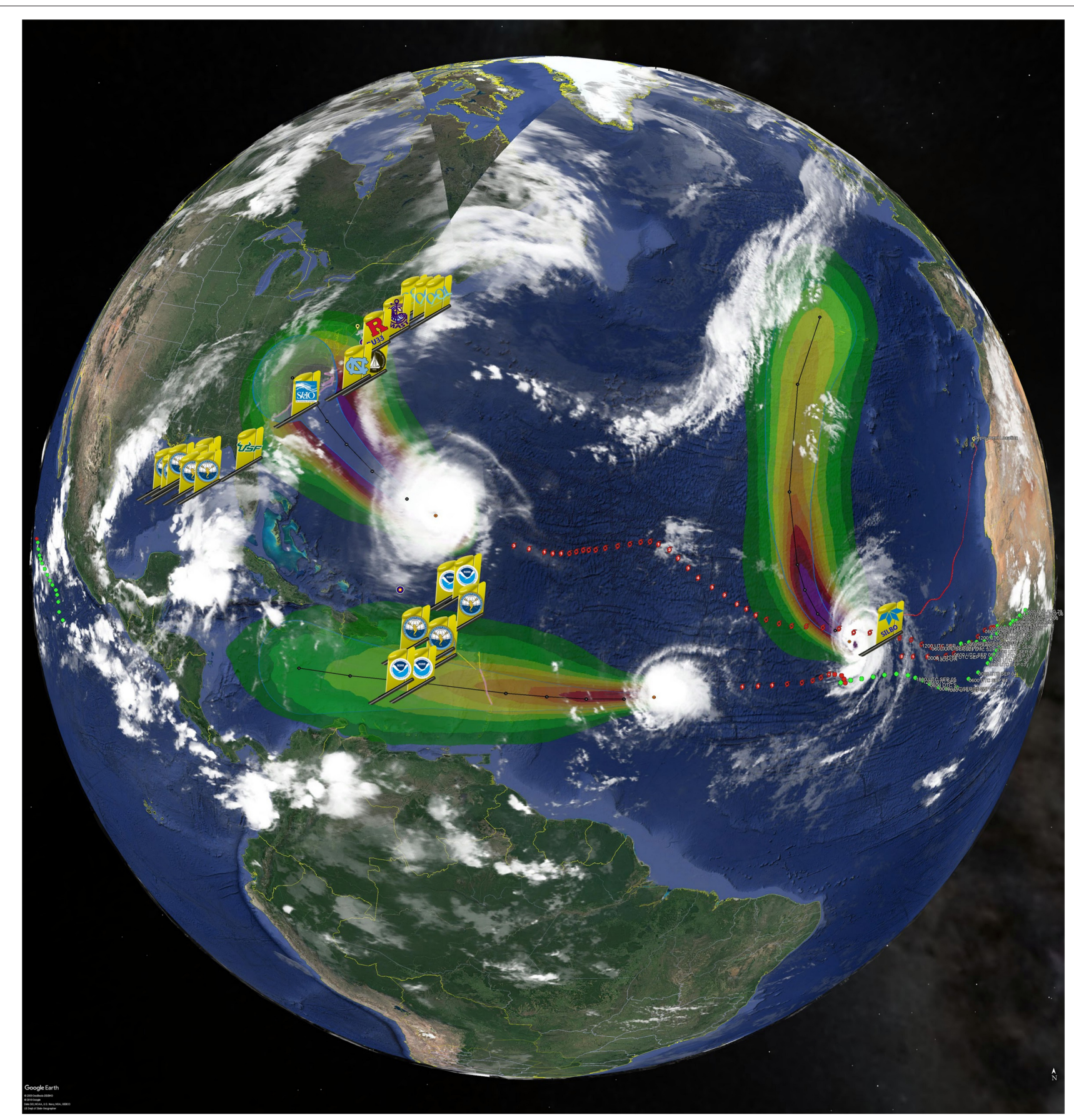

FIGURE 8 | Hurricane Florence, Isaac and Helene cloudtops (left to right) on September 11, 2018, with NHC best tracks behind each hurricane, NHC probability of tropical storm force winds ahead of each hurricane, and the tails of the diverse fleet of ocean glider in the picket lines transmitting upper ocean data in near-real time to forecasters.

cooling), its feedback on storm intensity, sediment resuspension and transport processes, and ecosystem response.

Ocean gliders are complementary to other storm sampling systems in their ability to relatively rapidly profile the upper ocean and transmit data to land even during the most severe storm conditions (Domingues et al., 2019). They provide unique datasets for studies of rapid upper ocean evolution and high-value profile data for assimilation in both operational forecast and research models before, during and after storms. Ocean glider measurements have revealed rapid changes in the distribution of water properties (temperature, salinity), and suspended sediment and chlorophyll (proxy for phytoplankton 

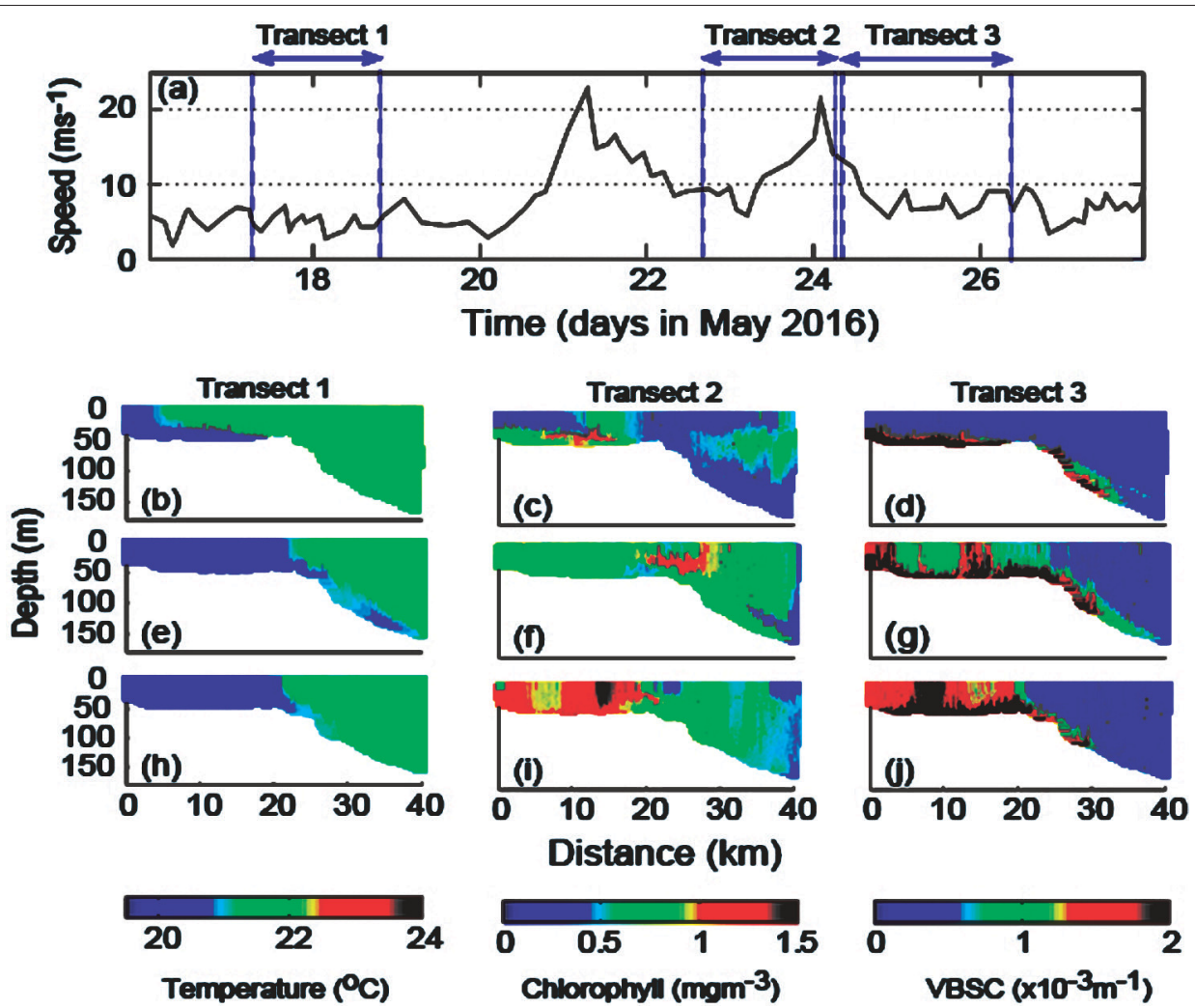

FIGURE 9 | (a) Wind speed and direction at Rottnest Island, south-west Australia. The vertical dashed lines represent timing of the ocean glider transects; Ocean glider vertical cross-sections of: (b,e,h) temperature $\left({ }^{\circ} \mathrm{C}\right)$; $(\mathbf{c}, \mathbf{f}, \mathbf{i})$ chlorophyll (mg. $\left.\mathrm{m}^{-3}\right)$; and, (d,g,j) backscatter $\left(\mathrm{x} 10^{-3} \mathrm{~m}^{-1}\right)$ across the Rottnest continental shelf. The time series of wind indicate calm winds (speeds $\sim 5 \mathrm{~m} \cdot \mathrm{s}^{-1}$ ) followed by two winter storms (speeds $>20 \mathrm{~m} \cdot \mathrm{s}^{-1}$ ). The wind speeds reduced to $\sim 7 \mathrm{~m} \cdot \mathrm{s}^{-1}$ on $23 \mathrm{May}$ before increasing again to $>20 \mathrm{~m} \cdot \mathrm{s}^{-1}$. There were 3 cross-shore ocean glider transects during this period. During the calm period (17-18 May 2016), a well-mixed water column with cooler $\left(20^{\circ} \mathrm{C}\right)$ water was present on the inner-shelf region to $5 \mathrm{~km}$ from the coast. Seaward of $5 \mathrm{~km}$, a dense shelf water cascade (DSWC, Pattiaratchi et al., 2011) was present and extended along the sea bed to the shelf break. On the inner shelf, chlorophyll concentrations and backscatter values were higher within the DSWC and low in the surface layer. The two storms vertically mixed the continental shelf resulting in a well-mixed water column, increased suspended sediment elevated chlorophyll concentrations (modified from Chen et al., in review).

biomass) concentrations. Gliders with turbulence packages are being used to quantify the strength of storm driven mixing and its relevance in supporting prolonged phytoplankton production (Swart et al., 2015; Nicholson et al., 2016) as also highlighted by data collected on the inner continental shelf along the Rottnest continental shelf in south-west Australia (Figure 9).

\section{Water Transformation}

Physical, chemical, and biological properties are imported, redistributed, mixed and exported in substantial amounts by the oceanic circulation and processes. Any attempt to understand, model, and predict the evolution of the global and regional climates and marine ecosystems must include observations of their variability and their local and remote sensitivities to external changes. Indeed, fluctuation in any aspect is to lead to changes in the others, with the potential for feedback loops between them. While average conditions of the oceanic circulation and processes have been studied and assessed, little is known about the shifts in the system because of difficulties in observing water transformation phenomena directly and determining their (physical, chemical, biological) impacts.
Water transformation processes occur at relatively small scales and high frequencies not presently addressed by the GOOS. They are critical phenomena, however, that need to be assessed to better understand and model the evolution of the global/regional oceans, and in particular, their deep reservoirs of heat, salt, nutrients, etc. We do not know how these ocean processes influence change in these water properties. To fill this gap, the OceanGliders program proposes the long term and sustained observation of these phenomena with gliders whose unique capabilities (including under ice operations) and versatility allow the monitoring of such processes, in combination with other observing techniques, with sufficient accuracy. OceanGliders aims to address the two following global needs in ocean observations, by considering several key regions where water transformation processes that are important for the global (physical, chemical and biological) ocean occur.

\section{Open Sea and Shelf Water Formation}

Much of what is known about the oceanic circulation derives from the fundamental concept of water mass. The global/regional ocean is composed of a limited number of water masses that 
are formed (or transformed) in particular regions because of favorable local conditions (atmospheric regimes, stratification, topography, general circulation and major currents interactions) that can trigger buoyancy changes and the vertical mixing of the resident water masses in the surface and/or bottom boundary layers. Due to preconditioning effects (bottom topography, atmospheric forcing, stratification) the water formation processes lead to large mixed patches $(100 \mathrm{~s} \mathrm{~km})$ presenting quasihomogeneous (physical, chemical and biological) properties, and intermediate (100s of $\mathrm{m}$, shelf/slope bottom) or sometimes deep (1-2 km, bottom) mixed layer depths, or thick (100s of m) bottom boundary layers.

The buoyancy decrease can be due to strong air-sea interactions (Swart et al., 2015; Houpert et al., 2016), sea ice and polynya formation in winter (Queste et al., 2015; Schofield et al., 2015), rough bottom topography (Beaird et al., 2013; Ruan et al., 2017), and major current instabilities (Schaeffer and Roughan, 2015). The water formation processes are common in winter in the subpolar gyres and high latitudes leading to the formation of the open ocean and shelf waters (Pattiaratchi et al., 2011; Durrieu de Madron et al., 2013; Bourrin et al., 2015; Peterson et al., 2017-Figure 9). It is so-called deep convection in few areas in the world where the mixing can reach great depths and ventilate the deep layers of the ocean due to peculiar and regional conditions (Testor et al., 2018). Later, in spring, these regions restratify, while the new water masses spread (or cascade on the ocean bottom) and mix with their surroundings. During this phase, intense blooms occur as the vertical mixing brought a large amount of nutrients in the euphotic layer and this can be sustained for a while by restratification processes (Queste et al., 2015; Schofield et al., 2015; Mayot et al., 2017), while the impacts on the benthic ecosystems can be important because of resuspended sediments. Mixing due to rough topography can also occur in overflow regions (Antarctic, Mediterranean, Denmark Strait) leading to the formation of new water masses and sediment resuspension (Durrieu de Madron et al., 2013, 2017; Venables et al., 2017) and through upwelling dynamics. The ice edge, presently in retreat toward the shelf, is a region of particular interest for water mass transformation, and gliders are ideal tools for exploring the marginal ice zone, as demonstrated in studies close to Greenland (Lee and Thomson, 2017; Våge et al., 2018).

These processes lead to the formation of water masses that move (together with their properties) through the oceanic basins interacting at the large scale with other water masses. This mixing can "buffer" or "memorize" climatic (physical, biogeochemical and biological) signals for long periods of time, until these water masses are mixed again vertically in the following years/decades/centuries, possibly far away (1,000s of $\mathrm{km}$ ) from their formation areas. This water mass transformations can lead to rapid changes in the ocean, both locally and in remote places (Schroeder et al., 2017; Bosse et al., 2018).

Presently the large-scale formation of mode waters in winter is relatively well-covered by the present GOOS, but not by other open sea and shelf water mass formations that are more constrained by the regional scale. These processes are critical to the ventilation of the ocean and the evolution of the marine ecosystem, and this limits our understanding of the present state and evolution of the ocean and marine ecosystem. They occur sometimes in local patches on the shelf and in open sea, and on an intermittent basis, and are consequently not well resolved (temporally and spatially) at present. In addition, they generally result from different oceanic and atmospheric factors that encompass at least a year, owing to preconditioning effects (Durrieu de Madron et al., 2011; Bosse et al., 2018). This implies that sustained in-situ observing efforts must often be carried out in relatively large areas throughout the year to fully grasp the phenomena, with efforts occurring at a high frequency, and with high horizontal resolution to resolve the features that are involved. Moreover, in case of strong air-sea interactions in winter/spring, it is challenging to carry out traditional in situ measurements due to severe conditions at sea, for example winter convection in the Labrador Sea (deYoung et al., 2018). The observation of such phenomena remained a challenge until the use of autonomous underwater gliders, in combination with more classical ocean observing techniques. Much progress has been made during the last decade thanks to these relatively new platforms as demonstrated by many new publications on that subject (see introduction) and has led to a paradigm shift for deep convection (Figure 10). OceanGliders supports initiatives to fill these observational gaps in regions of water mass transformation in the coastal and open ocean.

\section{Mesoscale and Submesoscale Phenomena}

Mesoscale eddies (10-100 km horiz.) occur throughout the ocean and are not well-resolved by the present GOOS, particularly their vertical structure. They are responsible for large fluxes of energy and matter in the ocean. Depending on whether they rotate cyclonically or anticyclonically, they can be rich or poor in nutrients and can provide favorable or unfavorable conditions for phytoplankton and other organisms. They can be surface constrained, centered at intermediate depths or even extend down to the bottom (even the abyssal plain) and resuspend sea-floor sediments (Durrieu de Madron et al., 2017). Between their cores and their surroundings, temperature can vary by several degrees and practical salinity by $1 \mathrm{~g} / \mathrm{kg}$ or more, while biogeochemical properties such as oxygen saturation can vary from 0 to $100 \%$ and $\mathrm{pH}$ by more than 1 (Bosse et al., 2017; Karstensen et al., 2017-Figure 11).

Mesoscale eddies can have a sub-surface expression, typical of the water mass composing their cores, and some are undetectable by satellite which makes their observation a challenge. They can be very coherent and dissipate mainly through very small-scale processes (diffusion, microturbulence) making their lifetimes extend to months or even years (Yu et al., 2017). They are able to transport the physical, biogeochemical, and biological properties of the waters composing their cores over great distances $(1,000 \mathrm{~s}$ $\mathrm{km}$ ) after their formation before they finally dissipate (Fan et al., 2013; Pelland et al., 2013; Bosse et al., 2015, 2016, 2017; Meunier et al., 2018a). They can dissipate due to dramatic events like vertical mixing driven by atmospheric forcing reaching into their cores or by interactions with other eddies, currents or topography. Their properties, particularly their biological ones, can also change drastically throughout their lifetime due to such 


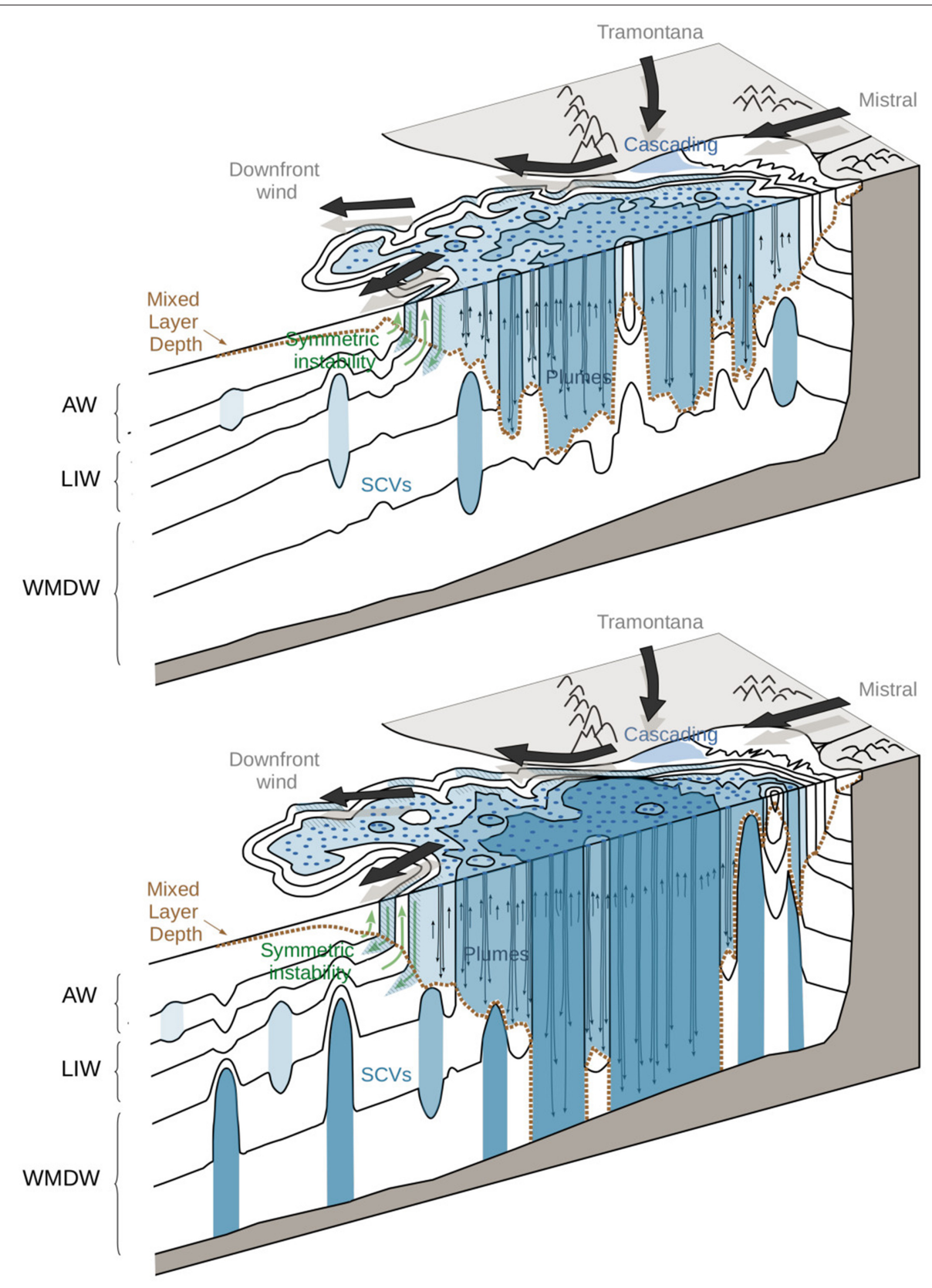

FIGURE 10 | Schematic diagram of the evolution of the convection area during the violent mixing phase in a period of 1-2 weeks. Underlying stratification/outcrop is shown by selected isopycnals (continuous black lines). The volume of fluid just mixed by convection is shaded and color coded according to potential density classes. (Figure 13 from Testor et al., 2018). Numerous glider deployments have allowed to objectively map the (physical and biogeochemical) evolution of the deep convection area on a 10-days basis for quantitative estimates while high resolution measurements allowed to investigate the small scale processes at stake.

external factors (McClatchie et al., 2012; Ainley et al., 2015; Villar et al., 2015; Durrieu de Madron et al., 2017). The impact of such factors on the properties of the eddy cores clearly depends on their vertical structure which in turn, depends on the oceanic (and atmospheric) conditions at their formation.

Mesoscale eddies can be formed through vertical mixing (due to air-sea-ice interactions or induced by rough topography, major current barotropic/baroclinic instabilities and/or detachments from the boundary circulation due to the continental slope curvature (Caldeira et al., 2014) and/or other effects like upwelling (Bosse et al., 2015). Mesoscale eddies can be classified according to their formation mechanism because they present similar characteristics and core properties. It has been shown that a number of different types of eddies (Loop Current Eddies, Agulhas rings, Dead Zone Eddies, Gulf Stream rings, Meddies, Suddies, Weddies, Algerian/Sardinian Eddies, deep 


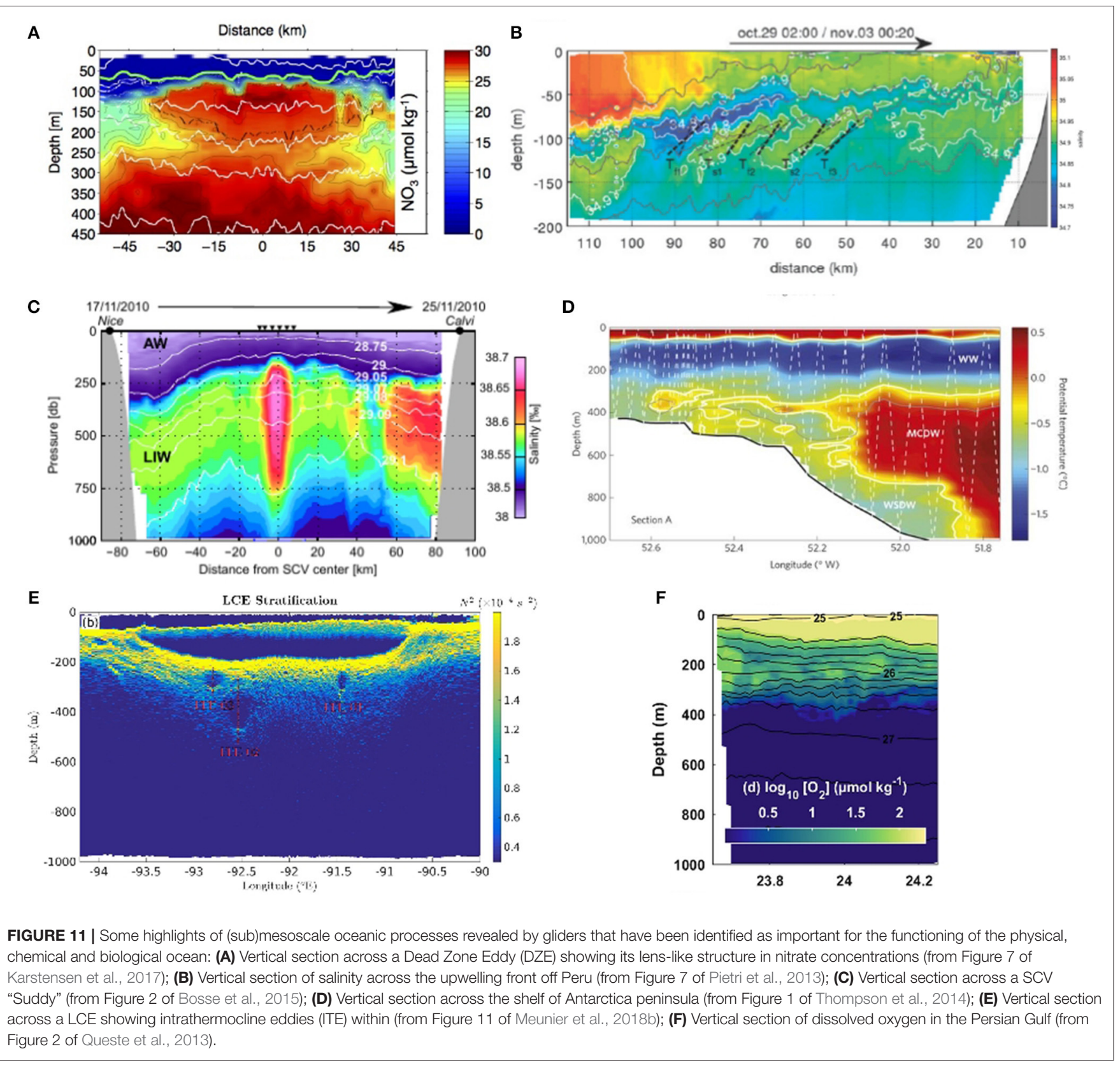

convection SCVs, ITEs...) can have a great impact on the ocean circulation/ecosystem state and evolution through their particular structures and transport mechanisms. Other fine scale processes are clearly involved in the ocean mixing, like microturbulence (Fer et al., 2014; Palmer et al., 2015; Schultze et al., 2017) or frontogenesis, filamentation due to stirring or symmetric instability (Figure 11 and Ruiz et al., 2012; Thompson et al., 2014, 2016; Thomsen et al., 2016; Pietri et al., 2013; Brannigan et al., 2017; Buffett et al., 2017; Du Plessis et al., 2017; Pascual et al., 2017; Kolodziejczyk et al., 2018) that can lead to significant vertical velocities and fluxes. However, the extent and variability of their impact over long periods of time still needs to be assessed. The "mesoscale" dynamics and associated "submesoscale" features are important contributors to the ocean state and are of crucial importance for biogeochemical and biological processes in the ocean. Gliders offer a new highresolution lens for observing the full seasonal cycle, a dominant mode of the earth system, in their ability to observe the physicalbiological coupling at sub-seasonal and sub-mesoscale (Martin et al., 2009; Swart et al., 2012, 2015; Monteiro et al., 2015; Thomalla et al., 2015; Du Plessis et al., 2017).

It is difficult for an in situ ocean observing system to capture all these important but relatively small circulation features, but a regular (annual) statistical assessment of the numbers and properties (and impact) of the main families of eddies and smaller processes can be achieved through subsurface, continuous and sustained glider observations of sufficient horizontal resolution. The time and space resolution 
of the glider sampling, for a variety of different sensors, make gliders essential observing platforms for studies and continuous assessments of the role of (sub)mesoscale processes in the ocean circulation and ecosystem. Over the last decade, a remarkable number of articles on (sub)mesoscale dynamics and smaller scale mixing processes based on underwater glider data and their impact on biogeochemistry and biology has been published (see introduction). The importance of Submesoscale Coherent Vortices (SCV), filaments along fronts and around mesoscale eddies, and induced vertical movement, has been demonstrated from ground truth and their impact can now be monitored on the long term in key regions with gliders (Hristova et al., 2014; Bosse et al., 2016; Yu et al., 2017).

Underwater gliders do sample the vertical structure of the ocean in an unprecedented way, with high resolution along the horizontal over long periods of time. Gliders also transmit the observational data in near real-time. This remote access to observational data that resolves the (sub)mesoscale can improve forecasting the ocean dynamics, biogeochemistry and ecosystem. The glider data is a perfect match for assimilation in regional/coastal numerical models, providing ocean state estimates at small scales with increased accuracy benefiting societal applications. Gliders can map the subsurface ocean at high resolution and provide powerful tools for monitoring previously inaccessible ecological processes. OceanGliders promotes and supports all physical, biogeochemical and biological studies focusing on these small-scale processes and encourages long-term continuation of these studies. The anomalies caused by these (sub)mesoscale variabilities exceed by one order of magnitude those attributed to changes in large scale circulation and marine ecosystem variability brought about by a warming planet, as assessed by the IPCC (Bates et al., 2018) and must be considered to further our understanding and monitoring of the physical, biogeochemical and biological ocean.

\section{END-USER BENEFITS}

In section Addressing global observing needs, we have detailed the unique "oceanographic" monitoring space that gliders occupy. Here we describe how this translates to benefit for the end users of a fully integrated observing system, i.e., what key roles (primary and supporting) a global sustained glider network can play in delivering services for both science and society.

Gliders can make sustained observations at high resolution, bringing temporal and spatial scales, hourly to sub seasonal and from $10 \mathrm{~m}$ to $1,000 \mathrm{~km}$ 's, relevant for a number of key ocean processes within economic reach. They are navigable and can be directed to sample ocean phenomena in real-time and with a fleet of gliders monitoring can be continuous, if required, and operational. Glider sensor payloads are expanding and their unique role in acoustic monitoring is already being exploited. They can sample in extreme conditions and to increasing depths, from surface to $6,000 \mathrm{~m}$ depth.

Gliders require pilots; however navigation is increasingly automated as a result of advances in platform reliability, community experience and piloting support tools. Glider observations require careful data processing protocols, an area that is being actively resolved, with tools and services emerging, and standard products from several deployments (e.g., gridded sections, geostrophic currents, etc.) that could be more accessible to non-expert users, many of which are from the OceanGliders community. Although gliders are relatively "slow" samplers, this is not an impediment to providing sampling capability at key space and time scales for the global observing system.

Gliders are uniquely poised to deliver sustained and responsive observations to the GOOS in the following areas:

- Connecting coast to open ocean: key for monitoring the regional effects of climate variability, and of processes (circulation, currents, upwelling) that have an impact on regional ecosystems.

- Boundary current monitoring: key to the transport of heat, salt, biogeochemical variables (nutrients) and plankton, they influence ecosystems and therefore variability in ocean productivity, and impact flood levels, erosion and commercial activity.

- The observation of ocean state variables at a high density in time and space in order to gain insight into the variability/statistical distribution of these variables locally given the turbulent nature of ocean flows.

- Surface to deep profiles in extreme conditions: observing ocean structure that affects the strength of violent storms (e.g., hurricanes) and of violent ocean mixing.

- Sustained observations in the polar regions where ship persistence is challenging due to ice and harsh conditions.

- Fast deployment and real-time navigation enabling delivery of vital information for environmental disaster management.

Looking at these key sampling capabilities under the GOOS theme areas of climate, operational services and ocean health, it is clear that sustained glider monitoring, as part of a fully integrated global ocean observing system, delivers a range of benefits.

\section{Climate}

- Monitoring boundary currents delivers knowledge on subseasonal variability and long-term trends that affect climate, leading to improved climate prediction. This information is used for adaptation to climatic change.

- Sustained 3D observations of deep and shelf water formation, a key component of our climate and ocean circulation system, provide knowledge to assess deep storage of heat, salt, nutrients and carbon sequestration. They uniquely can aid our understanding of variability in water formation and the impact of this on the global ocean budgets.

- Monitoring the subsurface development of climate oscillations (e.g., el Niño) aid prediction, support advanced warning capability and improved parameterization of climate patterns that affect seasonal forecasts.

\section{Operational Services}

- Monitoring lines across key coast-to-open ocean transects (often boundary current regions) increase the accuracy of regional ocean forecasts, which have economic impact (e.g., offshore wind, powerful eddies that affect oil platform drilling, flood hazard warnings, abundance and location of commercial 
species) supporting reanalysis and prediction models, good for getting real time data back to inform the next modeling cycle.

- Glider deployments in the path of hurricanes and violent storms (tropical and extratropical) provide in situ water profiles of ocean structure and heat/salt content assimilated real-time into models, significantly increasing the accuracy of the storm intensity prediction, which is vital to regional government and emergency services.

- Speedy deployments of gliders at pollution events, provide simultaneous data on ocean circulation and pollutants, either to track the pollutants or to improve ocean forecasts by providing data for assimilation. This supports decision making by better disaster management services and thus can reduce environmental impact.

- Speedy and flexible deployments of gliders can enable colocated measurements with other air/ocean observing systems, which are key for advancing scientific understanding of marine biogeochemical-physical interactions and/or air-sea flux interactions across the oceanic surface. These can also help provide precious data points for future coupled data assimilation methods under active consideration for balanced initialization of coupled earth system models.

- Sustained ocean sound monitoring delivers real time information on key marine mammal species, for ship avoidance decisions. Increasingly, this is a must for conservation of populations as new shipping routes increasingly intersect with marine mammal habitats.

- Monitoring boundary currents or water transformation in key areas delivers knowledge on ocean changes, both sub-seasonal variability and long-term trends, that affect climate. Real-time information on these key components of the global circulation better constrain models and are used, for example, to increase the accuracy of forecasts for coastal regions.

\section{Ocean Health}

- Sustained transects from coastal to open ocean, including boundary currents and water transformation areas, are key for monitoring the regional effects of ocean variability on regional ecosystems. Physical, chemical and biological information from these sections improves understanding of ecosystem response to environmental stressors (e.g., low dissolved oxygen, ocean acidification), aids regional ecosystem management and can provide ocean health monitoring indicators.

- Sustained acoustic (fish tags, passive acoustics for mammals, active acoustics for zooplankton) and video monitoring from coast to open ocean, deliver information assessing distributions and stocks as well as behaviors of marine organisms and response to environmental conditions that enables improved physical/ecosystem modeling, prediction, and resource management.

\section{THE WAY FORWARD}

At present, global glider operations are still at the pilot stage and are not fully developed. There are some regional operations, e.g., the repeated glider transects off the west coast of the
United States, that are well-established and fully operational but full coordination of glider missions at the regional, basin or global scale, as discussed, remain in the planning stages. There has been enough activity to prove that we have the capability to conduct such operations but the development of clear scientific and operational goals for the proposed network remains under discussion. Indeed, this white paper is a contribution to that discussion and is meant to further stimulate consideration of the potential opportunities to fill gaps in the present networks of global ocean sampling.

Further developments should be framed with clear measurement goals and analysis of the appropriate technological solutions to address the observational challenges. There are now many different options to address the three themes of the GOOS: Climate, Operational Services and Ocean Health, including autonomous surface and underwater craft, drifters, subsurface moorings, ships of opportunity and research ships and satellite systems. All of the options should be considered to determine which solution, or mix of platforms, best meets the observational goals. We have some of the tools needed for this analysis but also need to work together as a community to optimize the design of the global observing system.

Ocean gliders, and other autonomous marine vehicles, are evolving and improving at a remarkable pace. Their endurance, related to battery capacity and sensor performance, continues to improve, as does their range of operations in both the coastal and open sea environments. It is now possible to sample the deep ocean with gliders, with developments that will enable us to routinely reach depths of $6,000 \mathrm{~m}$, while missions of many months or longer are now routine. There is also a growing range of private companies building these systems providing a wider range of options. This diversity shows the wide interest in these platforms and builds our confidence in their further development and availability, which is a key aspect of sustainability. Performance in extreme conditions, such as winter conditions, and navigation under sea-ice, is improving, and there are very few places on the planet where they cannot operate. Autonomy continues to develop, while full operational independence is still quite a few years away. As with many new platforms, in the first few years enormous effort is required to setup and deploy them. After two decades of operation, the learning curve for new users is not as steep as it was because of technological improvements and because the global community supports new users. Internationally, the OceanGliders program will help the glider community focus on the GOOS requirements. It builds on several long-term glider observational programs that exist in Europe, Australia, Canada, the United States, Mexico, Peru, Chile, South Africa, New Zealand, etc. Further development and coordination among these initiatives, and new ones that form, will provide support for coordinated global operations.

Global observing systems have shifted from a primarily physical focus to expanded measurements, spanning biological and biogeochemical variables. Essential Ocean Variables (EOV) within the GOOS now span a wide range, including biogeochemistry, biology and ecosystems. There has been 
a lot of progress in developing such sensors for gliders, for example, fluorometers for measuring phytoplankton have been in development for a long-time. So too have active/passive multi-frequency acoustic sensors been deployed on gliders to measure oceanic currents, surface wind intensity, zooplankton, and to detect acoustic small/large fish tags, marine mammals, sharks etc. Other sensors include imagery, as well as nitrate, oxygen and $\mathrm{pH}$, carbon dioxide sensors, and various optical sensors to detect light, backscatter, attenuation, particles, harmful algal blooms and ocean acidification. However, the battery capacity of the gliders still limits the total range of sensors that can be deployed on a single vehicle. It is clear that further battery and sensor developments will enable a wider range of possibilities and demonstrate that the platform has potential for making an even wider range of observations than at the moment.

Data from ocean gliders are presently being used in operational ocean models and operational weather forecast models. The data are typically streamed in real-time through the GTS and are then available to all operational users. They have been used in research or pre-operational systems and improved weather forecast modeling and operational global and regional ocean forecasts such as Mercator Ocean, FOAM (Met Office), MFS (Mediterranean Forecasting System), BLUELink (Bureau of Meteorology, Australia), CONCEPTS (Fisheries and Oceans, Environment and Climate Change Canada and Department of National Defence, Canada), HYCOM/NCODA (USA), NAVOCEANO (US Naval Oceanographic Office), REMO (Brazil), TOPAZ/NERSC (Norway). Observation impact studies show the value of sub-surface hydrographic observations, such as those from gliders, in improving prediction. Moreover, data products can be created, such as data aggregations and mean fields, that are easily usable for model validation and assessment. In this paper we have presented plans to deploy gliders in the waters near hurricanes, in ocean boundary currents and in key areas of water transformation. Data from such deployments could provide critical information to improve the performance of ocean forecast models as ocean dynamics in such regions remains a modeling challenge for the next decade. Improved prediction at sub-seasonal to seasonal (S2S) scales requires use of ensembles (or super-ensembles) including those from ocean models. These ensembles can also provide a good representation of quantified uncertainty in time and space which could be targeted by future flexible positioning of underwater gliders in real-time or near real-time. Having a large network of gliders, potentially with different sensor packages and/or different measurement goals, will lead to piloting challenges on a day-to-day basis for individuals. Eventually the sampling patterns might be autonomously determined through use of data-assimilating models, remote sensing products, and other in situ measurements.

The increasing operational interest in gliders and glider teams' capability suggests that the applications mentioned in section End-user benefits could all become operationally routine within a decade. Looking further ahead there is much capacity for the use of gliders to expand, particularly in relation to ocean health and human pressures.
We envision that:

- Increase in sensor capability of gliders will increase their use for early warning of environmental stress or pollution (Verfuss et al., 2019), for example to manage compliance areas of ecosystem sensitivity.

- The weather/modeling community may invest in gliders in key ocean areas to support improved prediction, perhaps with artificial intelligence, smart models autopiloting the gliders in real-time in the regions of greatest uncertainty.

- Deep gliders will deliver the same insight on deep variability of currents, water mass, heat, salt, biogeochemical and biological variables, fundamentally changing our ability to model deep flow and thus climate scale predictions and seasonal forecasts. They will also be our cost-effective eyes and ears on the deep, policing infringement of deep mining and reporting on deep ecosystem health.

- Increasing battery life, introducing novel energy sources, and improving solutions to bio-fouling, will lower costs and extend glider operation time. This will allow for the monitoring of open ocean areas at low cost (there will still be a need to deploy them from small boats).

- International consortia will share sites for recovery/deployment, facilities for refurbishment, and even pilots to optimize operations worldwide and reduce the costs of operation and the loss probability.

- The cost of the gliders will decline as their numbers increase and the number of users worldwide increase.

- The glider's payload space will increase enabling them to carry a wider range of sensors and/or a different battery configuration.

In considering the application of gliders to problems such as boundary currents, water transformations or storms, a careful analysis of the measurement challenge should include consideration of other approaches to ocean observation. Gliders have strengths and limitations, as do all platforms and sensors, and both should be taken into account when designing an observing solution to address critical gaps in our global ocean observing strategy. Formal design exercises must be carried out with the other components of the GOOS considering its 3 themes: Climate, Operational Services and Ocean Health. Such design studies must consider all the societal benefits and needs of GOOS applications, including human impact, ecosystem, biodiversity and pollution assessments as well as sustainable management and marine hazard response (cf. GOOS strategic mapping ${ }^{13}$ ).

Numerical simulation experiments, using sophisticated coupled ocean-atmosphere models to determine the best mix of platforms and the tradeoffs in ocean sampling that result from deploying different systems should be carried out. However, this must be done while keeping a critical eye on the model's performances and this must not be the only basis when producing a design. While gliders may fill a critical role for a particular system, for example a particular boundary current, it

\footnotetext{
${ }^{13} \mathrm{http}$ ///www.goosocean.org/index.php?option=com_content\&view=article\&id= 120\&Itemid $=277$
} 
may still be the case that a mix of moorings, drifters and other platforms would provide the best observational solution because of logistical constraints. It could be that biological requirements balance the needs of operational services, in a particular region in terms of resources optimization or the contrary, and so on.

The OceanGliders program can contribute to societal development and sustainability, and there are many examples of this potential already being achieved. These can be exemplified by activities that contribute toward achieving the United Nations Sustainable Development Goals (SDGs) ${ }^{14}$, of which SDG2 (Zero Hunger), SDG13 (Climate Action) and SDG14 (Life Below Water) are arguably most germane. Examples of glider networks making such contributions include deployments in climatically sensitive regions that are also important breeding and nursery grounds for foodwebs, and the focus of a significant fishing industry. Sustained glider missions in these areas conducted as part of whole-ecosystem research programs provide the underpinning scientific knowledge for ecosystems-based fishery management. Glider networks provide enhanced data collection and improved transfer of knowledge to policymakers, so as to support such societally-relevant sustainability activities.

It is important to consider the targeted phenomena, their space/time scales and EOV since they will impose requirements in terms of sampling. The different OceanGliders TT will define what "operational" means for them. The Boundary Currents TT requirements of sampling the seasonal cycle implies that "operational" means having gliders in water year-round, while Storms requirements imply having gliders in the water only during the storm periods, and Water Transformation requirements could be year-round or focus only on the winter/summer period depending on the water transformation phenomenon that is considered. Other requirements will emerge as the program develops with TT on biogeochemistry or polar regions for instance.

The world ocean will change. We need to assess those changes appropriately and must not underestimate what could be done with gliders. Without doubt, there will be more end-user engagements, new technologies on board, more connectivity, more sensors, more gliders and more users to address that. The flexibility of gliders allows complementarity, and this is an asset for their integration in the GOOS. The challenge for the next decade will be to build a GOOS glider component that will help the GOOS reach the right balance between its different components to deliver products for societal benefits and applications, through the monitoring of the required oceanic phenomena and EOV.

\section{VISION}

Our vision is for a mature sustained global glider observing network by 2030. It will not only support regional, sustained operational deployment of gliders serving the present societal needs around operational services, ocean health and climate, but also solely allow new ocean observing applications in this framework. The outstanding capacity of gliders to play a role

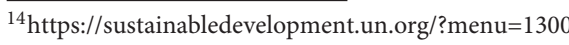

as an agent of integration, across scales, from the coast to the open ocean, and from physics to biology, needs to be used to enhance the GOOS, integrating with its other components (in situ and satellites). These global glider operations will likely have different schedules of operation, carry different sensors, and serve different needs but will have a shared support system through the OceanGliders program that will allow them to work together efficiently, to govern and support the system, coordinating global glider operations and ensuring that the needs of society for ocean data are best met.

OceanGliders will support global standards and best practices to ensure that the operations and the data delivered can be monitored at the global scale. Improved data interfaces and standardized data will ensure quality-controlled data are easily found and effectively used. By 2030 one should be able to effortlessly, perhaps unknowingly, find and acquire qualitycontrolled physical, biogeochemical and biological data from gliders alongside an already huge range of earth observations and use them to address scientific, commercial, or policy initiatives. Attaining our vision would ensure that the value of observations to society will never be lost, indeed, will increase over time as they are used and reused and in new ways not originally imagined.

Here, we have identified three key areas for the OceanGliders program to focus on: Boundary Currents, Storms and Water Transformation. These represent interests heard from the glider and user community, but we expect more to develop, as the OceanGliders program matures. Moving forward, OceanGliders will have, together with a wide range or stakeholders and participants, to conduct a value-chain assessment to explore further needs of users to ensure that the network continues to be fit-for-purpose, as discussed in the Framework on Ocean Observing. Through this paper, we have sought to demonstrate, through exploration of some key thematic examples, the opportunities and potential benefits of coordinated deployment of ocean gliders to fill some key gaps in the existing ocean observation system. The precise form of such activity requires a comprehensive and integrated analysis of the needs for observation, that is the most broadly defined societal needs, and an assessment of the different approaches to observation, just one of which is ocean gliders. Such an assessment will have to address needs related to the three key thematic areas of the GOOS: Ocean health, Operational services and Climate.

In his seminal paper, Stommel (1989), foresaw an operational fleet of 300-550 gliders at any time evolving in the world ocean to support the GOOS by 2025. Only a substantial increase in global resources would yield such an outcome by 2030 . We propose a more modest implementation of the OceanGliders global program for the next decade. Sustained observations of boundary currents are perhaps the most established capability of gliders relevant to the GOOS. A sensible goal is to have continuously 100 gliders in a sustained Boundary Ocean Observing Network within the next 10 years, with some additional gliders addressing Storms and Water Transformation issues where and when this fleet would not already do so. We are confident that operation of such a fleet of 100 gliders is achievable. Further development will rely on capacity building and would be driven by a combination 
of need and demonstrated benefit of the glider program. We have presented results from 25 boundary current sections sustained for a minimum of 1 year, and for as long as 12 years. While not all these 25 sections are currently sustained, the proof that they are operable has been made. An increase in this sampling by a factor of 4 is a relatively reasonable worldwide goal. The operational cost to keep one glider in the water for 1 year is approximately $\$ 200 \mathrm{~K}$, thus 100 gliders would cost $\$ 20 \mathrm{M}$ per year, a relatively affordable cost for a global component of the GOOS.

\section{AUTHOR CONTRIBUTIONS}

The editorial team for this paper (PT, BY, DR, SG, DHa, CL, CP, $\mathrm{KHi}, \mathrm{EH}$, and VT) has collected the contributions of the other co-authors and coordinated the writing of the paper.

\section{ACKNOWLEDGMENTS}

The editorial team would like to recognize the support of the global glider community to this paper. Our requests for

\section{REFERENCES}

Adams, K.A., Barth, J. A., and Shearman, R. K. (2016). Intraseasonal cross-shelf variability of hypoxia along the Newport, Oregon, hydrographic line. J. Phys. Oceanogr. 46, 2219-2238. doi: 10.1175/JPO-D-15-0119.1

Ainley, D. G., Ballard, G., Jones, R. M., Jongsomjit, D., Pierce, S. D., Smith, W. O. Jr., et al. (2015). Trophic cascades in the western Ross Sea, Antarctica: revisited. Marine Ecol. Progr. Series 534, 1-16. doi: 10.3354/meps11394

Albretsen, J., Aure, J., Sætre, R., and Danielssen, D. S. (2012). Climatic variability in the Skagerrak and coastal waters of Norway. ICES J. Mar. Sci. 69, 758-776. doi: 10.1093/icesjms/fsr187

Alford, M. H., Mickett, J. B., Zhang, S., MacCready, P., Zhao, Z., and Newton, J. (2012). Internal waves on the Washington continental shelf. Oceanography 25, 66-79. doi: 10.5670/oceanog.2012.43

Alkire, M.B., D’Asaro, E., Lee, C. M., Perry, M. J., Gray, A., Cetinic, I., et al. (2012). Estimates of net community production and export using high-resolution, Lagrangian measurements of $\mathrm{O}_{2}, \mathrm{NO}_{3}^{-}$, and POC through the evolution of a spring diatom bloom in the North Atlantic. Deep Sea Res. Part 1 Oceanogr. Res. Papers doi: 10.1016/j.dsr.2012.01.012

Alkire, M. B., Lee, C. M., D’Asaro, E. A., Perry, M. J., Briggs, N., Cetinić, I., et al. (2014). Net community production and export from Seaglider measurements in the North Atlantic after the spring bloom. J. Geophys. Res. 119, 6121-6139. doi: 10.1002/2014JC010105

Alvarez, A., Chiggiato, J., and Schroeder, K. (2013). Mapping sub-surface geostrophic currents from altimetry and a fleet of gliders. Deep Sea Res. Part I Oceanogr. Res. Papers 74, 115-129. doi: 10.1016/j.dsr.2012.10.014

Alvarez, A., and Mourre, B. (2014). Cooperation or coordination of underwater glider networks? An assessment from observing system simulation experiments in the Ligurian sea. J. Atmos. Ocean. Technol. 31, 2268-2277. doi: 10.1175/JTECH-D-13-00214.1

Andres, M., Mensah, V., Jam, S., Chang, M.-H., Yang, Y.-J., Lee, C. M., et al. (2017). Downstream evolution of the Kuroshio's time-varying transport and velocity structure. J. Geophys. Res. Oceans 122, 3519-3542. doi: 10.1002/2016JC012519

Anutaliya, A., Send, U., McClean, J. L., Sprintall, J., Rainville, L., Lee, C. M., et al. (2017). An undercurrent off the east coast of Sri Lanka. Ocean Sci. 13, 1035-1044. doi: 10.5194/os-13-1035-2017

Asper, V., Smith, W., Lee, C., Gobat, J., Heywood, K., Queste, B., et al. (2011). "Using gliders to study a phytoplankton bloom in the Ross Sea, Antarctica," in MTS/IEEE Kona Conference, OCEANS'11 (Kona, HI). data and information were met with enthusiasm and welcome contributions from around the globe, clearly demonstrating to us a point made in this paper that there are many active and dedicated teams of glider operators and users. We should also acknowledge the support that OceanGliders has received from the WMO/IOC JCOMM-OCG and JCOMMOPS that have allowed this program to develop, encouraging us to articulate a vision for the role of gliders in the GOOS. We acknowledge support from the EU Horizon 2020 AtlantOS project funded under grant agreement No. 633211 and gratefully acknowledge the many agencies and programs that have supported underwater gliders: AlterEco, ANR, CFI, CIGOM, CLASS Ellet Array, CNES, CNRS/INSU, CONACYT, CSIRO, DEFRA, DFG/SFB754, DFO, DGA, DSTL, ERC, FCO, FP7, and H2020 Europen Commission, HIMIOFoTS, Ifremer, IMOS, IMS, IOOS, IPEV, IRD, Israel MOST, JSPS, MEOPAR, NASA, NAVOCEANO (Navy), NERC, NFR, NJDEP, NOAA, NRC, NRL, NSF, NSERC, ONR, OSNAP, Taiwan MOST, SANAP-NRF, SENER, SIMS, Shell Exploration and Production Company, Sorbonne Université, SSB, UKRI, UNSW, Vettleson, Wallenberg Academy Fellowship, and WWF.

Aulicino, G., Cotroneo, Y., Ruiz, S., Sánchez Román, A., Pascual, A., Fusco, G., et al. (2018). Monitoring the Algerian Basin through glider observations, satellite altimetry and numerical simulations along a SARAL/AltiKa track. J. Marine Syst. 179, 55-71. doi: 10.1016/j.jmarsys.2017.11.006

Azaneu, M., Heywood, K. J., Queste, B. Y., and Thompson, A. F. (2017). Variability of the Antarctic slope current system in the Northwestern Weddell sea. J. Phys. Oceanogr. 47, 2977-2997. doi: 10.1175/JPO-D-17-0030.1

Baird, M. E., and Ridgway, K. R. (2012). The southward transport of sub-mesoscale lenses of Bass Strait Water in the centre of anti-cyclonic mesoscale eddies. Geophys. Res. Lett. 39:L02603. doi: 10.1029/2011GL050643

Baird, M. E., Suthers, I. M., Griffin, D. A., Hollings, B., Pattiaratchi, C., Everett, J. D., et al. (2011). The effect of surface flooding on the physical-biogeochemical dynamics of a warm-core eddy off southeast Australia. Deep Sea Res. Part II Top. Stud. Oceanogr. 58, 592-605. doi: 10.1016/j.dsr2.2010.10.002

Barceló-Llul, B., Pascual, A., Ruiz, S., Escudier, R., Torner, M., and Tintoré, J. (2019). Temporal and spatial hydrodynamic variability in the Mallorca channel (western Mediterranean Sea) from eight years of underwater glider data. J. Geophys. Res.: Oceans 124, 2769-2786. doi: 10.1029/2018JC0 14636

Bates, A. E., Helmuth, B., Burrows, M. T., Duncan, M. I., Garrabou, J., Guy-Haim, T., et al. (2018). Biologists ignore ocean weather at their peril. Nature 560, 299-301. doi: 10.1038/d41586-018-05869-5

Baumgartner, M. F., Fratantoni, D. M., Hurst, T. P., Brown, M. W., Cole, T. V. N., Van Parijs, S. M., et al. (2013). Real-time reporting of baleen whale passive acousticdetections from ocean gliders. J. Acoust. Soc. Am. 134, 1814-1823. doi: 10.1121/1.4816406

Baumgartner, M. F., Stafford, K. M., Winsor, P., StatScewich, F., and Fratantoni, D. M. (2014). Glider-based passive acoustic monitoring in the Arctic. Mar. Technol. Soc. J. 48, 40-51. doi: 10.4031/MTSJ.48.5.2

Beaird, N., Fer, I., Rhines, P., and Eriksen, C. (2012). Dissipation of turbulent kinetic energy inferred from seagliders: an application to the eastern Nordic seas overflows. J. Phys. Oceanogr. 42, 2268-2282. doi: 10.1175/JPO-D-12-094.1

Beaird, N. L., Rhines, P. B., and Eriksen, C. C. (2013). Overflow waters at the Iceland-Faroe ridge observed in multiyear seaglider surveys. J. Phys. Oceanogr. 43, 2334-2351. doi: 10.1175/JPO-D-13-029.1

Benoit-Bird, K. J., Patrick Welch, T., Waluk, C. M., Barth, J. A., Wangen, I., McGill, P., et al. (2018). Equipping an underwater glider with a new echosounder to explore ocean ecosystems. Limnol. Oceanogr. Methods 16, 734-749. doi: 10.1002/lom 3.10278 
Beszczynska-Möller, A., Woodgate, R. A., Lee, C., Melling, H., and Karcher, M. (2011). A synthesis of exchanges through the main oceanic gateways to the Arctic Ocean. Oceanography 24, 82-99. doi: 10.5670/oceanog.2011.59

Biddle, L. C., Kaiser, J., Heywood, K. J., Thompson, A. F., and Jenkins, A. (2015). Ocean glider observations of iceberg-enhanced biological production in the northwestern Weddell Sea. Geophys. Res. Lett. 42, 459-465. doi: 10.1002/2014GL062850

Boettger, D., Robertson, R., and Rainville, L. (2015). Characterizing the semidiurnal internal tide off Tasmania using glider data. J. Geophys. Res. Oceans 120, 3730-3746. doi: 10.1002/2015JC010711

Borrione, I., Falchetti, S., and Alvarez, A. (2016). Physical and dynamical characteristics of a $300 \mathrm{~m}$-deep anticyclonic eddy in the Ligurian Sea (Northwest Mediterranean Sea): evidence from a multi-platform sampling strategy. Deep Sea Res. Part I Oceanogr. Res. Papers 116, 145-164. doi: 10.1016/j.dsr.2016.07.013

Bosse, A., Fer, I., Søiland, H., and Rossby, T. (2018). Atlantic water transformation along its poleward pathway across the Nordic Seas. J. Geophys. Res. Oceans 123, 6428-6448. doi: 10.1029/2018JC014147

Bosse, A., Testor, P., Houpert, L., Damien, P., Prieur, L., Hayes, D., et al. (2016). Scales and dynamics of Submesoscale Coherent Vortices formed by deep convection in the northwestern Mediterranean Sea. J. Geophys. Res. Oceans 121, 7716-7742. doi: 10.1002/2016JC012144

Bosse, A., Testor, P., Mayot, N., Prieur, L., D’Ortenzio, F., Lavigne, H., et al. (2017). A submesoscale coherent vortex in the Ligurian Sea: from dynamical barriers to biological implications. J. Geophys. Res. Oceans 122, 6196-6217. doi: 10.1002/2016JC012634

Bosse, A., Testor, P., Mortier, L., Prieur, L., Taillandier, V., d'Ortenzio, F., et al. (2015). Spreading of Levantine Intermediate Waters by submesoscale coherent vortices in the northwestern Mediterranean Sea as observed with gliders. J. Geophys. Res. Oceans 120, 1599-1622. doi: 10.1002/2014JC010263

Bouffard, J., Pascual, A., Ruiz, S., Faugere, Y., and Tintore, J. (2010). Coastal and mesoscale dynamics characterization using altimetry and gliders: a case study in the Balearic Sea. J. Geophys. Res. Oceans 115:C10029. doi: $10.1029 / 2009$ jc006087

Bouffard, J., Renault, L., Ruiz, S., Pascual, A., Dufau, C., and Tintore, J. (2012). Sub-surface small-scale eddy dynamics from multi-sensor observations and modeling. Progr. Oceanogr. 106, 62-79. doi: 10.1016/j.pocean.2012. 06.007

Bourrin, F., Many, G., de Madron, X. D., Martín, J., Puig, P., Houpert, L., et al. (2015). Glider monitoring of shelf suspended particle dynamics and transport during storm and flooding conditions. Cont. Shelf Res. 109, 135-149. doi: 10.1016/j.csr.2015.08.031

Brannigan, L., Marshall, D. P., Garabato, A. C. N., Nurser, A. J. G., and Kaiser, J. (2017). Submesoscale instabilities in mesoscale eddies. J. Phys. Oceanogr. 47, 3061-3085. doi: 10.1175/JPO-D-16-0178.1

Briggs, N., Perry, M. J., Cetinic, I., Lee, C., D’Asaro, E., Gray, A. M., et al. (2011). High-resolution observations of aggregate flux during a sub-polar North Atlantic spring bloom. Deep Sea Res. Part I Oceanogr. Res. Papers 58, 1031-1039. doi: 10.1016/j.dsr.2011.07.007

Brito, M., Smeed, D., and Griffiths, G. (2014). Underwater glider reliability and implications for survey design. J. Atmos. Ocean. Technol. 31, 2858-2870. doi: 10.1175/JTECH-D-13-00138.1

Brito, M. P., and Griffiths, G. (2018). Updating autonomous underwater vehicle risk based on the effectiveness of failure prevention and correction. J. Atmos. Ocean. Technol. 35, 797-808. doi: 10.1175/JTECH-D-16-0252.1

Bröring, A., Schmid, S., Schindhelm, C., Khelil, A., Kabisch, S., Kramer, D., et al. (2017). Enabling IoT ecosystems through platform interoperability. IEEE Softw. Gener. 34, 54-61. doi: 10.1109/MS.2017.2

Buffett, G. G., Krahmann, G., Klaeschen, D., Schroeder, K., Sallares, V., Papenberg, C., et al. (2017). Seismic oceanography in the Tyrrhenian sea: thermohaline staircases. Eddies, and internal waves. J. Geophys. Res. Oceans 122, 8503-8523. doi: 10.1002/2017JC012726

Caballero, A., Rubio, A., Ruiz, S., Le Cann, B., Testor, P., Mader, J., et al. (2016). South-eastern Bay of Biscay eddy-induced anomalies and their effect on chlorophyll distribution. J. Mar. Syst. 162, 57-72. doi: 10.1016/j.jmarsys.2016.04.001

Caldeira, R., Stegner, A., Couvelard, X., Araújo, I. B., Testor, P., and Lorenzo, A. (2014). Evolution of an oceanic anticyclone in the lee of Madeira
Island: in situ and remote sensing survey. J. Geophys. Res. 119, 1195-1216. doi: 10.1002/2013JC009493

Carvalho, F., Kohut, J., Oliver, M. J., Sherrell, R. M., and Schofield, O. (2016). Mixing and phytoplankton dynamics in a submarine canyon in the West Antarctic Peninsula. J. Geophys. Res. Oceans 121, 5069-5083. doi: 10.1002/2016JC011650

Castelao, R., Glenn, S., and Schofield, O. (2010). Temperature, salinity, and density variability in the central Middle Atlantic Bight. J. Geophys. Res. 115;C10005. doi: 10.1029/2009JC006082

Cauchy, P., Heywood, K. J., Merchant, N. D., Queste, B. Y., and Testor, P. (2018). Wind speed measured from underwater gliders using passive acoustics. $J$. Atmos. Oceanic Technol. 35, 2305-2321. doi: 10.1175/JTECH-D-17-0209.1

Cetinić, I., Perry, M. J., Briggs, N. T., Kallin, E., D’Asaro, E. A., and Lee, C. M. (2012). Particulate organic carbon and inherent optical properties during 2008 North Atlantic bloom experiment. J. Geophys. Res. 117:C06028. doi: 10.1029/2011JC007771

Cetinić, I., Perry, M. J., D’Asaro, E., Briggs, N., Poulton, N., Sieracki, M. E., et al. (2015). A simple optical index shows spatial and temporal heterogeneity in phytoplankton community composition during the 2008 North Atlantic Bloom experiment. Biogeosciences 12, 2179-2194. doi: 10.5194/bg-12-2179-2015

Chang, D., Zhang, F., and Edwards, C. R. (2015). Real-time guidance of underwater gliders assisted by predictive ocean models. J. Atmos. Ocean. Tech. 32, 562-578. doi: 10.1175/JTECH-D-14-00098.1

Chao, Y., Farrara, J. D., Bjorkstedt, E., Chai, F., Chavez, F., Rudnick, D. L., et al. (2017a). The origins of the anomalous warming in the California coastal ocean and San Francisco Bay during 2014-2016. J. Geophys. Res. Oceans 122, 7537-7557. doi: 10.1002/2017JC013120

Chao, Y., Farrara, J. D., Zhang, H., Armenta, K. J., Centurioni, L., Chavez, et al. (2018). Development, implementation, and validation of a California coastal ocean modeling, data assimilation, and forecasting system. Deep Sea Research Part II: Topical Studies in Oceanography 151, 49-63. doi: 10.1016/j.dsr2.2017.04.013

Chao, Y., Farrara, J. D., Zhang, H., Armenta, K. J., Centurioni, L., Chavez, F., et al. (2017b). Development, implementation and validation of a California coastal ocean modeling, data assimilation and forecasting system. Deep Sea Res. Part II Top. Stud. Oceanogr. 151, 49-63. doi: 10.1016/j.dsr2.2017.04.013

Chave, R., Buermans, J., Lemon, D., Taylor, J.C., Lembke, C., DeCollibus, C., et al. (2018). "Adapting multi-frequency echo-sounders for operation on autonomous vehicles," in OCEANS'18 MTS/IEEE (Charleston, SC), 1-6.

Chen, K., He, R., Powell, B. S., Gawarkiewicz, G. G., Moore, A. M., and Arango, H. G. (2014). Data assimilative modeling investigation of Gulf Stream Warm Core Ring interaction with continental shelf and slope circulation. J. Geophys. Res. Oceans 119, 5968-5991. doi: 10.1002/2014JC009898

Chudong, P., Max, Y., Dmitri, N., and Hans, N. (2011). Variational assimilation of glider data in Monterey Bay. J. Mar. Res. 69, 331-346. doi: 10.1357/002224011798765259

Churnside, J. H., Marchbanks, R. D., Lembke, C., and Beckler, J. (2017). Optical backscattering measured by airborne lidar and underwater glider. Remote Sens. 9:379. doi: 10.3390/rs9040379

Cole, S. T., and Rudnick, D. L. (2012). The spatial distribution and annual cycle of upper ocean thermohaline structure. J. Geophys. Res. Oceans 117:C02027. doi: 10.1029/2011JC007033

Cotroneo, Y., Aulicino, G., Ruiz, S., Pascual, A., Budillon, G., Fusco, G., et al. (2016). Glider and satellite high resolution monitoring of a mesoscale eddy in the algerian basin: effects on the mixed layer depth and biochemistry. J. Mar. Syst. 162, 73-88. doi: 10.1016/j.jmarsys.2015.12.004

Couto, N., Martinson, D. G., Kohut, J., and Schofield, O. (2017). Distribution of upper circumpolar deep water on the warming continental shelf of the West Antarctic Peninsula. J. Geophys. Res. Oceans 122, 5306-5315. doi: 10.1002/2017JC012840

Cronin, M. F., Pelland, N. A., Emerson, S. R., and Crawford, W. R. (2015). Estimating diffusivity from the mixed layer heat and salt balances in the North Pacific. J. Geophys. Res. Oceans 120, 7346-7362. doi: 10.1002/2015JC 011010

Curry, B., Lee, C. M., Petrie, B., Moritz, R., and Kwok, R. (2014). Multiyear volume, liquid freshwater, and sea ice transports through Davis Strait, 2004-10. J. Phys. Oceanogr. 44, 1244-1266. doi: 10.1175/JPO-D13-0177.1 
Damerell, G. M., Heywood, K. J., Thompson, A. F., Binetti, U., and Kaiser, J. (2016). The vertical structure of upper ocean variability at the Porcupine Abyssal Plain during 2012-2013. J. Geophys. Res. Oceans 121, 3075-3089. doi: 10.1002/2015JC011423

Damien, P., Bosse, A., Testor, P., Marsaleix, P., and Estournel, C. (2017). Modeling post-convective submesoscale coherent vortices in the Mediterranean Sea. J. Geophys. Res. 122, 9937-9961. doi: 10.1002/2016JC012114

Davis, R., Eriksen, C., and Jones, C. (2002). "Autonomous Buoyancy-driven underwater gliders," in The Technology and Applications of Autonomous Underwater Vehicles', ed G. Griffiths (London: Taylor and Francis), 37-58.

Davis, R. E., Kessler, W. S., and Sherman, J. T. (2012). Gliders measure western boundary current transport from the south pacific to the equator. J. Phys. Oceanogr. 42, 2001-2013. doi: 10.1175/JPO-D-12-022.1

Dever, M., Hebert, D., Greenan, B. J. W., Sheng, J., and Smith, P. C. (2016). Hydrography and Coastal circulation along the halifax line and the connections with the Gulf of St. Lawrence. Atmos. Ocean 54, 199-217. doi: 10.1080/07055900.2016.1189397

deYoung, B., Oppeln-Bronikowski, N. J., Matthews, J.B.R., and Bachmayer, R. (2018). Glider operations in the Labrador sea. J. Ocean Technol. 13, 106-120.

Dobricic, S., Pinardi, N., Testor, P., and Send, U. (2010). Impact of data assimilation of glider observations in the Ionian Sea (Eastern Mediterranean). Dyn. Atmos. Oceans 50, 78-92. doi: 10.1016/j.dynatmoce.2010.01.001

Domingues, R., Goni, G., Bringas, F., Lee, S.-K., Kim, H.-S., Halliwell, G., et al. (2015). Upper ocean response to Hurricane Gonzalo, 2014: Salinity effects revealed by targeted and sustained underwater glider observations. Geophys. Res. Lett. 42, 7131-7138. doi: 10.1002/2015GL065378

Domingues, R., Kuwano-Yoshida, A., Cardon-Maldonado, P., Todd, R.E., Halliwell, G., Kim, H.-S., et al. (2019). Ocean observations in support of studies and forecasts of tropical and extratropical cyclones. Front. Mar. Sci. 6:446. doi: 10.3389/fmars.2019.00446

Dong, J., Domingues, R., Goni, G., Halliwell, G., Kim, H.-S., Lee, S.-K., et al. (2017). Impact of assimilating underwater glider data on Hurricane Gonzalo 2014 forecast. Weather Forecast. 32, 1143-1159. doi: 10.1175/WAF-D-16-0182.1

Drillet, Y., Lellouche, J. M., Levier, B., Drevillon, M., Le Galloudec, O., Reffray, G., et al. (2014). Forecasting the mixed-layer depth in the Northeast Atlantic: an ensemble approach, with uncertainties based on data from operational ocean forecasting systems. Ocean Sci. 10, 1013-1029. doi: 10.5194/os-10-1013-2014

Du Plessis, M. (2015). Dynamics and Variability of the Subantarctic Mixed-Layer as Determined From a High Resolution Glider Dataset. Cape Town: University of Cape Town.

Du Plessis, M., Swart, S., Ansorge, I. J., and Mahadevan, A. (2017). Submesoscale processes promote seasonal restratification in the Subantarctic Ocean. J. Geophys. Res. Oceans 122, 2960-2975. doi: 10.1002/2016JC012494

Du Plessis, M. D., Swart, S., Ansorge, I. J., Mahadevan, A., and Thompson, A. F. (2019). Southern Ocean seasonal restratification delayed by submesoscale wind-front interactions.. J. Phys. Oceanogr. 49, 1035-1053. doi: 10.1175/JPO-D-18-0136.1

Durand, F., Marin, F., Fuda, J.-L., and Terre, T. (2017). The east caledonian current: a case example for the intercomparison between altika and in situ measurements in a boundary current. Mar. Geodesy 40, 1-22. doi: 10.1080/01490419.2016.1258375

Durrieu de Madron, X., Guieu, C., Sempéré R., Conan, P., Cossa, D., D’Ortenzio, F., et al. (2011). Marine ecosystems' responses to climatic and anthropogenic forcings in the Mediterranean. Progr. Oceanogr. 91, 97-166. doi: 10.1016/j.pocean.2011.02.003

Durrieu de Madron, X., Houpert, L., Puig, P., Sanchez-Vidal, A., Testor, P., Bosse, A., et al. (2013). Interaction of dense shelf water cascading and open-sea convection in the northwestern Mediterranean during winter 2012. Geophys. Res. Lett. 40, 1379-1385. doi: 10.1002/grl.50331

Durrieu de Madron, X., Ramondenc, S., Berline, L., Houpert, L., Bosse, A., Martini, S., et al. (2017). Deep sediment resuspension and thick nepheloid layer generation by open-ocean convection. J. Geophys. Res. Oceans 122, 2291-2318. doi: 10.1002/2016JC012062

Durski, S. M., Kurapov, A. L., Allen, J. S., Kosro, P. M., Egbert, G. D., Shearman, R. K., et al. (2015). Coastal ocean variability in the US Pacific Northwest region: seasonal patterns, winter circulation, and the influence of the 2009-2010 El Nio. Ocean Dyn. 65, 1643-1663. doi: 10.1007/s10236-0150891-1
Edwards, C. A., Moore, A. M., Hoteit, I., and Cornuelle, B. D. (2015). Regional ocean data assimilation. Annu. Rev. Mar. Sci. 7, 21-42. doi: 10.1146/annurev-marine-010814-015821

Estournel, C., Testor, P., Damien, P., D’Ortenzio, F., Marsaleix, P., Conan, P., et al. (2016b). High resolution modelling of dense water formation in the north-western Mediterranean: impacts of initial conditions and atmospheric forcing, heat and salt budget of the convection zone. J. Geophys. Res. 5367-5392. doi: 10.1002/2016JC011935

Estournel, C., Testor, P., Taupier-Letage, I., Bouin, M. N., Coppola, L., Durand, P., et al. (2016a). HyMeX-SOP2, the field campaign dedicated to dense water formation in the northwestern Mediterranean. Oceanography 29, 196-206. doi: 10.5670/oceanog.2016.94

Evans, D.G., Lucas, N., Hemsley, V., Frajka-Williams, E., Naveira Garabato, A., Martin, A., et al. (2018). Annual cycle of turbulent dissipation estimated from Seagliders. Geophys. Res. Let. 45, 10560-10569. doi: 10.1029/2018GL079966

Evans, W., Hales, B., Strutton, P. G., Shearman, R. K., and Barth, J., A. (2015). Failure to bloom: intense upwelling results in negligible phytoplankton response and prolonged CO2 outgassing over the Oregon shelf. J. Geophys. Res. Oceans 120, 1446-1461. doi: 10.1002/2014JC010580

Evans, W., Mathis, J. T., Winsor, P., Statscewich, H., and Whitledge, T. E. (2013). A regression modeling approach for studying carbonate system variability in the northern Gulf of Alaska. J. Geophys. Res. Oceans 118, 476-489. doi: 10.1029/2012JC008246

Everett, J. D., Macdonald, H. S., Baird, M. E., Humphries, J., Roughan, M., and Suthers, I. M. (2015). Cyclonic entrainment of pre-conditioned shelf waters into a Frontal Eddy. J. Geophys. Res. Oceans 120, 677-691. doi: 10.1002/2014JC010301

Fan, X., Send, U., Testor, P., Karstensen, J., and Lherminier, P. (2013). Observations of Irminger sea anticyclonic eddies. J. Phys. Oceanogr. 43, 805-823. doi: 10.1175/JPO-D-11-0155.1

Farrar, J. T., Rainville, L., Plueddemann, A. J., Kessler, W. S., Lee, C., Hodges, B. A., et al. (2015). Salinity and temperature balances at the SPURS central mooring during fall and winter. Oceanography 28, 56-65. doi: 10.5670/oceanog.2015.06

Fer, I., Peterson, A. K., and Ullgren, J. E. (2014). Microstructure measurements from an underwater glider in the turbulent faroe bank channel overflow. $J$. Atmos. Oceanic Technol. 31, 1128-1150. doi: 10.1175/JTECH-D-13-00221.1

Fiedler, B., Grundle, D. S., Schütte, F., Karstensen, J., Löscher, C. R., Hauss, H., et al. (2016). Oxygen utilization and downward carbon flux in an oxygen-depleted eddy in the eastern tropical North Atlantic. Biogeosciences 13, 5633-5647. doi: 10.5194/bg-13-5633-2016

Foloni-Neto, H., Tanaka, M., Joshima, H., and Yamazaki, H. (2014). Contribution to the themed section: advances in plankton modelling and biodiversity evaluation. A comparison between quasi-horizontal and vertical observations of phytoplankton microstructure. J. Plankton Res. 38, 944-945. doi: 10.1093/plankt/fbv075

Fragoso, M. D. R., de Carvalho, G. V., Soares, F. L. M., Faller, D., Toste, R., Sancho, L., et al. (2016). A 4D-variational ocean data assimilation application for Santos Basin, Brazil. Ocean Dyn. 66, 419-434. doi: 10.1007/s10236-016-0931-5

Frajka-Williams, E., Eriksen, C. C., Rhines, P. B., and Harcourt, R. R. (2011). Determining vertical water velocities from seaglider. J. Atmos. Oceanic Technol. 28, 1641-1656. doi: 10.1175/2011JTECHO830.1

Fraser, N. J., Skogseth, R., Nilsen, F., and Inall, M. E. (2018). Circulation and exchange in a broad Arctic fjord using glider-based observations. Polar Res. 37:1. doi: 10.1080/17518369.2018.1485417

Freitas, F. H., Siegel, D. A., Washburn, L., Halewood, S., and Stassinos, E. (2016). Assessing controls on cross-shelf phytoplankton and suspended particle distributions using repeated bio-optical glider surveys. J. Geophys. Res. Oceans 121, 7776-7794. doi: 10.1002/2016JC011781

Gangopadhyay, A., Schmidt, A., Agel, L., Schofield, O., and Clark, J. (2013) Multiscale forecasting in the western North Atlantic: sensitivity of model forecast skill to glider data assimilation. Cont. Shelf Res. 63, S159-S176. doi: 10.1016/j.csr.2012.09.013

Glenn, S. M., Miles, T. N., Seroka, G. N., Xu, Y., Forney, R. K., Yu, F., et al. (2016) Stratified coastal ocean interactions with tropical cyclones. Nat. Commun. 7:10887. doi: $10.1038 /$ ncomms 10887

Goericke, R., and Ohman, M. D. (2015). Introduction to CCE-LTER: responses of the California current ecosystem to climate forcing. Deep Sea Res. Part Ii Top. Stud. Oceanogr. 112, 1-5. doi: 10.1016/j.dsr2.2014.12.001 
Goni, G. J., Todd, R. E., Jayne, S. R., Halliwell, G., Glenn, S., Dong, J., et al. (2017). Autonomous and Lagrangian ocean observations for Atlantic tropical cyclone studies and forecasts. Oceanography 30, 92-103. doi: 10.5670/oceanog.2017.227

Gourdeau, L., Verron, J., Chaigneau, A., Cravatte, S., and Kessler, W. (2017). Complementary use of Glider Data, altimetry, and model for exploring Mesoscale Eddies in the Tropical Pacific Solomon Sea. J. Geophys. Res. Oceans 122, 9209-9229. doi: 10.1002/2017JC013116

Gower, J., King, S., Statham, S., Fox, R., and Young, E. (2013). The Malaspina Dragon: a newly-discovered pattern of the early spring bloom in the Strait of Georgia, British Columbia, Canada. Progr. Oceanogr. 115, 181-188. doi: 10.1016/j.pocean.2013.05.024

Guihen, D., Fielding, S., Murphy, E. J., Heywood, K. J., and Griffiths, G. (2014). An assessment of the use of ocean gliders to undertake acoustic measurements of zooplankton: the distribution and density of Antarctic krill (Euphausia superba) in the Weddell Sea. Limnol. Oceanogr. Methods 12, 373-389. doi: 10.4319/lom.2014.12.373

Gula, J., Blacic, T. M., and Todd, R. E. (2019). Submesoscale coherent vortices in the Gulf Stream. Geophys. Res. Lett. 46, 2704-2714. doi: 10.1029/2019GL081919

Hall, R. A., Aslam, T., and Huvenne, V. A. I. (2017). Partly standing internal tides in a dendritic submarine canyon observed by an ocean glider. Deep Sea Res. Part I Oceanogr. Res. Papers 126, 73-84. doi: 10.1016/j.dsr.2017.05.015

Halliwell, G. R. Jr., Mehari, M. F., Le Henaff, M., Kourafalou, V. H., Androulidakis, I. S., Kang, H. S., et al. (2017). North Atlantic Ocean OSSE system: evaluation of operational ocean observing system components and supplemental seasonal observations for potentially improving tropical cyclone prediction in coupled systems. J. Oper. Oceanogr. 10, 154-175. doi: 10.1080/1755876X.2017.1322770

Hanson, C. E., L., Mun, Woo, P. L., Thomson, G., and Pattiaratchi, C. B. (2017). Observing the ocean with gliders: techniques for data visualization and analysis. Oceanography 30, 222-227. doi: 10.5670/oceanog.2017.210

Hayes, D., Dobricic, S., Gildor, H., Matsikaris, A., et al. (2019). Operational assimilation of glider temperature and salinity for an improved description of the Cyprus eddy. Deep Sea Res. Part II Topical Stud. Oceanogr. 164, 41-53. doi: 10.1016/j.dsr2.2019.05.015

Hemming, M. P., Kaiser, J., Heywood, K. J., Bakker, D. C. E., Boutin, J., Shitashima, K., et al. (2017). Measuring pH variability using an experimental sensor on an underwater glider. Ocean Sci. 13, 427-442. doi: 10.5194/os-13-427-2017

Hemsley, V. S., Smyth, T. J., Martin, A. P., Frajka-Williams, E., Thompson, A. F., Damerell, G., et al. (2015). Estimating oceanic primary production using vertical irradiance and chlorophyll profiles from ocean gliders in the North Atlantic. Environ. Sci. Technol. 49, 11612-11621. doi: 10.1021/acs.est.5b00608

Heslop, E. E., Ruiz, S., Allen, J., J., Luis Lopez-Jurado, Renault, L., and Tintore, J. (2012). Autonomous underwater gliders monitoring variability at "choke points" in our ocean system: a case study in the Western Mediterranean Sea. Geophys. Res. Lett. 39:L20604. doi: 10.1029/2012GL053717

Heslop, E. E., Sanchez-Roman, A., Pascual, A., Rodriguez, D., Reeve, K. A., Faugere, Y., et al. (2017). Sentinel-3A views ocean variability more accurately at finer resolution. Geophys. Res. Lett. 44, 12367-12374. doi: 10.1002/2017GL076244

Heywood, K. J., Schmidtko, S., Heuzé, C., Kaiser, J., Jickells, T. D., Queste, B. Y., et al. (2014). Ocean processes at the Antarctic continental slope. Philos Trans A Math Phys Eng Sci. 372:20130047. doi: 10.1098/rsta.2013.0047

Houpert, L., Inall, M. E., Dumont, E., Gary, S., Johnson, C., Porter, M., et al. (2018). Structure and transport of the North Atlantic Current in the eastern subpolar gyre from sustained glider observations. J. Geophys. Res. 123, 6019-6038. doi: 10.1029/2018JC014162

Houpert, L., Testor, P., de Madron, X. D., Somot, S., D’Ortenzio, F., Estournel, C., et al. (2015). Seasonal cycle of the mixed layer, the seasonal thermocline and the upper-ocean heat storage rate in the Mediterranean Sea derived from observations. Progr. Oceanogr. 132, 333-352. doi: 10.1016/j.pocean.2014. 11.004

Houpert, L., X., Durrieu de Madron, Testor, P., Bosse, A., D’Ortenzio, F., Bouin, M. N., et al. (2016). Observations of open-ocean deep convection in the northwestern Mediterranean Sea: seasonal and interannual variability of mixing and deep water masses for the 2007-2013 period. J. Geophys. Res. Oceans 121, 8139-8171. doi: 10.1002/2016JC011857

Høydalsvik, F., Mauritzen, C., Orvik, K. A., LaCasce, J. H., Lee, C. M., and Gobat, J. (2013). Transport estimates of the Western Branch of the Norwegian Atlantic
Current from glider surveys. Deep Sea Res. Part I Oceanogr. Res. Papers 79, 86-95. doi: 10.1016/j.dsr.2013.05.005

Hristova, H. G., Kessler, W. S., McWilliams, J. C., and Molemaker, M. J. (2014). Mesoscale variability and its seasonality in the Solomon and Coral Seas. J. Geophys. Res. Oceans 119, 4669-4687. doi: 10.1002/2013JC009741

Itoh, S., and Rudnick, D. L. (2017). Fine-scale variability of isopycnal salinity in the California current system. J. Geophys. Res. Oceans 122, 7066-7081. doi: 10.1002/2017JC013080

Jacox, M. G., Hazen, E. L., Zaba, K. D., Rudnick, D. L., Edwards, C. A., Moore, A M., et al. (2016). Impacts of the 2015-2016 El Nino on the california current system: early assessment and comparison to past events. Geophys. Res. Lett. 43, 7072-7080. doi: 10.1002/2016GL069716

Johnston, T. M. S., and Rudnick, D. L. (2015). Trapped diurnal internal tides, propagating semidiurnal internal tides, and mixing estimates in the California Current System from sustained glider observations, 20062012, Deep-Sea Research Part Ii-Topical Studies. Oceanography 112, 61-78. doi: 10.1016/j.dsr2.2014.03.009

Johnston, T. M. S., Rudnick, D. L., Alford, M. H., Pickering, A., and Simmons, H. L. (2013). Internal tidal energy fluxes in the South China Sea from density and velocity measurements by gliders. J. Geophys. Res. Oceans 118, 3939-3949. doi: 10.1002/jgrc.20311

Jones, E. M., Oke, P. R., Rizwi, F., and Murray, L. (2012). Assimilation of glider and mooring data into a coastal ocean model. Ocean Modell 47,1-13. doi: 10.1016/j.ocemod.2011.12.009

Jones, R. M., and Smith, W. O. Jr. (2017). The influence of short-term events on the hydrographic and biological structure of the southwestern Ross Sea. J. Marine Syst. 166, 184-195. doi: 10.1016/j.jmarsys.2016.09.006

Kahl, L. A., Schofield, O., and Fraser, W. R. (2010). “Autonomous gliders reveal features of the water column associated with foraging by adelie penguins. integrative and comparative biology," in Annual Meeting of the Society-forIntegrative-and-Comparative-Biology (Seattle, WA), 1041-1050.

Karstensen, J., Liblik, T., Fischer, J., Bumke, K., and Krahmann, G. (2014) Summer upwelling at the Boknis Eck time-series station (1982 to 2012) a combined glider and wind data analysis. Biogeosciences 11, 3603-3617. doi: 10.5194/bg-11-3603-2014

Karstensen, J., Schütte, F., Pietri, A., Krahmann, G., Fiedler, B., Grundle, D., et al. (2017). Upwelling and isolation in oxygen-depleted anticyclonic modewater eddies and implications for nitrate cycling. Biogeosciences 14, 2167-2181. doi: 10.5194/bg-14-2167-2017

Kaufman, D. E., Friedrichs, M. A. M., Smith, W. J. Jr., Queste, B. Y., and Heywood, K. J. (2014). Biogeochemical variability in the southern Ross Sea as observed by a glider deployment. Deep Sea Res. Part I Oceanogr. Res. Papers 92, 93-106. doi: 10.1016/j.dsr.2014.06.011

Kaufman, D. E., Friedrichs, M. A. M., Smith, W. O. Jr., Hofmann, E. E., Dinniman, M. S., and Hemmings, J. C. P. (2017). Climate change impacts on southern Ross Sea phytoplankton composition, productivity, and export. J. Geophys. Res. Oceans 122, 2339-2359. doi: 10.1002/2016JC012514

Kerry, C. G., Powell, B., Roughan, M., and Oke, P. (2016). Development and evaluation of a high-resolution reanalysis of the East Australian Current region using the Regional Ocean Modelling System (ROMS 3.4) and Incremental Strong-Constraint 4-Dimensional Variational data assimilation (IS4D-Var). Geosci. Model Dev. 9, 3779-3801 doi: 10.5194/gmd-9-37792016

Kerry, C. G., Roughan, M., and Powell, B. (2018). Observation impact in a regional reanalysis of the East Australian Current System. J. Geophys. Res. Oceans 123, 7511-7528. doi: 10.1029/2017JC013685

Klinck, H., Mellinger, D.K., Klinck, K., Bogue, N.M., Luby, J.C., et al. (2012). Nearreal-time acoustic monitoring of beaked whales and other cetaceans using a seaglider $^{\mathrm{TM}}$. PLoS ONE. 7:e36128. doi: 10.1371/journal.pone.0036128

Klymak, J. M., Simmons, H. L., Braznikov, D., Kelly, S., MacKinnon, J. A., Alford, M. H., et al. (2016). Reflection of linear internal tides from realistic topography: the tasman continental slope. J. Phys. Oceanogr. 46, 3321-3337. doi: 10.1175/JPO-D-16-0061.1

Kohut, J., Bernard, K., Fraser, W., Oliver, M. J., Statscevvich, H., Winsor, P., et al. (2014a). Studying the impacts of local oceanographic processes on adelie penguin foraging ecology. Marine Technol. Soc. J. 48, 25-34. doi: 10.4031/MTSJ.48.5.10 
Kohut, J., Haldeman, C., and Kerfoot, J. (2014b). Monitoring Dissolved Oxygen in New Jersey Coastal Waters Using Autonomous Gliders. Washington, DC: U.S. Environmental Protection Agency.

Kohut, J., Hunter, E., and Huber, B. (2013). Small-scale variability of the cross-shelf flow over the outer shelf of the Ross Sea. J. Geophys. Res. Oceans 118, 1863-1876. doi: $10.1002 /$ jgrc.20090

Kokkini, Z., Gerin, R., Poulain, P.-M., Mauri, E., Pasarić Z., Janecović I., et al. (2017). A multiplatform investigation of Istrian Front dynamics (north Adriatic Sea) in winter 2015. Mediterranean Marine Sci. 18/2, 344-354. doi: $10.12681 / \mathrm{mms} .1895$

Kolodziejczyk, N., Testor, P., Lazar, A., Echevin, V., Krahmann, G., Chaigneau, A., et al. (2018). Subsurface fine-scale patterns in an anticyclonic eddy off CapVert peninsula observed from glider measurements. J. Geophys. Res. Oceans 123, 6312-6329. doi: 10.1029/2018JC014135

Krug, M., Swart, S., and Gula, J. (2017). Submesoscale cyclones in the Agulhas current. Geophys. Res. Lett. 44, 346-354. doi: 10.1002/2016GL0 71006

Krug, M., Swart, S., and Hermes, J. (2018). Ocean gliders ride the research wave in the Agulhas Current. Eos 99. Available online at: https://eos.org/scienceupdates/ocean-gliders-ride-the-research-wave-in-the-agulhas-current

Kurapov, A. L., Pelland, N. A., and Rudnick, D. L. (2017). Seasonal and interannual variability in along-slope oceanic properties off the US West Coast: inferences from a high-resolution regional model. J. Geophys. Res. Oceans 122, 5237-5259. doi: 10.1002/2017JC012721

Kusel, E. T., Munoz, T., Siderius, M., Mellinger, D. K., and Heimlich, S. (2017). Marine mammal tracks from two-hydrophone acoustic recordings made with a glider. Ocean Sci. 13, 273-288. doi: 10.5194/os-13-273-2017

Lee, C.M., S., Jinadasa, U. P., Anutaliya, A., Centurioni, L. R., H., et al. (2016). Collaborative observations of boundary currents, water mass variability, and monsoon response in the southern Bay of Bengal. Oceanography 29, 102-111. doi: 10.5670/oceanog. 2016.43

Lee, C.M., Thomson, J., and the Marginal Ice Zone, and Arctic Sea State Teams. (2017). An autonomous approach to observing the seasonal ice zone in the western Arctic. Oceanography 30, 56-68. doi: 10.5670/oceanog.2017.222

Lee, C. M., and Rudnick, D. L. (2018). "Underwater gliders," in Observing the Oceans in Real Time, eds R. Venkatesan, A. Tandon, E. A. D'Asaro, and M. A. Atmanand (Cham: Springer), 123-139. doi: 10.1007/978-3-319-66493-4_7

Lee, C. M., and Thomson, J. (2017). An autonomous approach to observing the deasonal ice zone in the Western Arctic. Oceanography 30, 56-68. doi: 10.5670/oceanog.2017.222

L'Heveder, B., Mortier, L., Testor, P., and Lekien, F. (2013). A glider network design study for a synoptic view of the oceanic mesoscale variability. J. Atmos. Oceanic Technol. 30, 1472-1493. doi: 10.1175/JTECH-D-12-00053.1

Li, Z., Chao, Y., Farrara, J. D., and McWilliams, J. C. (2013). Impacts of distinct observations during the 2009 Prince William Sound field experiment: a data assimilation study. Continental Shelf Res. 63, S209-S222. doi: 10.1016/j.csr.2012.06.018

Lien, R.-C., Ma, B., Lee, C. M., Sanford, T. B., Mensah, V., Centurioni, L. R., et al. (2015). The kuroshio and luzon undercurrent east of luzon Island. Oceanography 28, 54-63. doi: 10.5670/oceanog.2015.81

Lien, R. C., Ma, B., Cheng, Y. H., Ho, C. R., Qiu, B., Lee, C. M., et al. (2014). Modulation of Kuroshio transport by mesoscale eddies at the Luzon Strait entrance. J. Geophys. Res. Oceans 119, 2129-2142. doi: 10.1002/2013JC009548

Little, H., Vichi, M., Thomalla, S., and Swart, S. (2018). Spatial and temporal scales of chlorophyll variability using high-resolution glider data. J. Mar. Syst. 187, 1-12. doi: 10.1016/j.jmarsys.2018.06.011

Loginova, A. N., Thomsen, S., and Engel, A. (2016). Chromophoric and fluorescent dissolved organic matter in and above the oxygen minimum zone off Peru. J. Geophys. Res. Oceans 121, 7973-7990. doi: 10.1002/2016JC011906

Lozier, M.S., Li, F., Bacon, S., Bahr, F., Bower, A. S., Cunningham, S. A., et al. (2019). A sea change in our view of overturning in the subpolar North Atlantic. Science 363, 516-521. doi: 10.1126/science.aau6592

Ma, W., Wang, Y., Yang, S., Wang, S., and Xiu, Z. (2018). Observation of internal solitary waves using an underwater glider in the northern south china sea. $J$. Coastal Res. 34, 1188-1195 doi: 10.2112/JCOASTRES-D-17-00193.1

Mahadevan, A., D’Asaro, E., Lee, C. M., and Perry, M. J. (2012). Eddy-driven stratification initiates the NorthAtlantic Spring Bloom. Science 337, 54-58. doi: $10.1126 /$ science. 1218740
Mahjabin, T., Pattiaratchi, C., and Hetzel, Y. (2016). "Factors influencing the occurrence of Dense Shelf Water Cascades in Australia, Journal of Coastal Research," in 14th International Coastal Symposium (ICS) (Sydney, NSW), 527-531.

Mainelli, M., DeMaria, M., Shay, L., and Goni, G. (2008). Application of oceanic heat content estimation to operational forecasting of recent Atlantic category 5 hurricanes. Weather Forecast 23, 3-16. doi: 10.1175/2007WAF2006111.1

Mancero-Mosquera, I., Poulain, P.-M., Gerin, R., Mauri, E., Hayes, D., Testor, P., et al. (2017). Analysis of frequency content of glider data via fourier and wavelet transforms. Bollettino di Geofisica Teorica ed Applicata, 58, 137-156. doi: 10.4430/bgta0194

Many, G., Bourrin, F., Durrieu de Madron, X., Pairaud, I., Gangloff, A., Doxaran, D., et al. (2016). Particle assemblage characterization in the Rhone River ROFI. J. Marine Syst. 157, 39-51. doi: 10.1016/j.jmarsys.2015.12.010

Margirier, F., Bosse, A., Testor, P., L'Heveder, B., Mortier, L., and Smeed, D. (2017). Characterization of convective plumes associated with oceanic deep convection in the northwestern mediterranean from high-resolution in situ data collected by gliders. J. Geophys. Res. Oceans 122, 9814-9826. doi: 10.1002/2016JC012633

Martin, J. P., Lee, C. M., Eriksen, C. C., Ladd, C., and Kachel, N. B. (2009). Glider observations of kinematics in a Gulf of Alaska eddy. J. Geophys. Res. 114:C12021. doi: 10.1029/2008JC005231

Martin, P., Lampitt, R. S., Perry, M. J., Sanders, R., Lee, C. M., and D’Asaro, E. (2011). Export and mesopelagic particle flux during a north atlantic spring diatom bloom. Deep Sea Res. 58, 338-349. doi: 10.1016/j.dsr.2011.01.006

Mauri, E., Gerin, R., and Poulain, P.-M. (2016). Measurements of water-mass properties with a glider in the South-western Adriatic Sea. J. Operational Oceanogr. 9(Suppl. 1), 3-9. doi: 10.1080/1755876X.2015.1117766

Mayot, N., D’Ortenzio, F., Taillandier, V., Prieur, L., de Fommervault, O. P., Claustre, H., et al. (2017). Physical and biogeochemical controls of the phytoplankton blooms in north western mediterranean sea: a multiplatform approach over a complete annual cycle (2012-2013 DEWEX Experiment). J. Geophys. Res. Oceans 122, 9999-10019. doi: 10.1002/2016JC012052

Mazzini, P. L. F., Barth, J. A., Shearman, R. K., and Erofeev, A. (2014). Buoyancydriven coastal currents off oregon during fall and winter. J. Phys. Oceanogr. 44, 2854-2876. doi: 10.1175/JPO-D-14-0012.1

McClatchie, S., Cowen, R., Nieto, K., Greer, A., Luo, J. Y., Guigand, C., et al. (2012). Resolution of fine biological structure including small narcomedusae across a front in the Southern California Bight. J. Geophys. Res. Oceans 117. doi: 10.1029/2011JC007565

Melet, A., Verron, J., and Brankart, J. M. (2012). Potential outcomes of glider data assimilation in the Solomon Sea: control of the water mass properties and parameter estimation. J. Marine Syst. 94, 232-246. doi: 10.1016/j.jmarsys.2011.12.003

Mensah, V., Andres, M., R.-C., Lien, Ma, B., Lee, C. M., and Jan, S. (2016). Combining observations from multiple platforms across the Kuroshio northeast of Luzon: a highlight on PIES data. J. Atmospheric Oceanic Technol. 33, 2185-2203. doi: 10.1175/JTECH-D-16-0095.1

Meunier, T., Pallàs-Sanz, E., Tenreiro, M., Portela, E., Ochoa, J., Ruíz-Angulo, A., et al. (2018a). The vertical structure of a Loop Current Eddy. J. Geophys. Res. 123, 6070-6090. doi: 10.1029/2018JC013801

Meunier, T., Tenreiro, M., Pallàs-Sanz, E., Ochoa, J., Ruíz-Angulo, A., Portela, E., et al. (2018b). Intrathermocline eddies embedded within an anticyclonic vortex ring. Geophys. Res. Lett. 45, 7624-7633. doi: 10.1029/2018GL0 77527

Miles, T., Glenn, S. M., and Schofield, O. (2013). Temporal and spatial variability in fall storm induced sediment resuspension on the Mid-Atlantic Bight. Continental Shelf Res. 63, S36-S49. doi: 10.1016/j.csr.2012.08.006

Miles, T., Seroka, G., and Glenn, S. (2017). Coastal ocean circulation during Hurricane Sandy. J. Geophys. Res. Oceans. 122, 7095-7114. doi: 10.1002/2017JC013031

Miles, T., Seroka, G., Kohut, J., Schofield, O., and Glenn, S. (2015). Glider observations and modeling of sediment transport in Hurricane Sandy. J. Geophys. Res. Oceans 120, 1771-1791. doi: 10.1002/2014JC0 10474

Monteiro, P. M. S., Gregor, L., Lévy, M., Maenner, S., Sabine, C. L., and Swart, S. (2015). Intraseasonal variability linked to sampling alias in airsea CO2 fluxes in the Southern Ocean. Geophys. Res. Lett. 42, 8507-8514. doi: 10.1002/2015GL066009 
Morrow, R., Carret, A., Birol, F., Nino, F., Valladeau, G., Boy, F., et al. (2017). Observability of fine-scale ocean dynamics in the northwestern Mediterranean Sea. Ocean Sci. 13, 13-29. doi: 10.5194/os-13-13-2017

Mourre, B., and Alvarez, A. (2012). Benefit assessment of glider adaptive sampling in the Ligurian Sea. Deep Sea Res. Part I Oceanogr. Res. Papers 68, 68-78. doi: 10.1016/j.dsr.2012.05.010

Mourre, B., and Chiggiato, J. (2014). A comparison of the performance of the 3-D super-ensemble and an ensemble Kalman filter for short-range regional ocean prediction. Tellus A: Dynamic Meteorol. Oceanogr. 66, 21640. doi: 10.3402/tellusa.v66.21640

Nelson, M. J. S., Queste, B. Y., Smith, I. J., Leonard, G. H., Webber, B. G. M., and Hughes, K. G. (2016). Measurements of Ice Shelf Water beneath the front of the Ross Ice Shelf using gliders. Ann. Glaciol. 58, 41-50. doi: 10.1017/aog.2017.34

Ngodock, H., and Carrier, M. (2014). A 4DVAR system for the navy coastal ocean model. Part II: strong and weak constraint assimilation experiments with real observations in monterey bay. Monthly Weather Rev. 142, 2108-2117. doi: 10.1175/MWR-D-13-00220.1

Nicholson, D. P., Wilson, S. T., Doney, S. C., and Karl, D. M. (2015). Quantifying subtropical North Pacific gyre mixed layer primary productivity from Seaglider observations of diel oxygen cycles. Geophys. Res. Lett. 42, 4032-4039. doi: 10.1002/2015GL063065

Nicholson, S.-A., Lévy, M., Llort, J., Swart, S., and Monteiro, P. M. S. (2016). Investigation into the impact of storms on sustaining summer primary productivity in the Sub-Antarctic Ocean. Geophys. Res. Lett. 43, 9192-9199. doi: 10.1002/2016GL069973

Ohman, M. D., Chekalyuk, R., Davis, D. L., Feely, A., Kahru, R. E., Kim, R. A., et al. (2013). Autonomous ocean measurements in the California Current Ecosystem. Oceanography 26, 18-25. doi: 10.5670/oceanog.2013.41

Oke, P. R., Larnicol, G., Jones, E. M., Kourafalou, V., Sperrevik, A. K., Carse, F., et al. (2015). Assessing the impact of observations on ocean forecasts and reanalyses: part 2, regional applications. J. Operational Oceanogr. 8, S63-S79. doi: 10.1080/1755876X.2015.1022080

Oke, P. R., Sakov, P., and Schulz, E. (2010). A comparison of shelf observation platforms for assimilation in an eddy-resolving ocean model. Dyn. Atmospheres Oceans 48, 121-142. doi: 10.1016/j.dynatmoce.2009.04.002

Olita, A., Capet, A., Mahadevan, A., Claret, A., Ruiz, S., Tintor,é, J., et al. (2017). Frontal dynamics boost primary production in the summer stratified Mediterranean Sea. Ocean Dynamics 67, 767-782. doi: 10.1007/s10236-017-1058-z

Olita, A., Sparnocchia, S., Cusi, S., Fazioli, L., Sorgente, R., Tintore, J., et al. (2014). Observations of a phytoplankton spring bloom onset triggered by a density front in NW Mediterranean. Ocean Sci. 10, 657-666. doi: 10.5194/os-10-657-2014

Oliver, M. J., Breece, M. W., Fox, D. A., Haulsee, D. E., Kohut, J. T., Manderson, J., et al. (2013). Shrinking the Haystack: using an AUV in an Integrated Ocean Observatory to map Atlantic Sturgeon in the Coastal Ocean. Fisheries 38, 210-216. doi: 10.1080/03632415.2013.782861

Oliver, M. J., Breece, M. W., Haulsee, D. E., Cimino, M. A., Kohut, J., Aragon, D., et al. (2017). Factors affecting detection efficiency of mobile telemetry Slocum gliders. Animal Biotelemet. 14:1. doi: 10.1186/s40317-017-0129-8

Omand, M. M., D’Asaro, E. A., Lee, C. M., Perry, M. J., Briggs, N., Cetinic, I., et al. (2015). Eddy-driven subduction exports particulate organic carbon from the spring bloom. Science 348, 222-225. doi: 10.1126/science. 1260062

Onken, R. (2017). Forecast skill score assessment of a relocatable ocean prediction system, using a simplified objective analysis method. Ocean Sci. 13, 925-945. doi: 10.5194/os-13-925-2017

Oschlies, A., Brandt, P., and Schmidtko, L., S. (2018). Drivers and mechanisms of ocean deoxygenation. Nat. Geosci. 11, 467-473. doi: 10.1038/s41561-018-0152-2

Osse, T. J., and Eriksen, C. C. (2007). "The deepglider: a full ocean depth glider for oceanographic research," in OCEANS 2007 (Vancouver, BC), 1-12.

Palmer, M. R., Stephenson, G. R., Mall, M. E., Balfour, C., Duesterhus, A., and Green, J. (2015). Turbulence and mixing by internal waves in the Celtic Sea determined from ocean glider microstructure measurements. J. Marine Syst. 144, 57-69. doi: 10.1016/j.jmarsys.2014.11.005

Pan, C., Jiang, M., Dalgleish, F. R., and Reed, J. K. (2017). Modeling the impacts of the Loop Current on circulation and water properties over the
Pulley Ridge region on the Southwest Florida shelf. Ocean Model. 112, 48-64. doi: 10.1016/j.ocemod.2017.02.009

Pan, C., Zheng, L., Weisberg, R. H., Liu, Y., and Lembke, C. E. (2014). Comparisons of different ensemble schemes for glider data assimilation on West Florida Shelf. Ocean Model. 81, 13-24. doi: 10.1016/j.ocemod.2014.06.005

Pascual, A., Ruiz, S., Olita, A., Troupin, C., Claret, M., Casas, B., et al. (2017). A multiplatform experiment to unravel meso- and submesoscale processes in an intense front (AlborEx). Front. Mar. Sci. 4:39. doi: 10.3389/fmars.2017.00039

Pascual, A., Ruiz, S., and Tintor,é, J. (2010). Combining new and conventional sensors to study the Balearic current. Sea Techn. 51, 32-36.

Pattiaratchi, C., Woo, L. M., Thomson, P. G., Hong, K. K., and Stanley, D. (2017). Ocean glider observations around australia. Oceanography 30, 90-91. doi: 10.5670/oceanog.2017.226

Pattiaratchi, C. B., Hollings, B., Woo, M., and Hanson, C. (2010). "Oceanographic observations of the Australian continental shelf and slope waters using autonomous ocean gliders," in Proceedings of OceanObs'09: Sustained Ocean Observations and Information for Society Conference/, 2009, eds J. Hall, D. E. Harrison, and D. Stammer (Venice: ESA publication WPP-306).

Pattiaratchi, C. B., Hollings, B., Woo, M., and Welhena, T. (2011). Dense shelf water formation along the south-west Australian inner shelf. Geophys. Res. Lett. 38:L10609. doi: 10.1029/2011GL046816

Pearlman, J., Bushnell, M., Coppola, L., Buttigieg, P. L., Chandler, C., Pearlman, F., et al. (2019). Evolving and sustaining ocean best practices and standards for the next decade. Front. Marine Sci. 6:277. doi: 10.3389/fmars.2019.00277

Pelland, N., Bennett, J., Steinberg, J. M., and Eriksen, C. E. (2018). Automated glider tracking of a california undercurrent eddy using the extended kalman filter. J. Atmos. Oceanic Technol. 35, 2241-2264. doi: 10.1175/JTECH-D-18-0126.1

Pelland, N. A., Eriksen, C. C., and Cronin, M. F. (2016). Seaglider surveys at ocean station papa: circulation and water mass properties in a meander of the North Pacific Current. J. Geophys. Res. Oceans 121, 6816-6846. doi: 10.1002/2016JC011920

Pelland, N. A., Eriksen, C. C., and Lee, C. M. (2013). Subthermocline eddies over the washington continental slope as observed by seagliders, 2003-09. J. Phys. Oceanogr. 43, 2025-2053. doi: 10.1175/JPO-D-12-086.1

Pelland, N. A., Sterling, J. T., Lea, M.-A., Bond, N. A., Ream, R. R., Lee, C. M., et al. (2014). Fortuitous encounters between seagliders and adult female northern fur seals (Callorhinus ursinus) off the Washington (USA) coast: upper ocean variability and links to top predator behavior. PLOS ONE. 9:0101268. doi: 10.1371/journal.pone.0101268

Peterson, A., and Fer, I. (2014). Dissipation measurements using temperature microstructure from an underwater glider. Methods Oceanogr. 10, 44-69. doi: 10.1016/j.mio.2014.05.002

Peterson, I., Greenan, B., Gilbert, D., and Hebert, D. (2017). Variability and wind forcing of ocean temperature and thermal fronts in the Slope Water region of the Northwest Atlantic. J. Geophys. Res. Oceans 122, 7325-7343. doi: 10.1002/2017JC012788

Pierce, S. D., Barth, J. A., Shearman, R. K., and Erofeev, A. Y. (2012). Declining oxygen in the northeast pacific. J. Phys. Oceanogr. 42, 495-501. doi: 10.1175/JPO-D-11-0170.1

Piero Mazzini, L. F., Craig Risien, M., John Barth, A., Stephen Pierce, D., Erofeev, A., Dever, E. P., et al. (2015). Anomalous near-surface low-salinity pulses off the central Oregon coast. Sci Rep. 5:17145. doi: 10.1038/srep 17145

Pietri, A., Echevin, V., Testor, P., Chaigneau, A., Mortier, L., Grados, C., et al. (2014). Impact of a coastal-trapped wave on the near? Coastal circulation of the Peru upwelling system from glider data. J. Geophys. Res. 119, 2109-2120. doi: 10.1002/2013JC009270

Pietri, A., Testor, P., Echevin, V., Chaigneau, A., Mortier, L., Eldin, G., et al. (2013). Finescale vertical structure of the upwelling system off southern peru as observed from glider data. J. Phys. Oceanogr. 43, 631-646. doi: 10.1175/JPO-D-12-035.1

Piterbarg, L., Taillandier, V., and Griffa, A. (2013). Investigating frontal variability from repeated glider transects in the Ligurian Current (North West Mediterranean Sea). J. Mar. Sys. 129, 381-395. doi: 10.1016/j.jmarsys.2013.08.003

Pizarro, O., Ramirez, N., Castillo, M. I., Cifuentes, U., Rojas, W., and Pizarro-Koch, M. (2016). Underwater glider observations in the oxygen 
minimum zone off central chile. Bull. Am. Meteorol. Soc. 97, 1783-1789. doi: 10.1175/BAMS-D-14-00040.1

Portela, E., Tenreiro, M., Pallàs-Sanz, E., Meunier, T., Ruiz-Angulo, A., SosaGutiérrez, R., et al. (2018). Hydrography of the central and western Gulf of Mexico. J. Geophys. Res. Oceans 123, 5134-5149. doi: 10.1029/2018JC 013813

Porter, M., Inall, M. E., Hopkins, J., Palmer, M. R., Dale, A. C., Aleynik, D., et al. (2016). Glider observations of enhanced deep water upwelling at a shelf break canyon: a mechanism for cross-slope carbon and nutrient exchange. J. Geophys. Res. Oceans 121, 7575-7588. doi: 10.1002/2016JC012087

Powell, J. R., and Ohman, M. D. (2012). Use of glider-class acoustic Doppler profilers for estimating zooplankton biomass. J. Plankton Res. 34, 563-568. doi: 10.1093/plankt/fbs023

Powell, J. R., and Ohman, M. D. (2015). Covariability of zooplankton gradients with glider-detected density fronts in the Southern California Current System. Deep Sea Res. II 112, 79-90. doi: 10.1016/j.dsr2.2014.04.002

Qiu, C., Mao, H., Yu, J., Xie, Q., Wu, J., Lian, S., et al. (2015). Sea surface cooling in the Northern South China Sea observed using Chinese sea-wing underwater glider measurements. Deep Sea Res. Part I Oceanogr. Res. Papers 105, 111-118. doi: 10.1016/j.dsr.2015.08.009

Queste, B. Y., Fernand, L., Jickells, T. D., Karen J. H. (2013). Spatial extent and historical context of North Sea oxygen depletion in August 2010. Biogeochemistry 113, 53-68. doi: 10.1007/s10533-012-9729

Queste, B. Y., Heywood, K. J., Smith, W. O. Jr., Kaufman, D. E., Jickells, T. D., and Dinniman, M. S. (2015). Dissolved oxygen dynamics during a phytoplankton bloom in the Ross Sea polynya. Antarctic Sci. 27, 362-372. doi: 10.1017/S0954102014000881

Rainville, L., Gobat, J. I., Lee, C. M., and Shilling, G. B. (2017). Multi-month dissipation estimates using microstructure from autonomous underwater gliders. Oceanography 30, 49-50. doi: 10.5670/oceanog.2017.219

Rainville, L., Lee, C. M., Rudnick, D. L., and Yang, K.-C. (2013). Propagation of internal tides generated near Luzon Strait: observations from autonomous gliders. J. Geophys. Res. Oceans 118, 4125-4138. doi: 10.1002/jgrc. 20293

Ramp, S. R., Davis, R. E., Leonard, N. E., Shulman, I., Chao, Y., Robinson, A. R., et al. (2009). Preparing to predict: the Second Autonomous Ocean Sampling Network (AOSN-II) experiment in the Monterey Bay. Deep Sea Res. Part II Topical Stud. Oceanogr. 56, 68-86. doi: 10.1016/j.dsr2.2008.08.013

Ramp, S. R., Lermusiaux, P. F. J., Shulman, I., Chao, Y., Wolf, R. E., and Bahr, F. L. (2011). Oceanographic and atmospheric conditions on the continental shelf north of the Monterey Bay during August 2006. Dynam. Atmospheres Oceans 52, 192-223. doi: 10.1016/j.dynatmoce.2011.04.005

Rayburn, J. T., and Kamenkovich, V. M. (2013). Comparison of the observed mixed layer depth in the lee of the hawaiian island to the modeled mixed layer depth of the regional navy coastal ocean model. Marine Technol. Soc. J. 47, 55-66. doi: 10.4031/MTSJ.47.1.3

Ridgway, K. R., and Godfrey, J. S. (2015). The source of the Leeuwin Current seasonality. J. Geophys. Res. Oceans 120, 6843-6864. doi: 10.1002/2015JC011049

Ross, T., Craig, S. E., Comeau, A., Davis, R., Dever, M., and Beck, M. (2017). Blooms and subsurface phytoplankton layers on the Scotian Shelf: insights from profiling gliders. J. Marine Syst. 172, 118-127. doi: 10.1016/j.jmarsys.2017.03.007

Ruan, X., Thompson, A. F., Flexas, M. M., and Sprintall, J. (2017). Contribution of topographically generated submesoscale turbulence to Southern Ocean overturning. Nat. Geosci. 10, 840. doi: 10.1038/ngeo3053

Rudnick, D. L. (2016). Ocean research enabled by underwater gliders. Ann. Rev. Marine Sci. 8, 519-541. doi: 10.1146/annurev-marine-122414-033913

Rudnick, D. L., and Cole, S. T. (2011). On sampling the ocean using underwater gliders. J. Geophys. Res. 116:C08010. doi: 10.1029/2010JC 006849

Rudnick, D. L., Davis, R. E., and Sherman, J. T. (2016a). Spray underwater glider operations. J. Atmospheric Oceanic Technol. 33, 1113-1122. doi: 10.1175/JTECH-D-15-0252.1

Rudnick, D. L., Gopalakrishnan, G., and Cornuelle, B. D. (2015). Cyclonic Eddies in the Gulf of Mexico: observations by underwater gliders and simulations by numerical model. J. Phys. Oceanogr. 45, 313-326. doi: 10.1175/JPO-D-14-0138.1
Rudnick, D. L., Owens, B., Johnston, S., and Karnauskas, K. (2016b). Underwater Glider Observations of the Ongoing El Niño. New Orleans, LA: Ocean Sciences Meeting.

Rudnick, D. L., Sherman, J. T., and Wu, A. P. (2018). Depth-average velocity from Spray underwater gliders. J. Atmospheric Oceanic Technol. 35,1665-1673. doi: 10.1175/JTECH-D-17-0200.1

Rudnick, D. L., Zaba, K. D., Todd, R. E., and Davis, R. E. (2017). A climatology of the California Current System from a network of underwater gliders. Progr. Oceanogr. 154, 64-106. doi: 10.1016/j.pocean.2017.03.002

Ruiz, S., Renault, L., Garau, B., and Tintore, J. (2012). Underwater glider observations and modeling of an abrupt mixing event in the upper ocean. Geophys. Res. Lett. 39:L01603. doi: 10.1029/2011GL050078

Saba, G. K., Wright-Fairbanks, E., Chen, B., Cai, W.-J., Barnard, A. H., Jones, C. P., et al. (2018). "Developing a profiling glider $\mathrm{pH}$ sensor for high resolution coastal ocean acidification monitoring," in OCEANS'18 MTS/IEEE. (Charleston, SC), 1-8.

Saldias, G. S., Shearman, R. K., Barth, J. A., and Tufillaro, N. (2016). Optics of the offshore Columbia River plume from glider observations and satellite imagery. J. Geophys. Res. Oceans 121, 2367-2384. doi: 10.1002/2015JC011431

Schaeffer, A., and Roughan, M. (2015). Influence of a western boundary current on shelf dynamics and upwelling from repeat glider deployments. Geophys. Res. Lett. 42, 121-128. doi: 10.1002/2014GL062260

Schaeffer, A., Roughan, M., Austin, T., Everett, J. D., Griffin, D., Hollings, B., et al. (2016a). Mean hydrography on the continental shelf from 26 repeat glider deployments along Southeastern Australia. Sci. Data, 3:160070. doi: $10.1038 /$ sdata.2016.70

Schaeffer, A., Roughan, M., Jones, E. M., and White, D. (2016b). Physical and biogeochemical spatial scales of variability in the East Australian Current separation from shelf glider measurements. Biogeosciences 13, 1967-1975. doi: 10.5194/bg-13-1967-2016

Schaeffer, A., Roughan, M., and Wood, J., E. (2014). Observed bottom boundary layer transport and uplift on the continental shelf adjacent to a western boundary current. J. Geophys. Res. Oceans 119, 4922-4939. doi: 10.1002/2013JC009735

Scheifele, B., Waterman, S., Merckelbach, L., and Carpenter, J. (2018). Measuring the dissipation rate of turbulent kinetic energy in strongly stratified, low-energy environments: a case study from the Arctic Ocean. J. Geophys. Res. Oceans 123, 5459-5480. doi: 10.1029/2017JC013731

Schlundt, M., Brandt, P., Dengler, M., Hummels, R., Fischer, T., Bumke, K., et al. (2014). Mixed layer heat and salinity budgets during the onset of the 2011 Atlantic cold tongue. J. Geophys. Res. Oceans 119, 7882-7910. doi: 10.1002/2014JC010021

Schofield, O., Miles, T., Alderkamp, A.-C., Lee, S., Haskins, C., Rogalsky, E., et al. (2015). In situ phytoplankton distributions in the Amundsen Sea Polynya measured by autonomous gliders. Elementa Sci. Anthropocene 3, 1-17. doi: 10.12952/journal.elementa.000073

Schönau, M. C., and Rudnick, D. L. (2015). Glider observations of the North Equatorial Current in the western tropical Pacific. J. Geophys. Res. Oceans 120, 3586-3605. doi: 10.1002/2014JC010595

Schönau, M. C., and Rudnick, D. L. (2017). Mindanao current and undercurrent: thermohaline structure and transport from repeat glider observations. J. Phys. Oceanogr. 47, 2055-2075. doi: 10.1175/JPO-D-16-0274.1

Schönau, M. C., Rudnick, D. L., Cerovecki, I., Gopalakrishnan, G., Cornuelle, B. D., McClean, J. L., et al. (2015). The mindanao current mean structure and connectivity. Oceanography 28, 34-45. doi: 10.5670/oceanog. 2015.79

Schroeder, K., Chiggiato, J., Josey, S. A., Borghini, M., Aracri, S., and Sparnocchia, S. (2017). Rapid Response to Climate Change in a Marginal Sea. Scientific Reports 7:4065. doi: 10.1038/s41598-017-04455-5

Schuette, F., Karstensen, J., Krahmann, G., Hauss, H., Fiedler, B., Brandt, P., et al. (2016). Characterization of 'dead-zone' eddies in the eastern tropical North Atlantic. Biogeosciences 13, 5865-5881. doi: 10.5194/bg-13-5865-2016

Schultze, L. K. P., Merckelbach, L. M., and Carpenter, J. R. (2017). Turbulence and mixing in a shallow shelf sea from underwater gliders. J. Geophys. Res. Oceans 122, 9092-9109. doi: 10.1002/2017JC012872

Seegers, B. N., Birch, J. M., Marin, R. III, Scholin, C. A., Caron, D. A., Seubert, E. L., Howard, M. D. A., et al. (2015). Subsurface seeding of surface harmful algal blooms observed through the integration of autonomous gliders, moored 
environmental sample processors, and satellite remote sensing in southern California. Limnol. Oceanogr. 60, 754-764. doi: 10.1002/lno.10082

Seim, H. E., and Edwards, C. R. (2019). Upper-slope jets and Gulf Stream filaments inshore of the Charleston Bump during Winter 2012. J. Phys. Oceanogr. 49, 1423-1438. doi: 10.1175/JPO-D-18-0205.1

Send, U., Regier, L., and Jones, B. (2013). Use of underwater gliders for acoustic data retrieval from subsurface oceanographic instrumentation and bidirectional communication in the deep ocean. J. Atmos. Oceanic Technol. 30, 984-998. doi: 10.1175/JTECH-D-11-00169.1

Seroka, G., Miles, T., Xu, Y., Kohut, J., Schofield, O., and Glenn, S. (2016). Hurricane Irene sensitivity to stratified coastal ocean cooling. Mon. Weather Rev. 144, 3507-3530. doi: 10.1175/MWR-D-15-0452.1

Seroka, G., Miles, T., Xu, Y., Kohut, J., Schofield, O., and Glenn, S. (2017). Rapid shelf-wide cooling response of a stratified coastal ocean to hurricanes. J. Geophys.Res. Oceans 122, 4845-4867. doi: 10.1002/2017JC012756

Shay, L. K., Goni, G. J., and Black, P. G. (2000). Effects of warm oceanic features on hurricane opal. Mon. Weather Rev. 128, 131-148. doi: 10.1175/1520-0493(2000)128<1366:EOAWOF>2.0.CO;2

Sherwin, T. J., Aleynik, D., Dumont, E., and Inall, M. E. (2015). Deep drivers of mesoscale circulation in the central Rockall Trough. Ocean Sci. 11, 343-359. doi: 10.5194/os-11-343-2015

Sherwin, T. J., Read, J. F., Holliday, N. P., and Johnson, C. (2012). The impact of changes in North Atlantic Gyre distribution on water mass characteristics in the Rockall Trough. ICES J. Marine Sci. 69, 751-757. doi: 10.1093/icesjms/f $\operatorname{sr} 185$

Shulman, I., Anderson, S., Rowley, C., DeRada, S., Doyle, J., and Ramp, S. (2010). Comparisons of upwelling and relaxation events in the Monterey Bay area. J. Geophys. Res. Oceans 115:C06016. doi: 10.1029/2009JC0 05483

Smedstad, L. F., Barron, C. N., Bourg, R. N., Brooking, M. W., Bryant, D. A., Carr, R. J., et al. (2015). "An expansion of glider observation strategies to systematically transmit and analyze preferred waypoints of underwater gliders, ocean sensing and monitoring VIII," in Proceedings SPIE, Vol. 9459, eds W. Hou and R. Arnone (Baltimore, MD: SPIE Defense + Security), 1-12. doi: $10.1117 / 12.2176560$

St Laurent, L., and Merrifield, S. (2017). Measurements of near-surface turbulence and mixing from autonomous ocean gliders. Oceanography 30, 116-125. doi: $10.5670 /$ oceanog.2017.231

Stommel, H. (1989). The slocum mission. Oceanography 22-25. doi: $10.5670 /$ oceanog.1989.26

Swart, S., Thomalla, S. J., and Monteiro, P. M. S. (2015). The seasonal cycle of mixed layer dynamics and phytoplankton biomass in the Sub-Antarctic Zone: a high-resolution glider experiment. J. Mar. Syst. 147, 103-115. doi: 10.1016/j.jmarsys.2014.06.002

Swart, S., Thomalla, S. J., Monteiro, P. M. S., and Ansorge, I. J. (2012). Mesoscale features and phytoplankton biomass at the GoodHope line in the Southern Ocean during austral summer. African J. Marine Sci. 34, 511-524. doi: 10.2989/1814232X.2012.749811

Swart, S., Zietsman, J. J., Coetzee, J. C., Goslett, D. G., Hoek, A., Needham, D., et al. (2016). Ocean robotics in support of fisheries research and management. Afr. J. Mar. Sci. 38, 525-538. doi: 10.2989/1814232X.2016.1251971

Tanhua, T., Pouliquen, S., Hausman, J., O’brien, K., Bricher, P., Bruin, T. D., et al. (2019). Ocean FAIR data services. Front. Marine Sci. 6:440. doi: $10.3389 /$ fmars. 2019.00440

Taylor, J. C., and Lembke, C. (2017). Echosounder for biological surveys using ocean gliders extending fishery ecosystem assessments to remote places. Sea Technol. 58, 35-38.

Testor, P., Bosse, A., Houpert, L., Margirier, F., Mortier, L., Legoff, H., et al. (2018). Multi-scale observations of deep convection in the northwestern Mediterranean Sea during winter 2012-2013 using multiple platforms. J. Geophys. Res. 123, 1745-1776. doi: 10.1002/2016JC 012671

Testor, P., Meyers, G., Pattiaratchi, C., Bachmayer, R., Hayes, D., Pouliquen, S., et al. (2010). "Gliders as a component of future observing systems," in Proceedings of OceanObs'09: Sustained Ocean Observations and Information for Society (Vol. 2), eds J. Hall, D. E. Harrison, and D. Stammer (Venice: ESA Publication), 21-25.
Thomalla, S. J., Ogunkoya, A. G., Vichi, M., and Swart, S. (2017). Using optical sensors on gliders to estimate phytoplankton carbon concentrations and chlorophyll-to-carbon ratios in the southern ocean. Front. Mar. Sci. 4:34. doi: $10.3389 /$ fmars.2017.00034

Thomalla, S. J., Racault, M.-F., Swart, S., and Monteiro, P. M. S. (2015). Highresolution view of the spring bloom initiation and net community production in the Subantarctic Southern Ocean using glider data. J. Marine Sci. 72, 1999-2020. doi: 10.1093/icesjms/fsv105

Thompson, A. F., Heywood, K. J., Schmidtko, S., and Stewart, A. L. (2014). Eddy transport as a key component of the Antarctic overturning circulation. Nat. Geosci. 7, 879-884. doi: 10.1038/ngeo2289

Thompson, A. F., Lazar, A., Buckingham, C., Naveira Garabato, A. C., Damerell, G. M., and Heywood, K. J. (2016). Open-ocean submesoscale motions: a full seasonal cycle of mixed layer instabilities from gliders. J. Phys. Oceanogr. 46, 1285-1307. doi: 10.1175/JPO-D-15-0170.1

Thomsen, S., Kanzow, T., Colas, F., Echevin, V., Krahmann, G., and Engel, A. (2016). Do submesoscale frontal processes ventilate the oxygen minimum zone off Peru. Geophys. Res. Lett. 43, 8133-8142.doi: 10.1002/2016GL0 70548

Thorpe, S. A. (2012). Measuring overturns with gliders. J. Marine Res. 70, 93-117. doi: $10.1357 / 002224012800502417$

Timmermans, M.-L., and Winsor, P. (2013). Scales of horizontal density structure in the Chukchi Sea surface layer. Continental Shelf Res. 52, 39-45. doi: 10.1016/j.csr.2012.10.015

Todd, R. E. (2017). High-frequency internal waves and thick bottom mixed layers observed by gliders in the Gulf Stream. Geophys. Res. Lett., 44, 6316-6325. doi: 10.1002/2017GL072580

Todd, R. E., Asher, T. G., Heiderich, J., Bane, J. M., and Luettich, R. A. (2018). Transient response of the Gulf Stream to multiple hurricanes in 2017. Geophys. Res. Lett. 45, 10,509-10,519. doi: 10.1029/2018GL0 79180

Todd, R. E., Chavez, F. P., Clayton, S., Cravatte, S., Goes, M., Graco, M., et al. (2019). Global perspectives on observing ocean boundary current systems. Front. Mar. Sci. 6:423. doi: 10.3389/fmars.2019.00423

Todd, R. E., Gawarkiewicz, G. G., and Owens, W. B. (2013). Horizontal scales of variability over the middle atlantic bight shelf break and continental rise from finescale observations. J. Phys. Oceanogr. 43, 222-230. doi: 10.1175/JPO-D-12-099.1

Todd, R. E., and Locke-Wynn, L. (2017). Underwater glider observations and the representation of western boundary currents in numerical models. Oceanography 30, 88-89. doi: 10.5670/oceanog.2017.225

Todd, R. E., Owens, W. B., and Rudnick, D. L. (2016). Potential vorticity structure in the North Atlantic western boundary current from underwater glider observations. J. Phys. Oceanogr. 46, 327-348. doi: 10.1175/JPO-D-150112.1

Todd, R. E., Rudnick, D. L., Davis, R. E., and Ohman, M. D. (2011b). Underwater gliders reveal rapid arrival of El Niño effects off California’s coast. Geophys. Res. Lett. 38:L03609. doi: 10.1029/2010GL046376

Todd, R. E., Rudnick, D. L., Mazloff, M. R., Cornuelle, B. D., and Davis, R. E. (2012). Thermohaline structure in the California Current System: observations and modeling of spice variance. J. Geophys. Res. Oceans 117:C02008. doi: 10.1029/2011JC007589

Todd, R. E., Rudnick, D. L., Mazloff, M. R., Davis, R. E., and Cornuelle, B. D. (2011a). Poleward flows in the southern california current system: glider observations and numerical simulation. J. Geophys. Res. 116:C02026. doi: 10.1029/2010JC006536

Todd, R. E., Rudnick, D. L., Sherman, J. T., Owens, W. B., and George, L. (2017). Absolute velocity estimates from autonomous underwater gliders equipped with Doppler current profilers. J. Atmos. Oceanic Technol. 34, 309-333. doi: 10.1175/JTECH-D-16-0156.1

Troupin, C., Beltran, J. P., Heslop, E., Torner, M., Garau, B., Allen, J., and Ruiz,S. J. (2005). A toolbox for glider data processing and management. Methods Oceanogr. 13-14, 13-23. doi: 10.1016/j.mio.2016.01.001

Ullgren, J. E., Fer, I., Darelius, E., and Beaird, N. (2014). Interaction of the faroe bank channel overflow with iceland basin intermediate waters. J. Geophys. Res. Oceans 119, 228-240. doi: 10.1002/2013JC0 09437 
Våge, K., Papritz, L., Håvik, L., Spall, M. A., and Moore, G. W. K. (2018). Ocean convection linked to the recent ice edge retreat along east Greenland. Nat. Commun. 9:1287. doi: 10.1038/s41467-018-03468-6

Venables, H. J., and Meredith, M. P. (2014). Feedbacks between ice cover, ocean stratification, and heat content in Ryder Bay, western Antarctic Peninsula. J. Geophys. Res. Oceans 119, 5323-5336. doi: 10.1002/2013JC009669

Venables, H. J., Meredith, M. P., and Brearley, J. A. (2017). Modification of deep waters in Marguerite Bay, western Antarctic Peninsula, caused by topographic overflows. Deep Sea Res. Part II Topical Stud. Oceanogr. 139, 9-17. doi: 10.1016/j.dsr2.2016.09.005

Verdy, A., Cornuelle, B., Mazloff, M. R., and Rudnick, D. L. (2017). Estimation of the tropical pacific ocean state 2010-13. J. Atmospheric Oceanic Technol. 34, 1501-1517. doi: 10.1175/JTECH-D-16-0223.1

Verfuss, U. K., Aniceto, A. S., Harris, D. V., Gillespie, D., Fielding, S., Jiménez, G., Johnston, P., et al. (2019). A review of unmanned vehicles for the detection and monitoring of marine fauna. Marine Pollut. Bull. 140, 17-29. doi: 10.1016/j.marpolbul.2019.01.009

Viglione, G. A., Thompson, A. F., Flexas, M. M., Sprintall, J., and Swart, S. (2018). Abrupt transitions in submesoscale structure in southern drake passage: glider observations and GCM results. J. Phys. Oceanogr. 48, 2011-2017.

Villar, E., Farrant, G. K., Follows, M., Garczarek, L., Speich, S., Audic, S., et al. (2015): Environmental characteristics of Agulhas rings affect interocean plankton transport. Science. 348:6237. doi: 10.1126/science. 1261447

Wall, C. C., Lembke, C., and Mann, D. A. (2012). Shelf-scale mapping of sound production by fishes in the eastern Gulf of Mexico, using autonomous glider technology. Mar. Ecol. Prog. Ser. 449, 55-64. doi: 10.3354/ meps09549

Webster, S. E., Freitag, L. E., Lee, C. M., and Gobat, J. I. (2015). “Towards real-time under-ice acoustic navigation at mesoscale ranges," in Proceedings, IEEE International Conference on Robotics and Automation (ICRA) (Seattle, WA), 1-8.

Weingartner, T., Dobbins, E., Danielson, S., Winsor, P., Potter, R., and Statscewich, H. (2013). Hydrographic variability over the northeastern Chukchi Sea shelf in summer-fall 2008-2010. Continental Shelf Res. 67, 5-22. doi: 10.1016/j.csr.2013.03.012

Wilkin, J. L., and Hunter, E. J. (2013). An assessment of the skill of real-time models of Mid-Atlantic Bight continental shelf circulation. J. Geophys. Res. Oceans 118, 2919-2933. doi: 10.1002/jgrc.20223

Xu, Y., Chant, R., Gong, D., Castelao, R., Glenn, S., and Schofield, O. (2011). Seasonal variability of chlorophyll a in the Mid-Atlantic Bight. Continental Shelf Res. 31, 1640-1650. doi: 10.1016/j.csr.2011.05.019

Yang, K. C., Wang, J., Lee, C. M., Ma, B., Lien, R. C., Jan, S., et al. (2015). Two Mechanisms cause dual velocity maxima in the kuroshio east of taiwan. Oceanography 28, 64-73. doi: 10.5670/oceanog.2015.82

Yaremchuk, M., Nechaev, D., and Pan, C. (2011). A hybrid background error covariance model for assimilating glider data into a coastal ocean model. Monthly Weather Rev. 139, 1879-1890. doi: 10.1175/2011MWR3510.1

Yu, L. S., A., Bosse, I., Fer, K. A., Orvik, E. M., Bruvik, I., et al. (2017). The Lofoten Basin eddy: three years of evolution as observed by Seagliders. J. Geophys. Res. Oceans 122, 6814-6834. doi: 10.1002/2017JC0 12982

Zaba, K., Rudnick, D. L., Cornuelle, B., Gopalakrishnan, G., and Mazloff, M. (2018). Annual and interannual variability in the California Current System: comparison of an assimilating state estimate with a network of underwater gliders. J. Phys. Oceanogr. 48, 2965-2988. doi: 10.1175/JPO-D-18-0037.1

Zaba, K. D., and Rudnick, D. L. (2016). The 2014-2015 warming anomaly in the Southern California Current System observed by underwater gliders. Geophys. Res. Lett. 43, 1241-1248. doi: 10.1002/2015GL067550

Zacharia, S., Seshasayanan, R., Sudhakar, T., Atmanand, M. A., and Rao, R. R. (2017). Observed variability of surface layer in the Central Bay of
Bengal: results of measurements using glider. Curr. Sci. 113, 2151-2159. doi: 10.18520/cs/v113/i11/2151-2159

Zarokanellos, N. D., Papadopoulos, V. P., Sofianos, S. S., and Jones, B. H. (2017). Physical and biological characteristics of the winter-summer transition in the Central Red Sea. J. Geophys. Res. Oceans 122, 6355-6370. doi: 10.1002/2017JC012882

Zhang, W. G., Wilkin, J. L., and Arango, H. G. (2010a). Towards an integrated observation and modeling system in the New York Bight using variational methods. Part I: 4DVAR data assimilation. Ocean Model. 35, 119-133. doi: 10.1016/j.ocemod.2010.08.003

Zhang, W. G., Wilkin, J. L., and Levin, J. C. (2010b). Towards an integrated observation and modeling system in the New York Bight using variational methods. Part II: repressenter-based observing strategy evaluation. Ocean Model. 35, 134-145. doi: 10.1016/j.ocemod.2010.06.006

Zhao, J., Hu, C., Lenes, J. M., Weisberg, R. H., Lembke, C., English, D., et al. (2013). Three-dimensional structure of a Karenia brevis bloom: observations from gliders, satellites, and field measurements. Harmful Algae 29, 22-30. doi: 10.1016/j.hal.2013.07.004

Conflict of Interest: YC, SM, RP, and MS were employed by companies Seatrec, FishOcean, Shell, and Applied Ocean Sciences respectively.

The remaining authors declare that the research was conducted in the absence of any commercial or financial relationships that could be construed as a potential conflict of interest.

Citation: Testor P, de Young B, Rudnick DL, Glenn S, Hayes D, Lee CM, Pattiaratchi C, Hill K, Heslop E, Turpin V, Alenius P, Barrera C, Barth JA, Beaird N, Bécu G, Bosse A, Bourrin F, Brearley JA, Chao Y, Chen S, Chiggiato J, Coppola L, Crout $R$, Cummings J, Curry B, Curry R, Davis R, Desai K, DiMarco S, Edwards C, Fielding S, Fer I, Frajka-Williams E, Gildor H, Goni G, Gutierrez D, Haugan P, Hebert D, Heiderich J, Henson S, Heywood K, Hogan P, Houpert L, Huh S, E. Inall $M$, Ishii M, Ito S-i, Itoh S, Jan S, Kaiser J, Karstensen J, Kirkpatrick B, Klymak J, Kohut J, Krahmann G, Krug M, McClatchie S, Marin F, Mauri E, Mehra A, Meredith MP, Meunier T, Miles T, Morell JM, Mortier L, Nicholson S, O'Callaghan J, O'Conchubhair D, Oke P, Pallàs-Sanz E, Palmer M, Park J, Perivoliotis L, Poulain PM, Perry R, Queste B, Rainville L, Rehm E, Roughan M, Rome N, Ross T, Ruiz $S$, Saba G, Schaeffer A, Schönau M, Schroeder K, Shimizu Y, Sloyan BM, Smeed $D$, Snowden D, Song Y, Swart S, Tenreiro M, Thompson A, Tintore J, Todd RE, Toro C, Venables H, Wagawa T, Waterman S, Watlington RA and Wilson D (2019) OceanGliders: A Component of the Integrated GOOS. Front. Mar. Sci. 6:422. doi: $10.3389 /$ fmars.2019.00422

Copyright (C) 2019 Testor, de Young, Rudnick, Glenn, Hayes, Lee, Pattiaratchi, Hill, Heslop, Turpin, Alenius, Barrera, Barth, Beaird, Bécu, Bosse, Bourrin, Brearley, Chao, Chen, Chiggiato, Coppola, Crout, Cummings, Curry, Curry, Davis, Desai, DiMarco, Edwards, Fielding, Fer, Frajka-Williams, Gildor, Goni, Gutierrez, Haugan, Hebert, Heiderich, Henson, Heywood, Hogan, Houpert, Huh, E. Inall, Ishii, Ito, Itoh, Jan, Kaiser, Karstensen, Kirkpatrick, Klymak, Kohut, Krahmann, Krug, McClatchie, Marin, Mauri, Mehra, P. Meredith, Meunier, Miles, Morell, Mortier, Nicholson, O'Callaghan, O'Conchubhair, Oke, Pallàs-Sanz, Palmer, Park, Perivoliotis, Poulain, Perry, Queste, Rainville, Rehm, Roughan, Rome, Ross, Ruiz, Saba, Schaeffer, Schönau, Schroeder, Shimizu, Sloyan, Smeed, Snowden, Song, Swart, Tenreiro, Thompson, Tintore, Todd, Toro, Venables, Wagawa, Waterman, Watlington and Wilson. This is an open-access article distributed under the terms of the Creative Commons Attribution License (CC BY). The use, distribution or reproduction in other forums is permitted, provided the original author(s) and the copyright owner(s) are credited and that the original publication in this journal is cited, in accordance with accepted academic practice. No use, distribution or reproduction is permitted which does not comply with these terms. 